\title{
Flame Retardant Polypropylenes: A Review
}

\author{
Farzad Seidi ${ }^{1}$, Elnaz Movahedifar ${ }^{2}$, Ghasem Naderi ${ }^{2}$, Vahideh Akbari ${ }^{3}$, Franck Ducos ${ }^{4}$, \\ Ramin Shamsi ${ }^{5}$, Henri Vahabi ${ }^{3, *(D)}$ and Mohammad Reza Saeb ${ }^{3, *(D)}$ \\ 1 Provincial Key Lab of Pulp and Paper Science and Technology and Joint International Research Lab of \\ Lignocellulosic Functional Materials, Nanjing Forestry University, Nanjing 210037, China; \\ f_seidi@njfu.edu.cn \\ 2 Department of Polymer Processing, Iran Polymer and Petrochemical Institute, Tehran 14965/115, Iran; \\ el.movahedifar@gmail.com (E.M.); g.naderi@ippi.ac.ir (G.N.) \\ 3 Université de Lorraine, CentraleSupélec, LMOPS, F-57000 Metz, France; vahidehakbari1991@gmail.com \\ 4 Université de Lorraine, IUT de Moselle Est, IUTSGM, 57600 Forbach, France; franck.ducos@univ-lorraine.fr \\ 5 Research and Development Center, Marun Petrochemical Company, Mahshahr 63531 69311, Iran; \\ ramin.shamsi44@gmail.com \\ * Correspondence: henri.vahabi@univ-lorraine.fr (H.V.); mrsaeb2008@gmail.com or \\ saeb-mr@icrc.ac.ir (M.R.S.); Tel.: +33-(0)38-793-9186 (H.V.); +98-912-826-4307 (M.R.S.); \\ Fax: +33-(0)38-793-9101 (H.V.)
}

Received: 8 July 2020; Accepted: 28 July 2020; Published: 29 July 2020

\begin{abstract}
Polypropylene (PP) is a commodity plastic known for high rigidity and crystallinity, which is suitable for a wide range of applications. However, high flammability of PP has always been noticed by users as a constraint; therefore, a variety of additives has been examined to make PP flame-retardant. In this work, research papers on the flame retardancy of PP have been comprehensively reviewed, classified in terms of flame retardancy, and evaluated based on the universal dimensionless criterion of Flame Retardancy Index (FRI). The classification of additives of well-known families, i.e., phosphorus-based, nitrogen-based, mineral, carbon-based, bio-based, and hybrid flame retardants composed of two or more additives, was reflected in FRI mirror calculated from cone calorimetry data, whatever heat flux and sample thickness in a given series of samples. PP composites were categorized in terms of flame retardancy performance as Poor, Good, or Excellent cases. It also attempted to correlate other criteria like UL-94 and limiting oxygen index (LOI) with FRI values, giving a broad view of flame retardancy performance of PP composites. The collected data and the conclusions presented in this survey should help researchers working in the field to select the best additives among possibilities for making the PP sufficiently flame-retardant for advanced applications.
\end{abstract}

Keywords: flame retardancy; polypropylene; Flame Retardancy Index (FRI); cone calorimetry; flame retardants

\section{Introduction}

Polymers are building blocks of advanced materials and systems, but their flammability has been a serious constraint in their usage in advanced applications [1-3]. Polypropylene (PP) is a commodity plastic widely used in a variety of applications, particularly in the form of composites in load-bearing uses due to its high rigidity and crystallinity [4]. By the end of 2020, the PP market size is expected to reach $\$ 112$ billion, and it is estimated to reach $\$ 155$ billion by 2026 [5,6]. Its global production was 56.0 million metric tons in 2018, and it is estimated to reach around 88.0 million metric tons by 2026. This growing demand reflects the importance of PP for applications where low density, hardness, high flexural modulus, and chemical resistance are needed [7,8]. Moreover, PP is 
a low-cost plastic capable of being processed with various methods, e.g., extrusion, thermoforming, and injection molding $[9,10]$. Therefore, a huge number of PP products, including fibers, films, sheets, textiles, pipes, and profiles, have been developed and used in the automotive, electrical and electronic, packaging, and construction industries [11-14]. On the other hand, due to the inherent flammability, the use of flame-retardant additives in PP is necessary to minimize the risk of fire [15]. Different types of flame retardants have been used in PP including minerals, phosphorus-based, nitrogen-based, and intumescent [16-18]. It was recognized that additive selection plays a crucial role in achieving acceptable flame retardancy [19], where the type, the size, and the loading percentage of flame retardants control the fire behavior of PP matrix.

A diversity of additives are used in PP to make it flame retardant. There is a need for a comprehensive survey to classify PP composites in terms of flame retardancy. In the present paper, several families of flame retardants examined in PP have been identified and categorized to evaluate their flame retardancy performance in terms of Flame Retardancy Index $(F R I)[19,20]$. FRI is a universal dimensionless index that takes into account well-known parameters obtained from cone calorimeter test (peak of heat release rate (pHRR), the total heat release (THR), and the time to ignition (TTI)). FRI can be simply calculated using Equation (1):

$$
\text { FRI }=\frac{\left[\text { THR } \times\left(\frac{\mathrm{pHRR}}{\mathrm{TTI}}\right)\right]_{\text {Neat Polymer }}}{\left[\text { THR } \times\left(\frac{\mathrm{pHRR}}{\mathrm{TTI}}\right)\right]_{\text {Composite }}}
$$

Basically, the use of $F R I$ makes it possible to semi-qualitatively classify polymer composites by labeling them as Poor, Good, or Excellent flame retardancy performance and thus enables evaluation of the efficiency of the incorporated flame retardant (FR). There has always been a need for fast-tracking and classifying polymers for their flame retardant performance. The use of FRI made possible classifying polymers and polymer composites in terms of flame retardancy in a simple manner. For FRI values below $10^{0}$ obtained by the use of Equation (1), we have the case (namely Poor) where the addition of FR adversely affects flame retardancy of polymer. When FRI takes values in the range of $10^{0}-10^{1}$, we name it Good flame retardancy performance, such that addition of FR enhances the resistance of polymer against fire. For $F R I$ values above $10^{1}$, which is rare in practical cases, we have an Excellent case, where FR significantly improves flame retardancy. It is worth mentioning that some important parameters of testing such as irradiance and sample thickness as well as sample weight can be neglected due to the fact that, in the FRI formula, the parameters related to the neat polymer are divided by those of polymer/FR composite. Thus, the dimensionless value obtained can be used as a reliable measure of the efficiency of FR in polymer. In this survey, the data from the literature were extracted first, and five families of flame retardants that served as PP were considered including phosphorus-based, nitrogen-based, mineral, carbon-based, and bio-based flame retardants, and hybrid cases composed of the aforementioned five categories were distinguished. The main aim of the present survey is to give the readers a broad view of FR systems used in PP via FRI classification method. Certainly, this classification is not a precise and unique data set for FR selection for PP, but it can be considered as a database to compare different systems. The focus of this work was particularly placed on the reports in which cone calorimetry test was carried out. However, some other parameters such as smoke quantity or the percentage of FR elements (phosphorus, nitrogen, ... ) were not systematically given in this research paper due to the lack of data, which could lead to unreliable judgments. For some papers, limiting oxygen index (LOI) and UL-94 data were also available, which were used in finding possible correlations between the FRI variation and other criteria.

\section{Phosphorus-Based Flame Retardants}

Various types of phosphorus-based flame retardants have been incorporated into PP to make it flame-retardant [21-23]. Table 1 reviews the names and the percentages of these flame retardants 
incorporated into PP. Moreover, the values obtained from cone calorimetry such as the peak of heat release rate (pHRR), the total heat release (THR), and the time to ignition (TTI) are summarized in this Table. The FRI value, calculated from cone calorimetry parameters, as well as the LOI and UL-94 values, are also presented in Table 1. In some cases, if LOI and/or UL-94 values were not available, the sign "—" was used.

Table 1. Flame-retardant PP materials containing phosphorus-based (P) flame retardants. Data are extracted from the literature: cone calorimetry parameters (TTI, pHRR, THR), LOI, and UL-94 values. The FRI values were calculated by authors of the present review. The name and the percentage of flame retardants are provided in separate columns. "wt.\%" was used for loading level of additives, while "_" stands for the systems free of additive or the neat PP. * FR means flame retardant. Since all comparisons were made in terms of FRI, classification of polymers in terms of their flame retardant properties was not surveyed based on the chemistry of additives, heat flux, sample thickness, etc.

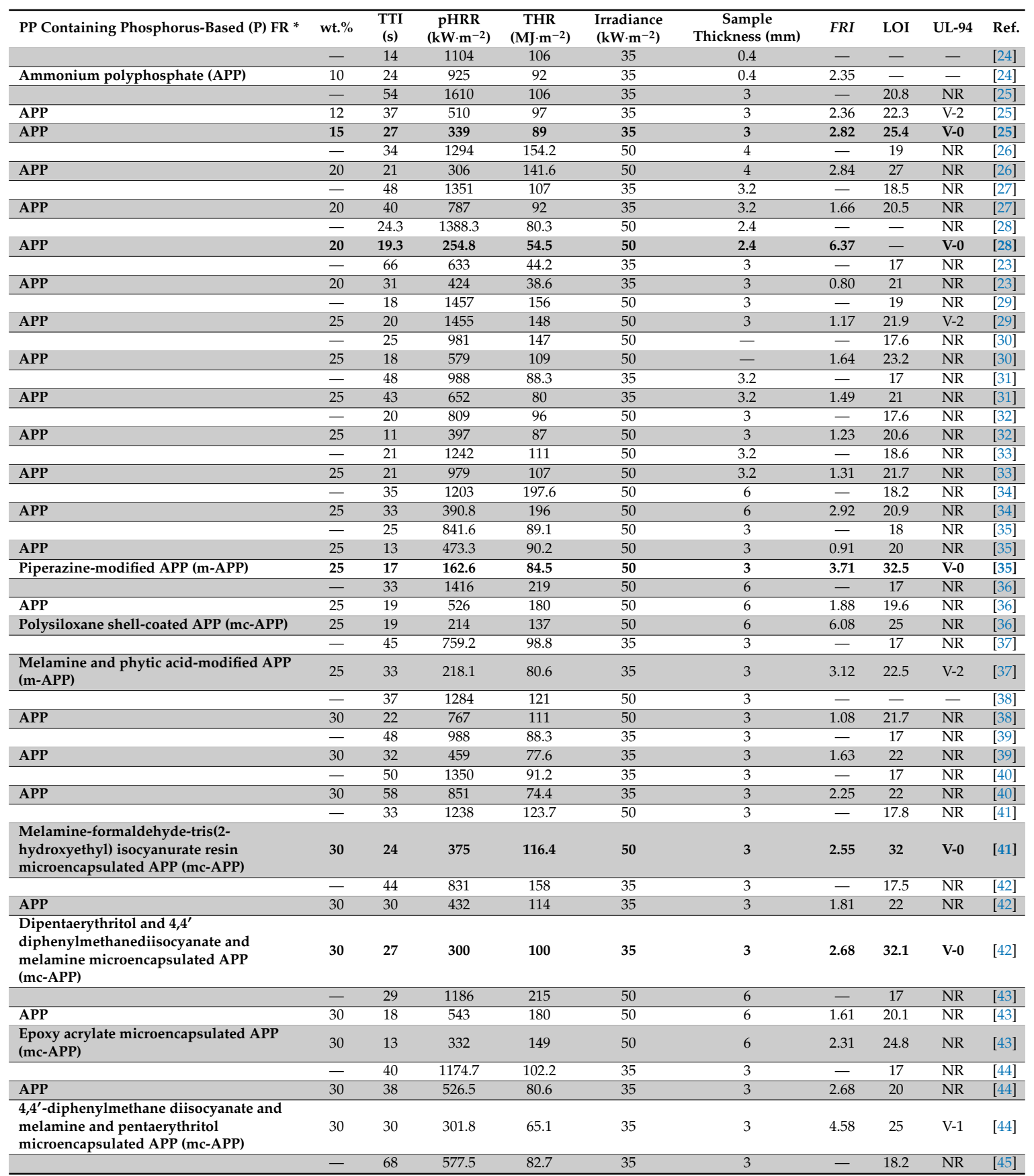


Table 1. Cont

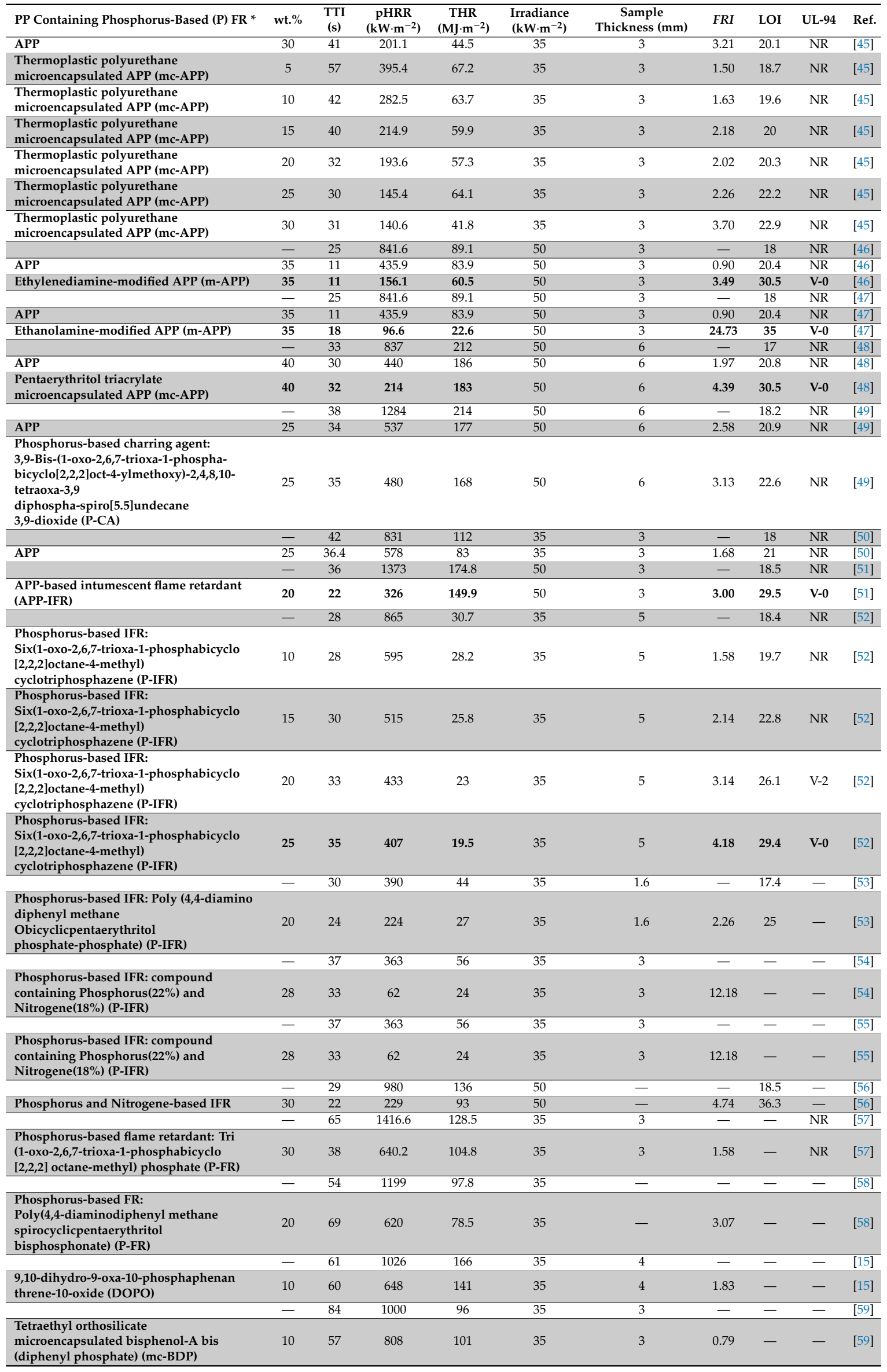


Table 1. Cont.

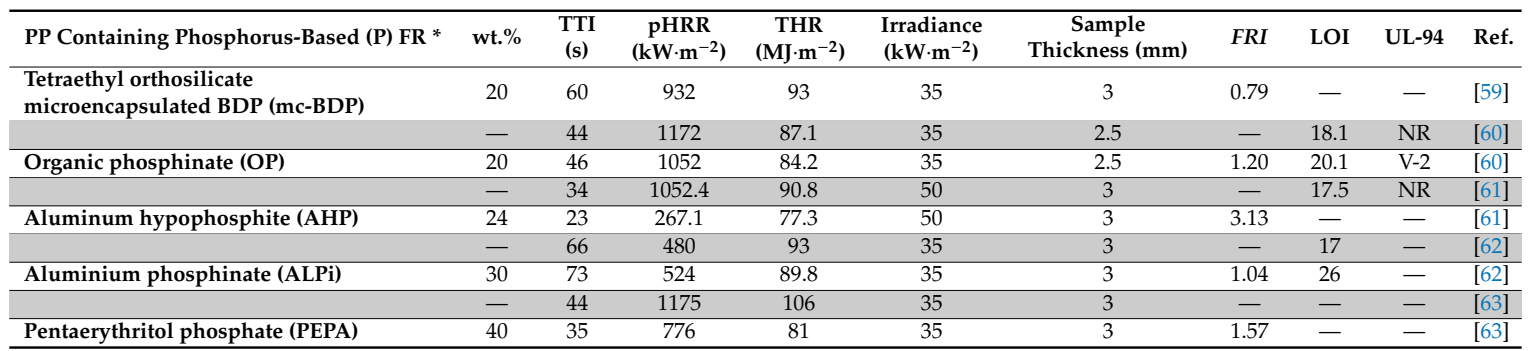

The information provided in Table 1 clearly reveals that APP is quite frequently used as a major phosphorus flame retardant in PP matrix. The percentage of incorporation of phosphorus flame retardants was variable from 10 to $40 \mathrm{wt} . \%$. Figure 1 displays the $F R I$ as a function of wt.\% phosphorus-based FR in PP systems. The name/type of each phosphorus flame retardant is provided in the caption of Figure 1. Three formulations reached the Excellent level of flame retardancy, which is quite rare among such data pool. The loading percentage of FR in these formulations varied from 28 to $35 \mathrm{wt} . \%$. Many additives were modified APP and modified phosphorus-nitrogen flame retardants. It can also be speculated that a high loading percentage cannot necessarily guarantee the Excellent level of flame retardancy; besides, the type of phosphorus FR is also an important parameter. Figure 1 also reveals that the majority of points are located in the Good zone of FRI. Therefore, it can be concluded that phosphorus-based flame retardants have quite satisfactorily reinforced PP against flame.

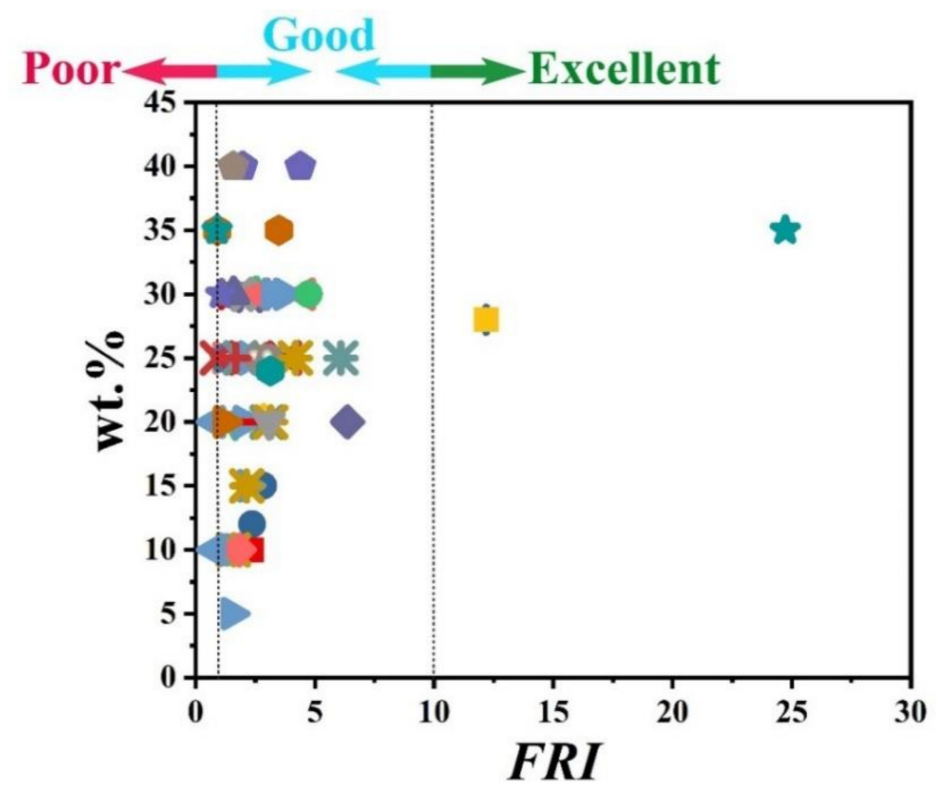

Figure 1. Flame Retardancy Index (FRI) values as a function of phosphorus flame retardant (FR) type and content. Symbols are indicative of different types of phosphorus flame retardant used. Here: APP-10 [24], - APP-12, APP-15 [25], $\triangle$ APP-20 [26], $\nabla$ APP-20 [27], A APP-20 [28], \ APP-20 [23], - APP-25 [29], APP-25 [30], * APP-25 [31], APP-25 [32], APP-25 [33], + APP-25 [34], X APP-25, m-APP-25 [35], * APP-25, mc-APP-25 [36], - m-APP-25 [37], I APP-30 [38], ם APP-30 [39], - APP-30 [40], $\triangle$ mc-APP-30 [41], $\nabla$ APP-30, mc-APP-30 [42], $\diamond$ APP-30, mc-APP-30 [43], $\triangleleft$ APP-30, mc-APP-30 [44], \ APP-30, mc-APP-5, mc-APP-10, mc-APP-15, mc-APP-20, mc-APP-25, mc-APP-30 [45], - APP-35, m-APP-35 [46], A APP-35, m-APP-35 [47], APP-40, mc-APP-40 [48], ๑ APP-25, P-CA-25 [49], + APP-25 [50], $\times$ APP-IFR-20 [51], * P-IFR-10, P-IFR-15, P-IFR-20, P-IFR-25 [52], - P-IFR-20 [53], 1

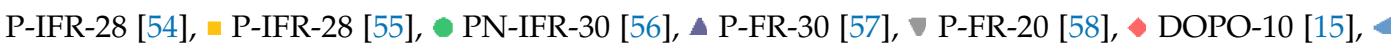
mc-BDP-10, mc-BDP-20 [59], O OP-20 [60], • AHP-24 [61], * ALPi-30 [62], • PEPA-40 [63]. 
There has always been interest in exploring possible correlations between the data collected from different analyses made on PP materials. Figure 2 shows the flame retardancy performance of phosphorus FR-containing PP in terms of FRI versus the corresponding UL-94 test outcomes. From these data, it is evident that no specified correlation exists between the qualitative results collected from UL-94 and the quantitative ones obtained in cone calorimeter measurements. However, in the case of LOI results, Figure 3 suggests a meaningful relationship can be drawn among data achieved from the calculated FRI and the LOI test results. The LOI value for pure PP is around 17; however, it is increased by addition of flame retardant up to 36, more than a two-fold rise.

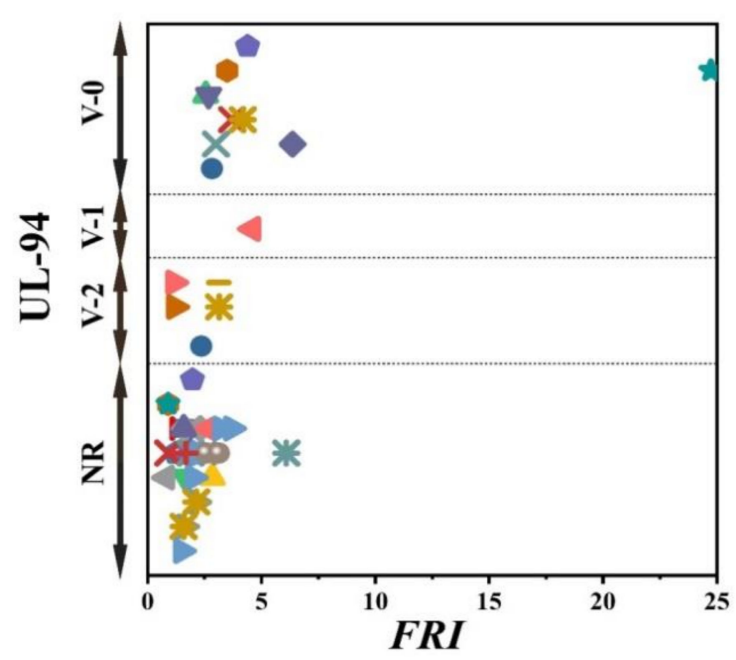

Figure 2. FRI values versus UL-94 test results. Symbols are indicative of different types of phosphorus flame retardant (FR) used. The vertical intervals in each category, i.e., V-0, V-1, V-2, and NR, are schematically representative of the amount of additive used. For example, two data distinguished by different symbols having the same or very close $F R I$ values (horizontal quantity) in a given category (e.g., V-1) may have different vertical quantities, e.g., both reveal V-1 behavior in the UL-94 test, but the upper contains more FR in Polypropylene (PP).

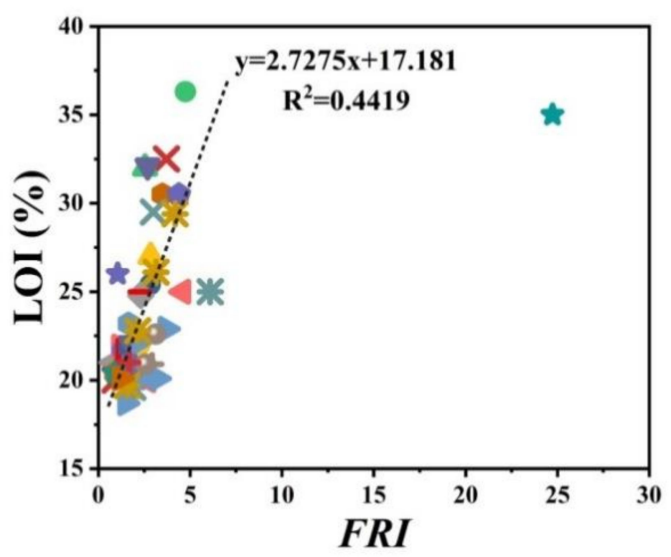

Figure 3. FRI values of PP as a function of limiting oxygen index (LOI) test results. Symbols are indicative of different types of phosphorus flame retardant used.

\section{Nitrogen-Based Flame Retardants}

Nitrogen-based flame retardants have also been used in PP to make it resistant against fire. Table 2 gives the names and the percentages of incorporation of these flame retardants, where the data were obtained in cone calorimetry (pHRR, THR, and TTI), FRI calculated from cone calorimetry parameters, as well as LOI and UL-94 values. Some of the nitrogen-based FRs listed in Table 2 also contain a 
phosphorus element. However, the percentage of nitrogen is more important, and therefore these FRs are listed in this Table.

Table 2. Flame retardant PP materials containing nitrogen-based $(\mathrm{N})$ flame retardants. Data are extracted from the literature: cone calorimetry parameters (TTI, pHRR, THR), LOI, and UL-94 values. The FRI values were calculated by authors of the present review. The name and the percentage of flame retardants are provided in separate columns. "wt.\%" was used for loading level of additives, while " - " stands for the systems free of additive or the neat PP. * FR means flame retardant. Since all comparisons were made in terms of FRI, classification of polymers in terms of their flame-retardant properties was not surveyed based on the chemistry of additives, heat flux, sample thickness, etc.

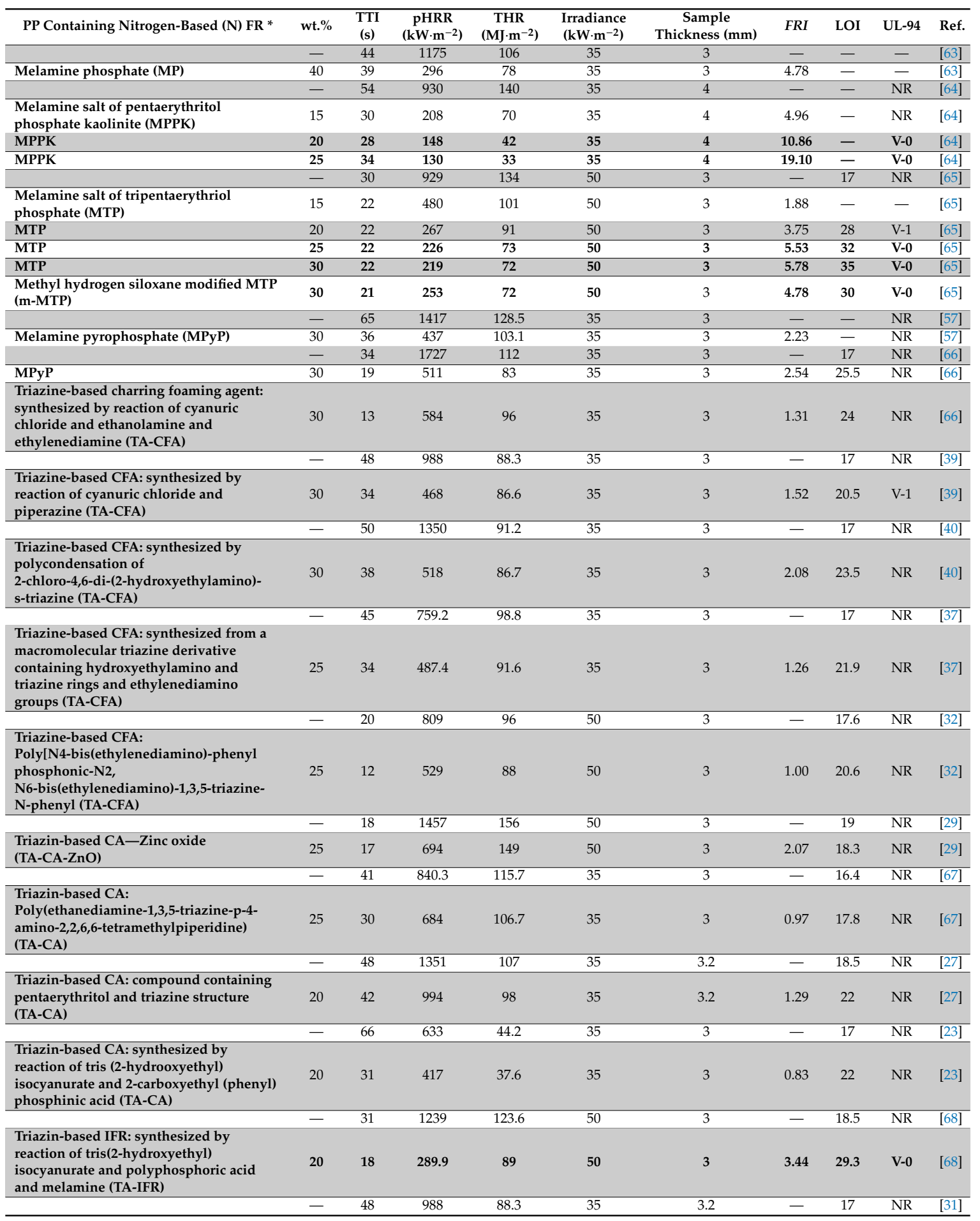


Table 2. Cont.

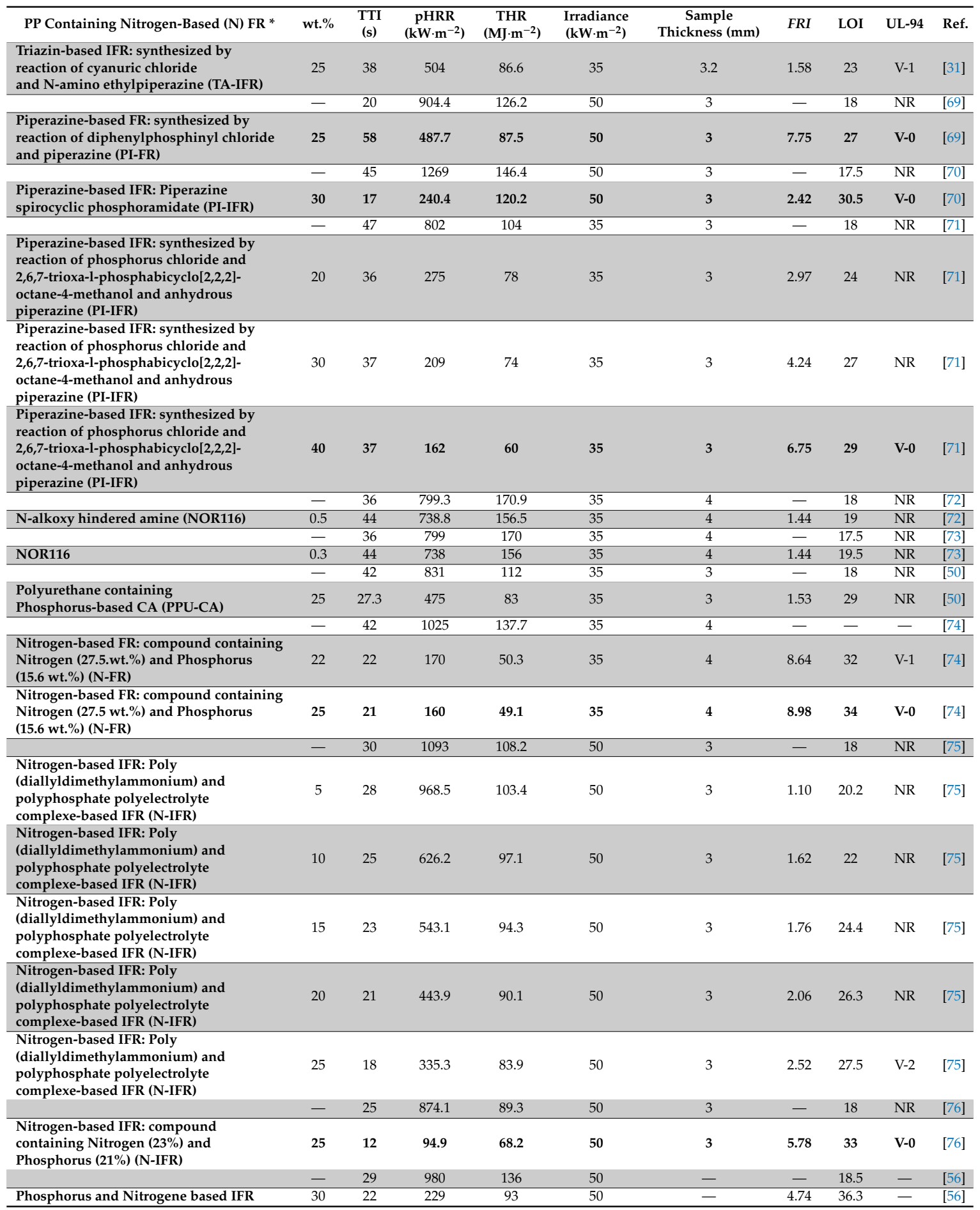

To give a bright view of the variation trend, Figure 4 illustrates the $F R I$ values as a function of $\mathrm{wt} . \%$ of nitrogen-based flame retardants incorporated into the PP. The percentage of incorporation was changed from 15 to $40 \mathrm{wt} . \%$. Of note, all points are located in the Good zone of FRI, except two points remarked as Excellent. These two points correspond to a kaolinite additive modified with nitrogen and phosphorus agents. A very noticeable point to be considered is that increasing the amount of diallyldimethylammonium (nominated with the symbol in Figure 4) from 5 to 25 has no serious effect on the value of $F R I$, so that they are aligned vertically around FRI values between 1.0 and 2.5. Overall, 
like what happened to other polymers $[77,78]$, combinatorial flame retardants may be the solution to flammability reduction of PP materials.

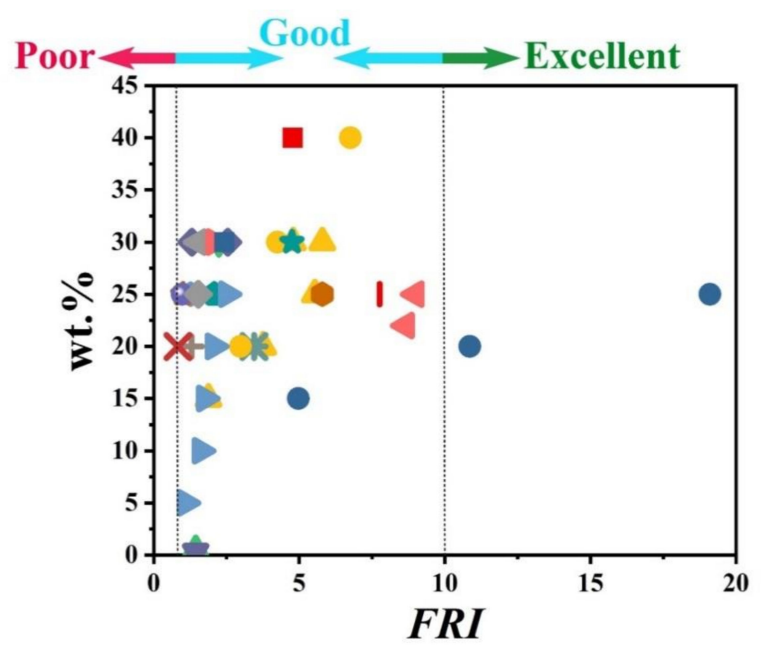

Figure 4. FRI values as a function of nitrogen FR type and content. Symbols are indicative of different types of nitrogen flame retardant used. Here: - MP-40 [63], - MPPK-15, MPPK-20, MPPK-25 [64], $\triangle$ MTP-15, MTP-20, MTP-25, MTP-30, m-MTP-30 [65], $\nabla$ MPyP-30 [57], $\bullet$ MPyP-30, TA-CFA-30 [66], $\checkmark$ TA-CFA-30 [39], > TA-CFA-30 [40], • TA-CFA-25 [37], * TA-CFA-25 [32], * TA-CA-ZnO-25 [29], • TA-CA-25 [67], + TA-CA-20 [27], × TA-CA-20 [23], * TA-IFR-20 [68], - TA-IFR-25 [31], I PI-FR-25 [69], • PI-IFR-30 [70], P PI-IFR-20, PI-IFR-30, PI-IFR-40 [71], $\triangle$ NOR116-0.5 [72], จ NOR116-0.3 [73], PPU-CA-25 [50], \ N-FR-22, N-FR-25 [74], \ N-IFR-5, N-IFR-10, N-IFR-15, N-IFR-20, N-IFR-25 [75], • N-IFR-25 [76], * PN-IFR-30 [56].

Figure 5 patterns UL-94 results as a function of $F R I$ for nitrogen-based flame retardant in PP. It can be observed that even at small quantities of $F R I, \mathrm{~V} 0$ in UL-94 was achieved. The diversity of data in Figure 5 can be taken as a signature of sensitivity of UL-94 to FRI. Figure 6 shows LOI values as a function of FRI. There is a quite reasonable correlation between the LOI and FRI values, up to FRI value of 6 .

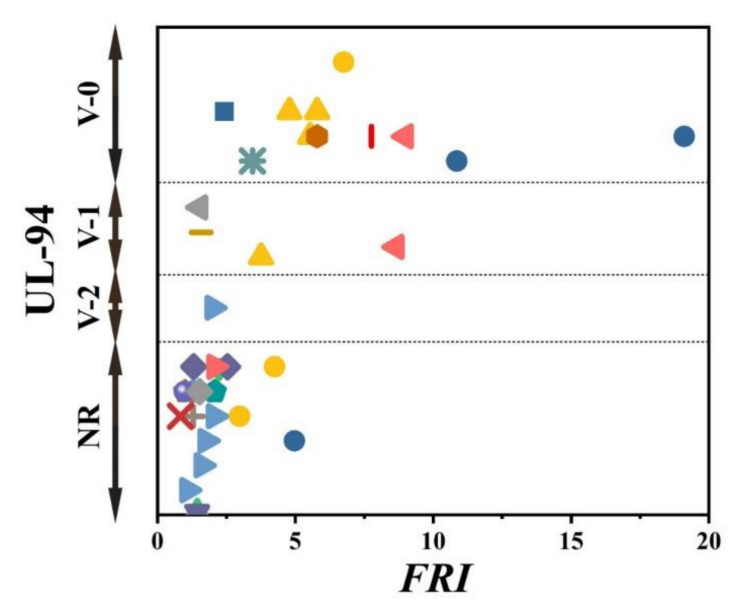

Figure 5. FRI values versus UL-94 test results. Symbols are indicative of different types of nitrogen flame retardant (FR) used. The vertical intervals in each category, i.e., V-0, V-1, V-2, and NR, are schematically representative of the amount of additive used. For example, two data distinguished by different symbols having the same or very close FRI values (horizontal quantity) in a given category (e.g., V-1), may have different vertical quantities; e.g., both reveal V-1 behavior in UL-94 test, but the upper contains more FR in PP. 


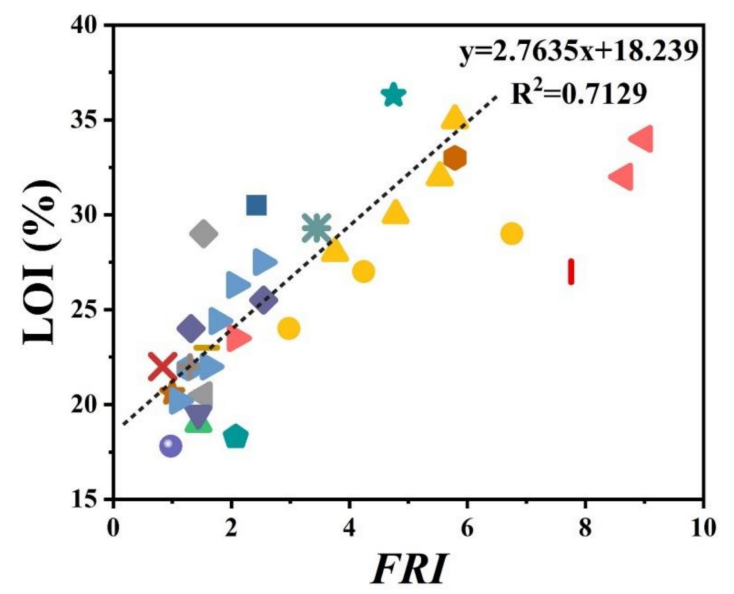

Figure 6. FRI values of PP as a function of LOI test results. Symbols are indicative of different types of nitrogen flame retardant used.

\section{Mineral-Based Flame Retardants}

Mineral additives have been widely used in polymers for their acceptable cost and properties [79]. Mineral-based flame retardants including clays are widely used in PP due to their low cost and acceptable thermal resistance. In this family, the most used flame retardants in volume were aluminum trihydroxide (ATH) and magnesium dihydroxide (MDH). However, due to their low efficiency, a high percentage of loading was necessary for achieving an acceptable level of flame retardancy of polymers. The name and the percentage of the used mineral-based flame retardants in PP are listed in Table 3. Cone calorimetry data, FRI, LOI, and UL-94 values are also given so as to make possible a detailed view on the status of flame retardant efficiency of PP materials.

Table 3. Flame-retardant PP materials containing mineral-based (M) flame retardants. Data are extracted from the literature: cone calorimetry parameters (TTI, pHRR, THR), LOI, and UL-94 values. The FRI values were calculated by authors of the present review. The name and the percentage of flame retardants are provided in separate columns. "wt.\%" was used for loading level of additives, while "- " stands for the systems free of additive or the neat PP. * FR means flame retardant. Since all comparisons were made in terms of FRI, classification of polymers in terms of their flame-retardant properties was not surveyed based on the chemistry of additives, heat flux, sample thickness, etc.

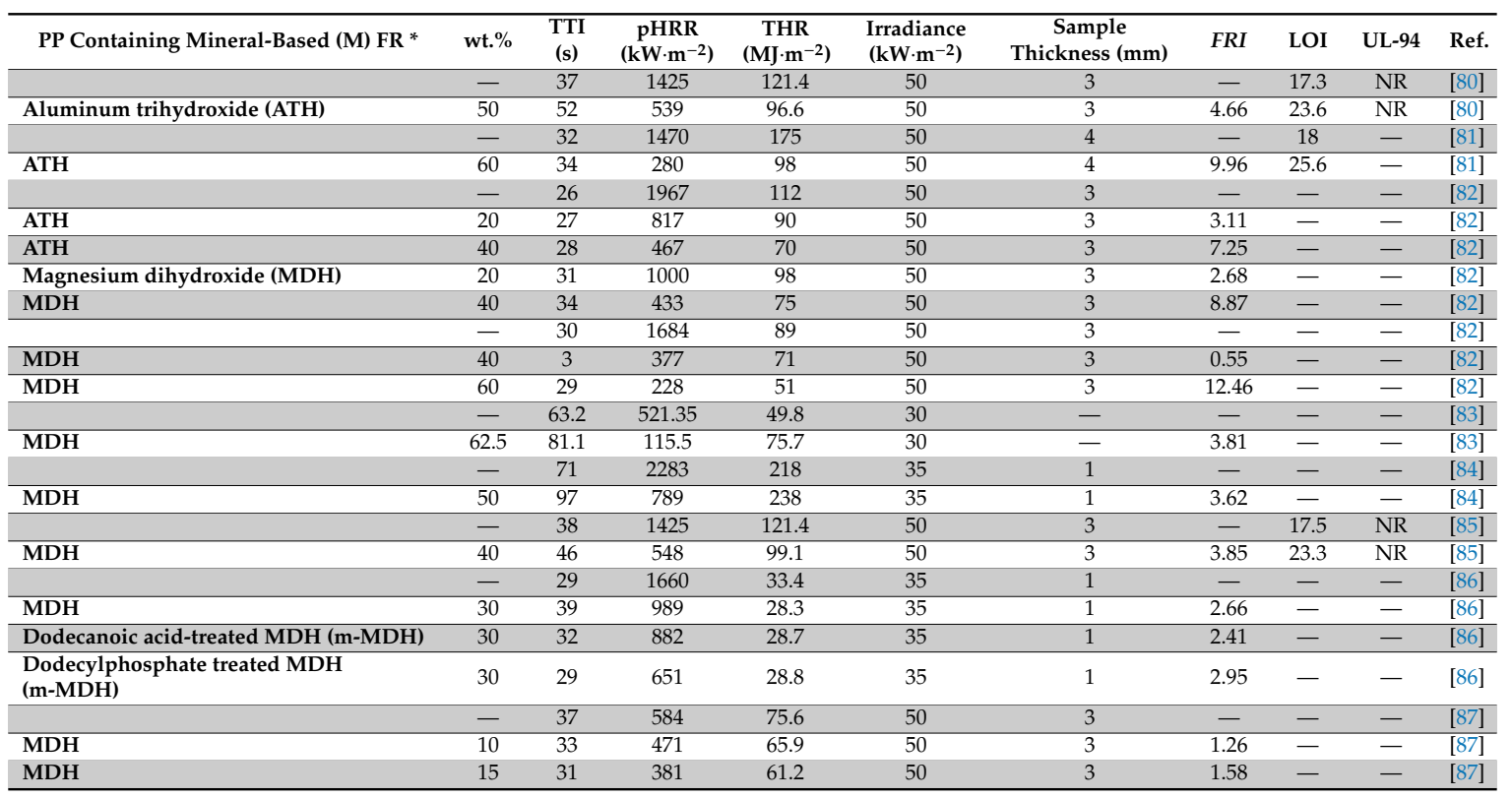


Table 3. Cont

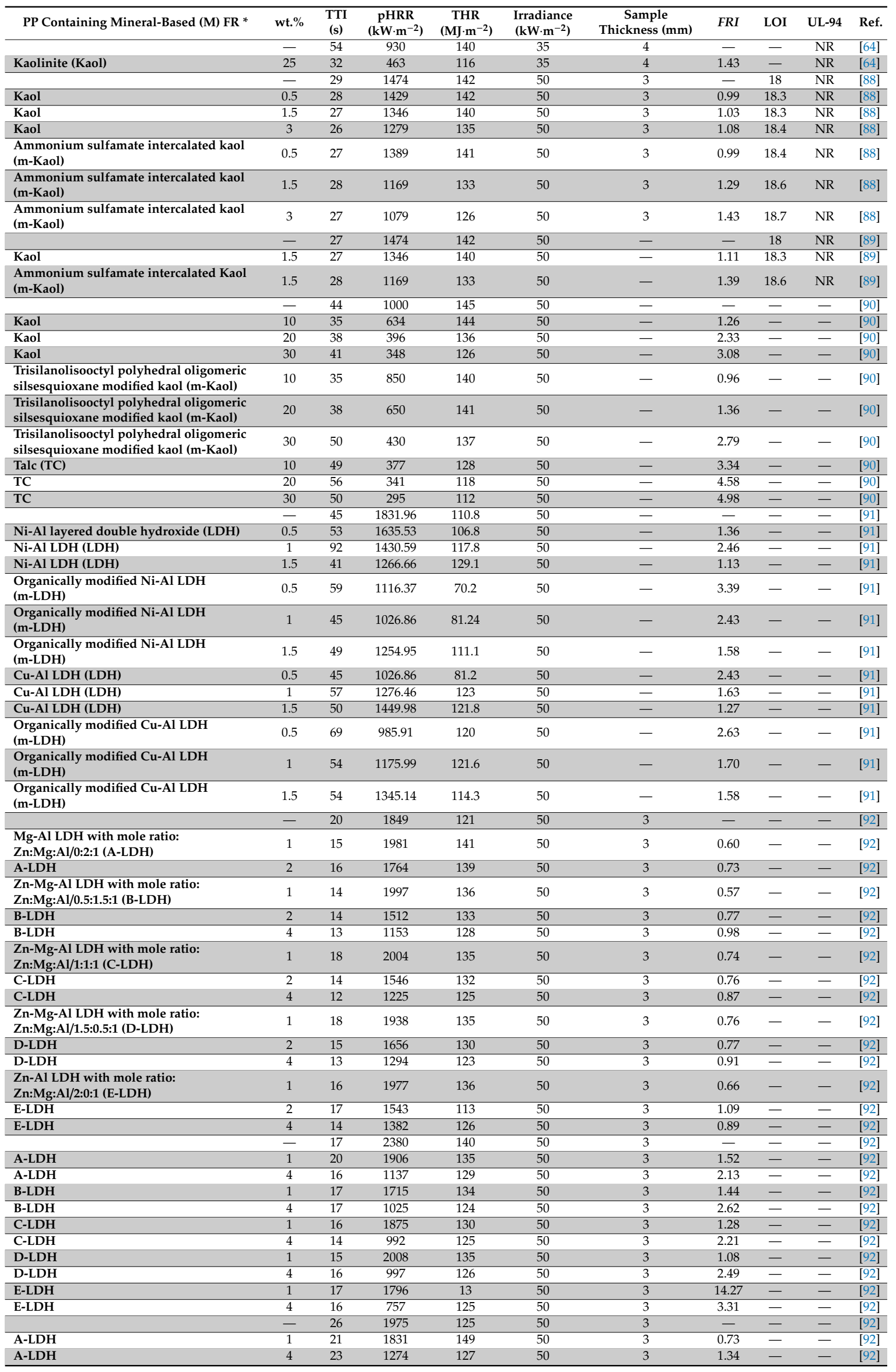


Table 3. Cont.

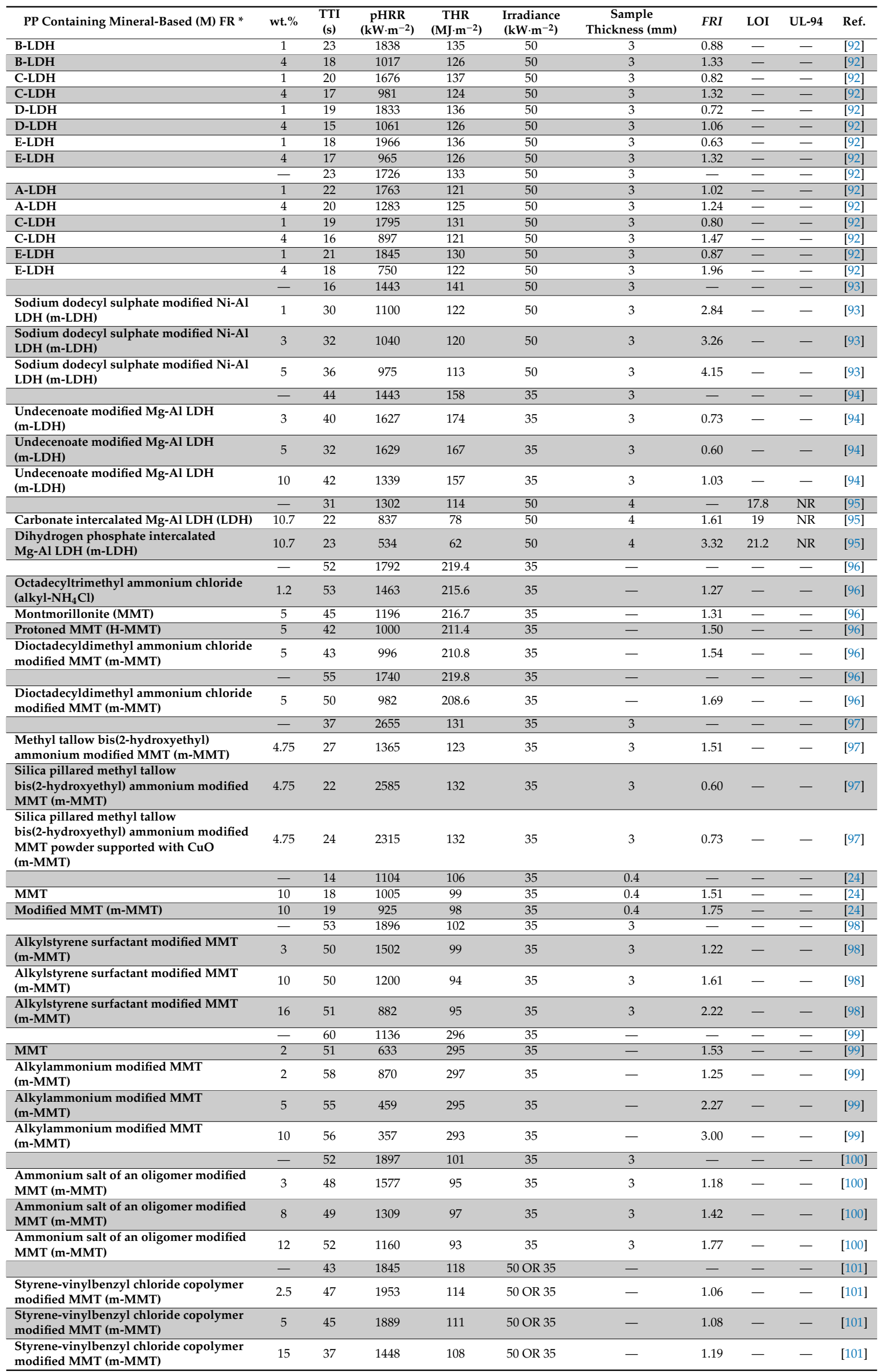


Table 3. Cont

\begin{tabular}{|c|c|c|c|c|c|c|c|c|c|c|}
\hline PP Containing Mineral-Based (M) FR * & wt. $\%$ & $\begin{array}{l}\text { TTI } \\
\text { (s) }\end{array}$ & $\begin{array}{c}\mathrm{pHRR} \\
\left(\mathrm{kW} \cdot \mathrm{m}^{-2}\right)\end{array}$ & $\begin{array}{c}\text { THR } \\
\left(\mathrm{MJ} \cdot \mathrm{m}^{-2}\right)\end{array}$ & $\begin{array}{l}\text { Irradiance } \\
\left(\mathbf{k W} \cdot \mathrm{m}^{-2}\right)\end{array}$ & $\begin{array}{c}\text { Sample } \\
\text { Thickness (mm) }\end{array}$ & $F R I$ & LOI & UL-94 & Ref. \\
\hline $\begin{array}{l}\text { Styrene-vinylbenzyl chloride copolymer } \\
\text { modified MMT (m-MMT) }\end{array}$ & 25 & 38 & 1191 & 102 & 50 OR 35 & - & 1.58 & - & - & [101] \\
\hline $\begin{array}{l}\text { Methyl methacrylate-vinylbenzyl } \\
\text { chloride copolymer modified MMT } \\
\text { (m-MMT) }\end{array}$ & 2.5 & 44 & 2025 & 123 & 50 OR 35 & - & 0.89 & - & - & [101] \\
\hline $\begin{array}{l}\text { Methyl methacrylate-vinylbenzyl } \\
\text { chloride copolymer modified MMT } \\
\text { (m-MMT) }\end{array}$ & 5 & 42 & 1738 & 120 & 50 OR 35 & - & 1.01 & - & - & [101] \\
\hline $\begin{array}{l}\text { Methyl methacrylate-vinylbenzyl } \\
\text { chloride copolymer modified MMT } \\
\text { (m-MMT) }\end{array}$ & 15 & 39 & 1651 & 115 & 50 OR 35 & - & 1.04 & - & - & [101] \\
\hline \multirow[t]{2}{*}{$\begin{array}{l}\text { Methyl methacrylate-vinylbenzyl } \\
\text { chloride copolymer modified MMT } \\
\text { (m-MMT) }\end{array}$} & 25 & 41 & 1139 & 105 & 50 OR 35 & - & 1.73 & - & - & [101] \\
\hline & - & 55 & 1586 & 113 & 35 & - & - & - & - & [102] \\
\hline $\begin{array}{l}\text { Methyl methacrylate modified MMT } \\
\text { (m-MMT) }\end{array}$ & 1 & 66 & 1108 & 104 & 35 & - & 1.86 & - & - & [102] \\
\hline $\begin{array}{l}\text { Methyl methacrylate modified MMT } \\
\text { (m-MMT) }\end{array}$ & 3 & 44 & 839 & 87 & 35 & - & 1.96 & - & - & [102] \\
\hline \multirow[t]{2}{*}{$\begin{array}{l}\text { Methyl methacrylate modified MMT } \\
\text { (m-MMT) }\end{array}$} & 5 & 35 & 557 & 77 & 35 & - & 2.65 & - & - & [102] \\
\hline & - & 50.2 & 789 & 156.6 & 35 & - & - & 17.5 & - & [103] \\
\hline Nanofil (Nf) & 5 & 48 & 739 & 173.4 & 35 & - & 0.92 & 22 & - & [103] \\
\hline \multirow[t]{2}{*}{ Organically modified bentonite (m-BT) } & 5 & 45.6 & 774 & 166.6 & 35 & - & 0.87 & 22 & - & [103] \\
\hline & - & 33 & 847 & 159.8 & 50 & - & - & 17.5 & - & [103] \\
\hline $\mathbf{N f}$ & 5 & 37 & 1047 & 174 & 50 & - & 0.83 & 22 & - & [103] \\
\hline \multirow[t]{2}{*}{ m-BT } & 5 & 36 & 1093 & 164 & 50 & - & 0.82 & 22 & - & [103] \\
\hline & - & 35 & 1622 & 103 & 35 & 3 & - & - & - & [104] \\
\hline $\begin{array}{l}\text { Cloisite 20A: Dimethyl, dihydrogenated } \\
\text { tallow ammonium modified MMT (C20A) }\end{array}$ & 1 & 33 & 1751 & 105 & 35 & 3 & 0.85 & - & - & [104] \\
\hline $\mathrm{C20A}$ & 3 & 34 & 1874 & 107 & 35 & 3 & 0.80 & - & - & [104] \\
\hline \multirow[t]{2}{*}{ C20A } & 5 & 39 & 1487 & 105 & 35 & 3 & 1.19 & - & - & [104] \\
\hline & & 44 & 1172 & 87.1 & 35 & 2.5 & - & 18.1 & NR & [60] \\
\hline \multirow[t]{2}{*}{$\begin{array}{l}\text { Cloisite 15A: dimethyl dehydrogenated } \\
\text { tallow ammonium cation modified } \\
\text { sodium MMT (C15A) }\end{array}$} & 5 & 41 & 1050 & 88.2 & 35 & 2.5 & 1.02 & 18.1 & NR & [60] \\
\hline & - & 88 & 565.9 & 71.9 & 35 & 3 & - & - & - & [105] \\
\hline $\mathrm{C20A}$ & 5 & 76 & 518.2 & 75.9 & 35 & 3 & 0.89 & 20 & - & [105] \\
\hline $\mathrm{C20A}$ & 5 & 89 & 415.6 & 73 & 35 & 3 & 1.35 & 20 & - & {$[105]$} \\
\hline \multirow{2}{*}{ Titanium dioxide $\left(\mathrm{TiO}_{2}\right)$} & 0.5 & 99 & 488.1 & 75 & 35 & 3 & 1.25 & 20 & - & [105] \\
\hline & - & 49 & 1247 & 114.2 & 35 & - & - & - & - & [106] \\
\hline \multirow[t]{2}{*}{ Activated alumina $\left(\mathrm{Al}_{2} \mathrm{O}_{3}\right)$} & 2 & 35 & 943 & 108.2 & 35 & - & 0.99 & - & - & [106] \\
\hline & - & 28 & 1633 & 132 & 50 & 4 & - & 18 & - & [107] \\
\hline $\mathrm{NiFeO}$ & 2 & 27 & 1372 & 129 & 50 & 4 & 1.17 & 18 & - & [107] \\
\hline \multirow[t]{2}{*}{$\mathrm{CoFeO}$} & 2 & 24 & 1335 & 127 & 50 & 4 & 1.08 & 18 & - & [107] \\
\hline & - & 38 & 1284 & 241 & 50 & 6 & - & - & - & [108] \\
\hline \multirow[t]{2}{*}{$\mathrm{Ni}_{2} \mathrm{O}_{3}$} & 7.5 & 53 & 655 & 161 & 50 & 6 & 4.09 & - & - & {$[108]$} \\
\hline & - & 64 & 1909 & 254 & 50 & 3 & - & - & - & [109] \\
\hline $\mathrm{Mo} / \mathrm{Mg} / \mathrm{Ni} / \mathrm{O}$ catalysts (Nmm-cat) & 1 & 62 & 490 & 205 & 50 & 3 & 4.67 & - & - & [109] \\
\hline Nmm-cat & 2 & 63 & 292 & 168 & 50 & 3 & 9.72 & - & - & [109] \\
\hline \multirow[t]{2}{*}{ Nmm-cat } & 3 & 60 & 275 & 149 & 50 & 3 & 11.09 & - & - & [109] \\
\hline & - & 52 & 915.7 & 112.5 & 50 & 3 & - & 18 & - & {$[110]$} \\
\hline Magnesium oxysulfate whisker (MOSw) & 30 & 62 & 259.1 & 90.4 & 50 & 3 & 5.24 & 24.7 & - & {$[110]$} \\
\hline \multirow[t]{2}{*}{$\begin{array}{l}\text { Dodecyl dihydrogen phosphate modified } \\
\text { MOSw (m-MOSw) }\end{array}$} & 30 & 64 & 243.3 & 72.8 & 50 & 3 & 7.15 & 26.1 & - & [110] \\
\hline & - & 48 & 195.5 & 28.6 & 35 & 2 & - & - & - & [111] \\
\hline Manganese oxide (MnO) & 10 & 54 & 233.7 & 31.8 & 35 & 2 & 0.84 & - & - & {$[111]$} \\
\hline Manganese oxide $\left(\mathrm{Mn}_{2} \mathrm{O}_{3}\right)$ & 10 & 48 & 271.3 & 31.5 & 35 & 2 & 0.65 & - & - & [111] \\
\hline Manganese oxalate $\left(\mathrm{MnC}_{2} \mathrm{O}_{4}\right)$ & 10 & 50 & 281.6 & 29.3 & 35 & 2 & 0.70 & - & - & [111] \\
\hline & - & 30 & 390 & 44 & 35 & 1.6 & - & 17.4 & - & [53] \\
\hline Zinc acetyl acetonate (Znacac) & 1 & 31 & 366 & 28 & 35 & 1.6 & 1.73 & 19.5 & - & [53] \\
\hline Chromium acetyl acetonate (Cracac) & 1 & 31 & 307 & 28 & 35 & 1.6 & 2.06 & 20.7 & - & {$[53]$} \\
\hline & - & 51 & 1053 & 117.6 & 35 & 3 & - & - & - & [112] \\
\hline Zirconium phenylphosphonate (ZrPP) & 2 & 34 & 754 & 99.4 & 35 & 3 & 1.10 & - & - & [112] \\
\hline & - & 40 & 364 & 40 & 35 & 2 & - & - & - & [113] \\
\hline Siloxane silsesquioxane resin (S4SQH) & 1 & 41 & 354 & 47 & 35 & 2 & 0.89 & - & - & [113] \\
\hline S4SQH & 5 & 21 & 500 & 44 & 35 & 2 & 0.34 & - & - & {$[113]$} \\
\hline S4SQH & 10 & 19 & 445 & 44 & 35 & 2 & 0.35 & - & - & {$[113]$} \\
\hline n-octyl functionalized S4SQH (m-S4SQH) & 1 & 43 & 227 & 29 & 35 & 2 & 2.37 & - & - & [113] \\
\hline n-octyl functionalized S4SQH (m-S4SQH) & 5 & 40 & 481 & 48 & 35 & 2 & 0.63 & - & - & {$[113]$} \\
\hline $\begin{array}{l}\text { n-octadecyl functionalized S4SQH } \\
\text { (m-S4SQH) }\end{array}$ & 1 & 40 & 168 & 22 & 35 & 2 & 3.93 & - & - & [113] \\
\hline $\begin{array}{l}\text { n-octadecyl functionalized S4SQH } \\
\text { (m-S4SQH) }\end{array}$ & 5 & 43 & 328 & 42 & 35 & 2 & 1.13 & - & - & [113] \\
\hline $\begin{array}{l}\text { n-octadecyl functionalized S4SQH } \\
\text { (m-S4SQH) }\end{array}$ & 10 & 47 & 391 & 47 & 35 & 2 & 0.93 & - & - & [113] \\
\hline & - & 25 & 981 & 147 & 50 & - & - & 17.6 & NR & [30] \\
\hline Polysiloxane based FR (Si-FR) & 25 & 18 & 624 & 110 & 50 & - & 1.51 & 24.1 & NR & {$[30]$} \\
\hline & - & 54 & 1610 & 106 & 35 & 3 & - & 20.8 & NR & [25] \\
\hline Sepiolite (SEP) & 0.5 & 48 & 1701 & 108 & 35 & 3 & 0.82 & 20 & NR & [25] \\
\hline Organically modified SEP (m-SEP) & 0.5 & 46 & 1665 & 106 & 35 & 3 & 0.82 & 19.2 & NR & [25] \\
\hline & - & 37 & 584 & 75.6 & 50 & 3 & - & - & - & [87] \\
\hline
\end{tabular}


Table 3. Cont.

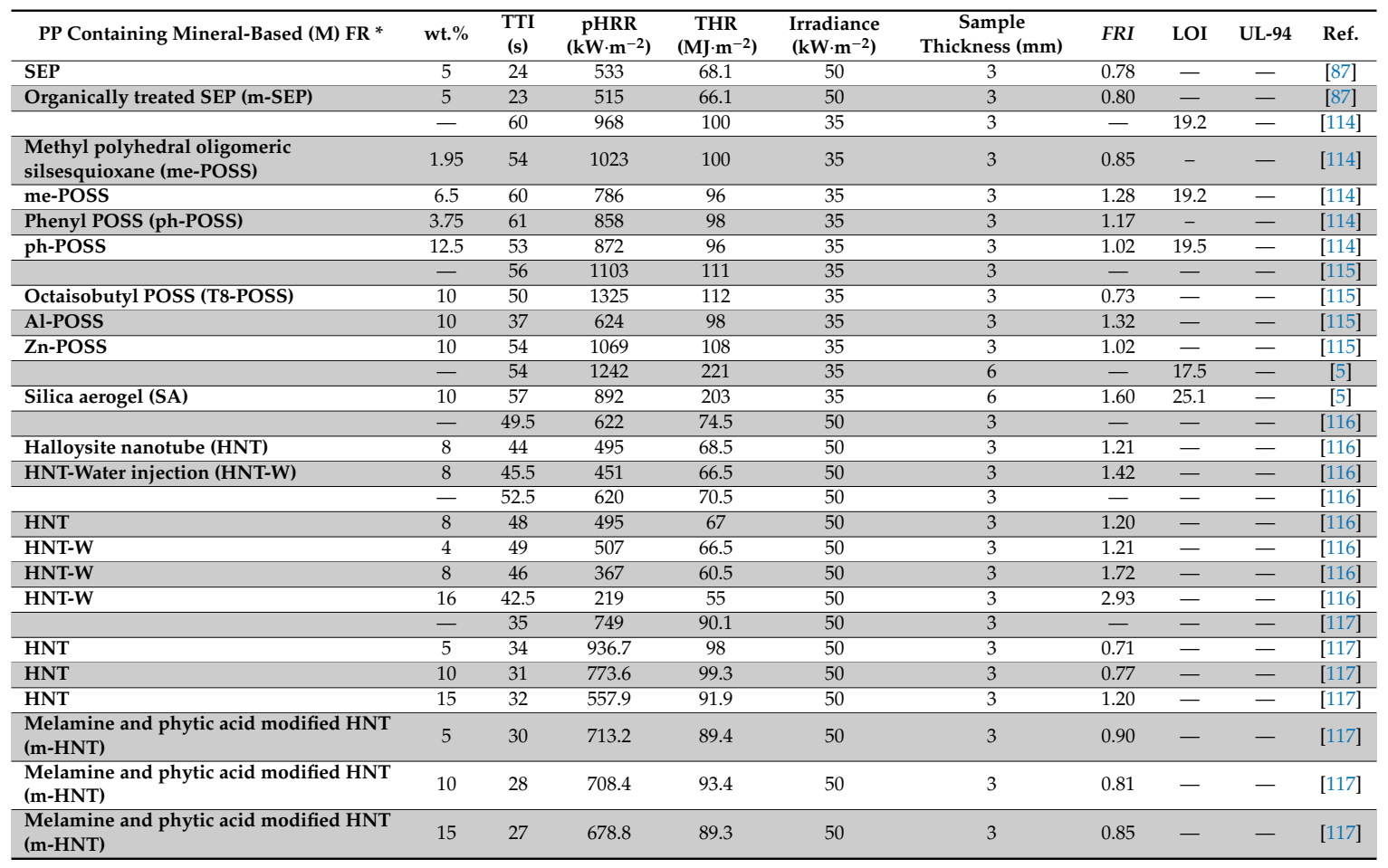

Figure 7 visualizes the variation of $F R I$ value as a function of flame retardant loading in PP systems (for the convenience of readers, two figures are added for giving a better zoom on data points). This figure clearly shows that even at low loading percentages, it is possible to achieve a relatively high FRI value depending on the type of mineral. There is no denying that some parameters such as the state of dispersion and size of particles are important factors affecting the flame retardant properties.
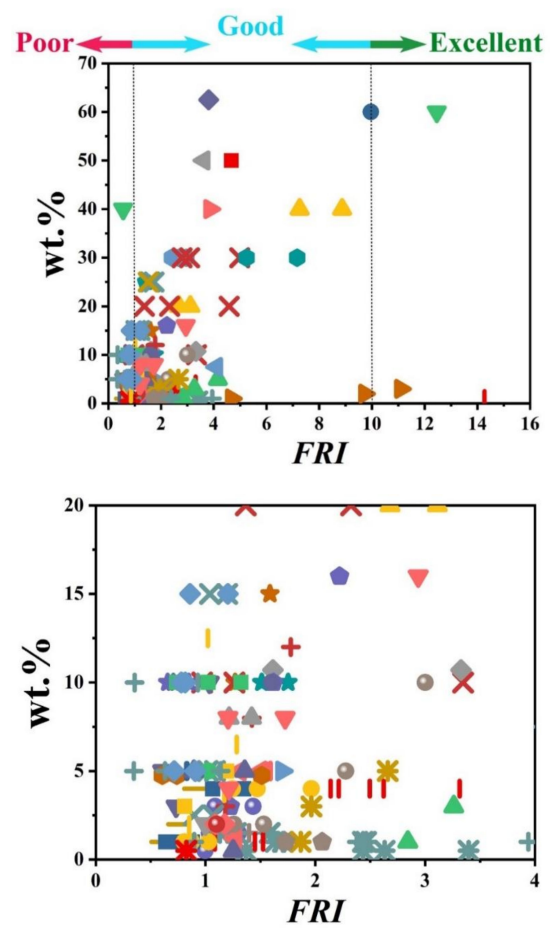

Figure 7. Cont. 


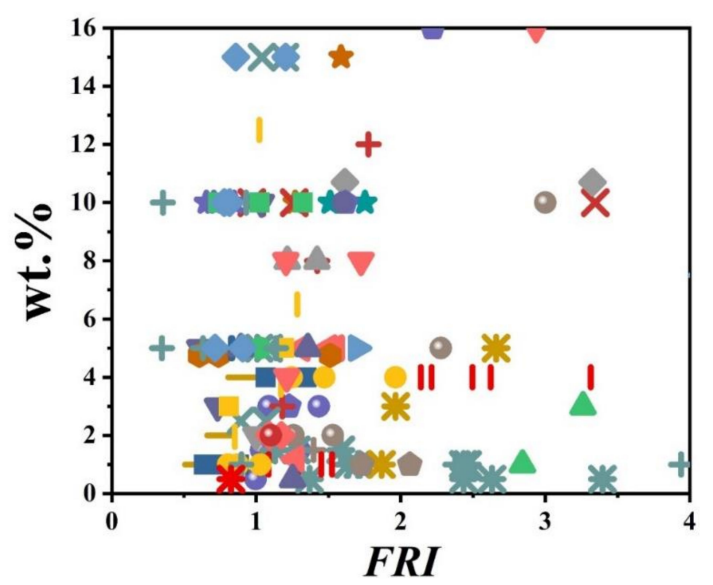

Figure 7. FRI values as a function of the mineral FR type and content from close-up and long-shot views. Symbols are indicative of different types of mineral flame retardant used. The diversity and abundance of data were reasons why such different scales were provided for detection of behavior of PP against flame. Here: - ATH-50 [80], ATH-60 [81], ATH-20, ATH-40, MDH-20, MDH-40 [82], $\nabla$ MDH-40, MDH-60 [82], • MDH-62.5 [83], \ MDH-50 [84], • MDH-40 [85], • MDH-30, m-MDH-30, m-MDH-30 [86], * MDH-10, MDH-15 [87], - Kaol-25 [64], • Kaol-0.5, Kaol-1.5, Kaol-3, m-Kaol-0.5, m-Kaol-1.5, m-Kaol-3 [88], + Kaol-1.5, m-Kaol-1.5 [89], × Kaol-10, Kaol-20, Kaol-30, m-Kaol-10, m-Kaol-20, m-Kaol-30, TC-10, TC-20, TC-30 [90], * LDH-0.5, LDH-1, LDH-1.5, m-LDH-0.5, m-LDH-1， m-LDH-1.5, LDH-0.5, LDH-1, LDH-1.5, m-LDH-0.5, m-LDH-1， m-LDH-1.5 [91], A-LDH-1, A-LDH-2, B-LDH-1, B-LDH-2, B-LDH-4, C-LDH-1, C-LDH-2, C-LDH-4, D-LDH-1, D-LDH-2, D-LDH-4, E-LDH-1, E-LDH-2, E-LDH-4 [92], I A-LDH-1, A-LDH-4, B-LDH-1, B-LDH-4, C-LDH-1, C-LDH-4, D-LDH-1, D-LDH-4, E-LDH-1, E-LDH-4 [92], A-LDH-1, A-LDH-4, B-LDH-1, B-LDH-4, C-LDH-1, C-LDH-4, D-LDH-1, D-LDH-4, E-LDH-1, E-LDH-4 [92], A-LDH-1, A-LDH-4, C-LDH-1, C-LDH-4, E-LDH-1, E-LDH-4 [92], $\triangle$ m-LDH-1, m-LDH-3, m-LDH-5 [93], $\nabla$ m-LDH-3, m-LDH-5, m-LDH-10 [94], $\diamond$ LDH-10.7, m-LDH-10.7 [95], \ alkyl-NH 4 Cl-1.2, MMT-5, H-MMT-5, m-MMT-5 [96], m-MMT-5 [96], • m-MMT-4.75, m-MMT-4.75, m-MMT-4.75 [97], * MMT-10, m-MMT-10 [24], • m-MMT-3, m-MMT-10, m-MMT-16 [98], @ MMT-2, m-MMT-2, m-MMT-5, m-MMT-10 [99], + m-MMT-3, m-MMT-8, m-MMT-12 [100], × m-MMT-2.5, m-MMT-5, m-MMT-15, m-MMT-25, m-MMT-2.5, m-MMT-5, m-MMT-15, m-MMT-25 [101], * m-MMT-1, m-MMT-3, m-MMT-5 [102], - Nf-5, m-BT-5 [103], I Nf-5, m-BT-5 [103], $₫ \mathrm{C} 20 \mathrm{~A}-1, \mathrm{C} 20 \mathrm{~A}-3, \mathrm{C} 20 \mathrm{~A}-5$ [104], $\bullet \mathrm{C} 15 \mathrm{~A}-5$ [60], $\triangle \mathrm{C} 20 \mathrm{~A}-5, \mathrm{C} 20 \mathrm{~A}-5, \mathrm{TiO}_{2}-0.5$ [105], v $\mathrm{Al}_{2} \mathrm{O}_{3}-2$ [106], $\triangleleft \mathrm{NiFeO}-2, \mathrm{CoFeO}-2$ [107], $\triangleleft \mathrm{Ni}_{2} \mathrm{O}_{3}-7.5$ [108], $\triangleright$ Nmm-cat-1, Nmm-cat-2, Nmm-cat-3 [109], - MOSw-30, m-MOSw-30 [110], $\star \mathrm{MnO}-10, \mathrm{Mn}_{2} \mathrm{O}_{3}-10, \mathrm{MnC}_{2} \mathrm{O}_{4}-10$ [111], Znacac-1, Cracac-1 [53], - ZrPP-2 [112], + S4SQH-1, S4SQH-5, S4SQH-10, m-S4SQH-1, m-S4SQH-5, m-S4SQH-1, m-S4SQH-5, m-S4SQH-10 [113], × Si-FR-25 [30], * SEP-0.5, m-SEP-0.5 [25], - SEP-5, m-SEP-5 [87], I me-POSS-1.95, me-POSS-6.5, ph-POSS-3.75, ph-POSS-12.5 [114], = T8-POSS-10, Al-POSS-10, Zn-POSS-10 [115], • SA-10 [5], ^ HNT-8, HNT-W-8 [116], จ HNT-8, HNT-W-4, HNT-W-8, HNT-W-16 [116], • HNT-5, HNT-10, HNT-15, m-HNT-5, m-HNT-10, m-HNT-15 [117].

Unfortunately, the number of papers in which cone calorimetry, UL-94, and LOI values were studied was indeed limited, but the ones available are used plotting Figure 8. It should be noted that no formulation among studied ones is rated at V0. In conclusion, it is quite difficult to find a correlation between quantitative and qualitative parameters based on such a tiny set of data. In regard to the relationship between LOI and FRI, a meaningful trend can still be seen in Figure 9. 


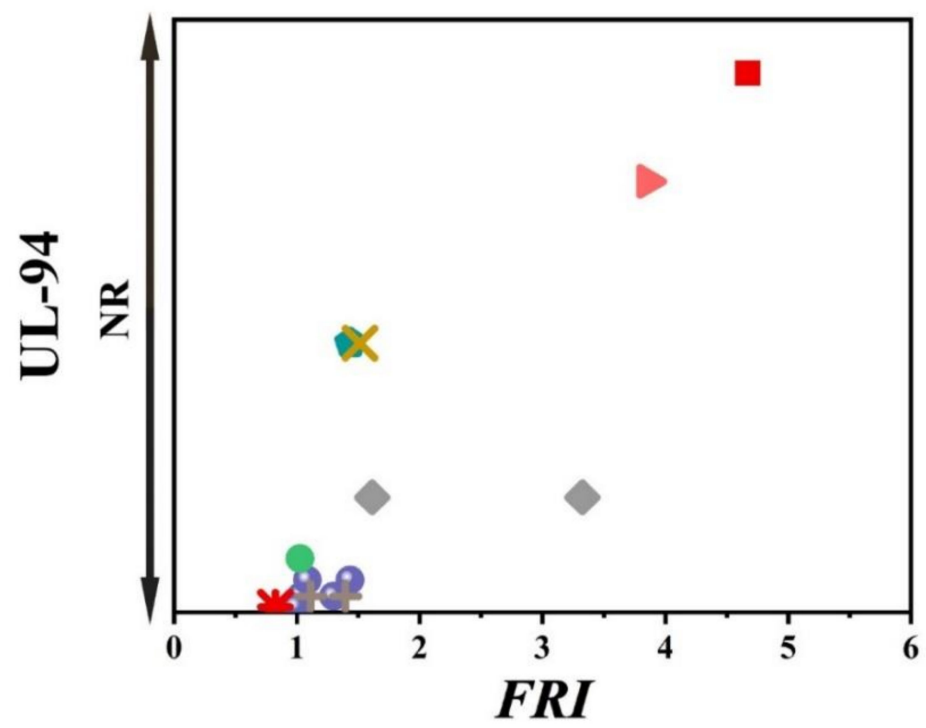

Figure 8. FRI values versus UL-94 test results. Symbols are indicative of different types of mineral flame retardant (FR) used. The vertical intervals in each category, i.e., V-0, V-1, V-2, and NR, are schematically representative of the amount of additive used. For example, two data distinguished by different symbols having the same or very close FRI values (horizontal quantity) in a given category (e.g., V-1), may have different vertical quantities, e.g., both reveal V-1 behavior in UL-94 test, but the upper contains more FR in PP.

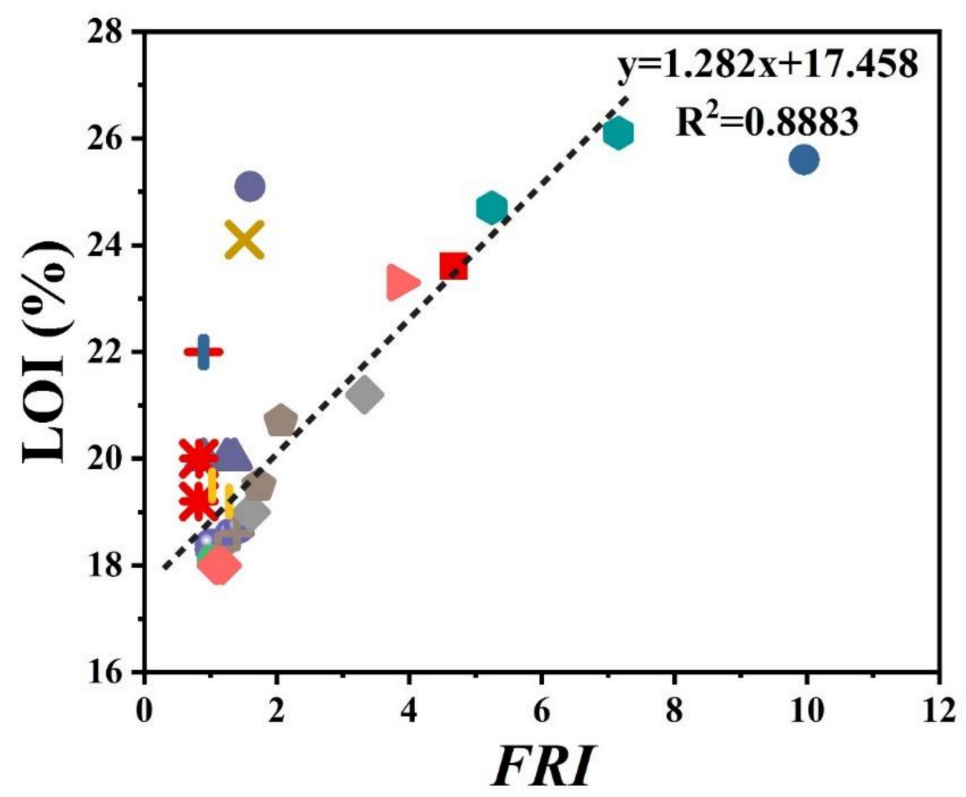

Figure 9. FRI values of PP as a function of LOI test results. Symbols are indicative of different types of mineral flame retardant used.

\section{Carbon-Based Flame Retardants}

Carbon-based additives have been widely used in developing polymer composites and nanocomposites [118-121]. However, due to expense and limited interaction with PP, a few works based on carbon-based flame retardants have been reported on flame-retardant PP materials. Table 4 summarizes all information available on the flame-retardant PP materials containing carbon-based additives. 
Table 4. Flame-retardant PP materials containing carbon-based (C) flame retardants. Data are extracted from the literature: cone calorimetry parameters (TTI, pHRR, THR), LOI, and UL-94 values. The FRI values were calculated by authors of the present review. The name and the percentage of flame retardants are provided in separate columns. "wt.\%" was used for loading level of additives, while "—" stands for the systems free of additive or the neat PP. * FR means flame retardant. Since all comparisons were made in terms of $F R I$, classification of polymers in terms of their flame-retardant properties was not surveyed based on the chemistry of additives, heat flux, sample thickness, etc.

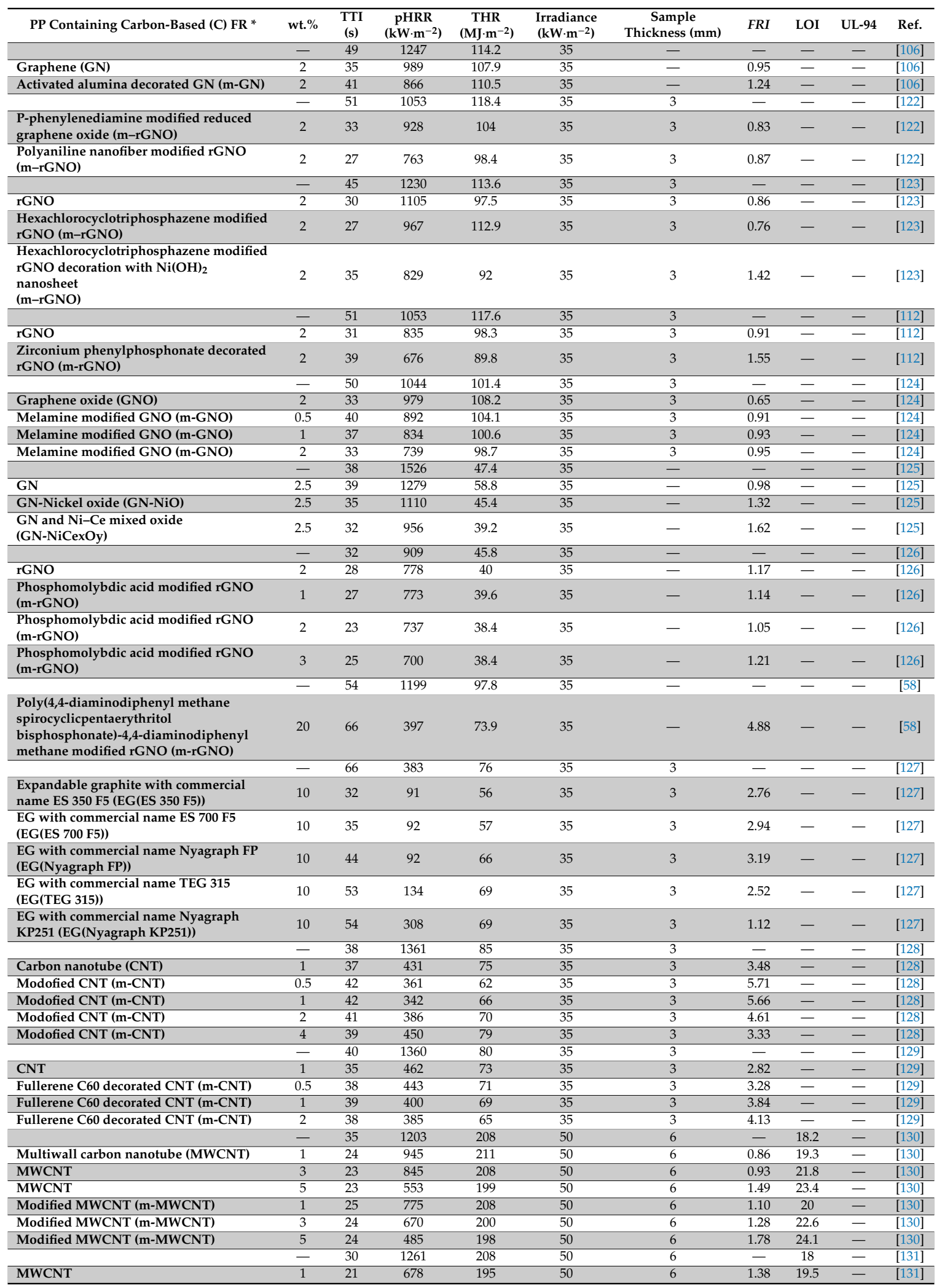


Table 4. Cont.

\begin{tabular}{|c|c|c|c|c|c|c|c|c|c|c|}
\hline PP Containing Carbon-Based (C) FR * & wt. $\%$ & $\begin{array}{c}\text { TTI } \\
\text { (s) }\end{array}$ & $\begin{array}{c}\mathrm{pHRR} \\
\left(\mathrm{kW} \cdot \mathrm{m}^{-2}\right)\end{array}$ & $\begin{array}{c}\text { THR } \\
\left(\mathrm{MJ} \cdot \mathrm{m}^{-2}\right)\end{array}$ & $\begin{array}{l}\text { Irradiance } \\
\left(\mathrm{kW} \cdot \mathrm{m}^{-2}\right)\end{array}$ & $\begin{array}{c}\text { Sample } \\
\text { Thickness (mm) }\end{array}$ & $F R I$ & LOI & UL-94 & Ref. \\
\hline MWCNT & - & 24 & 1620 & 110 & 50 & 3 & - & - & - & [132] \\
\hline MWCNT & 3 & 17 & 931 & 102 & 50 & 3 & 1.32 & - & - & [132] \\
\hline MWCNT & 10 & 25 & 367 & 199 & 50 & 6 & 2.47 & 24.6 & - & [133] \\
\hline \multirow[t]{2}{*}{ Carbon fiber (CF) } & 10 & 30 & 915 & 207 & 50 & 6 & 1.14 & 20.6 & - & [133] \\
\hline & - & 35 & 1212 & 198 & 50 & 6 & - & 18.2 & - & [134] \\
\hline \multirow[t]{2}{*}{ Carbon black (CB) } & 5 & 23 & 417 & 186 & 50 & 6 & 2.03 & 24.6 & - & [134] \\
\hline & - & 38 & 1284 & 241 & 50 & 6 & - & - & - & [108] \\
\hline \multirow[t]{2}{*}{ Activated carbon (AC) } & 7.5 & 15 & 682 & 185 & 50 & 6 & 0.96 & - & - & [108] \\
\hline & - & 48 & 1518 & 112.4 & 35 & 3.1 & - & - & - & [6] \\
\hline Vapor grown carbon nanofiber (VGCNF) & 4 & 35 & 610 & 113.1 & 35 & 3.1 & 1.80 & - & - & [6] \\
\hline VGCNF & 8 & 47 & 525 & 108.6 & 35 & 3.1 & 2.93 & - & - & [6] \\
\hline VGCNF & 12 & 49 & 547 & 102.4 & 35 & 2.9 & 3.10 & - & - & [6] \\
\hline
\end{tabular}

Figure 10 shows that with low loading percentage (1 wt.\%) of carbon nanotubes, it is possible to achieve the Good FRI. No data were available for UL-94 tests. Comparison between Figures 7 and 10 also suggests that low-cost minerals were used at higher loadings, while carbon-based additives were used almost at loadings below $10 \mathrm{wt} . \%$. A limited number of data have also been reported on LOI values. These points are plotted as a function of FRI in Figure 11, where a good correlation can be established between FRI and LOI values. Deeper understanding of the mechanism behind such correlation requires a detailed view of the origin of tests as well as the chemical structure of additives and possible interaction between the PP and additives.

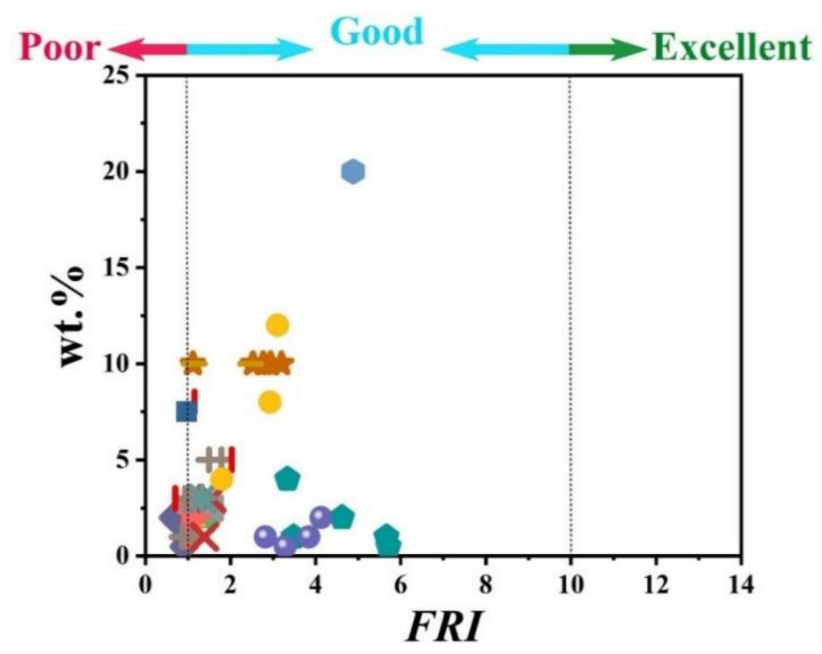

Figure 10. FRI values as a function of carbonaceous FR type and content. Symbols are indicative of different types of carbonaceous flame retardant used. Here: a GN-2, m-GN-2 [106], - m-rGNO-2, m-rGNO-2 [122], $\triangle$ rGNO-2, m-rGNO-2, m-rGNO-2 [123], $\nabla$ rGNO-2, m-rGNO-2 [112], $\bullet$ GNO-2, m-GNO-0.5, m-GNO-1, m-GNO-2 [124], \ GN-2.5, GN-NiO-2.5, GN-NiCe $\mathrm{O}_{\mathrm{y}}-2.5$ [125], $\gg \mathrm{rGNO}-2$, m-rGNO-1, m-rGNO-2, m-rGNO-3 [126], * m-rGNO-20 [58], * EG(ES 350 F5)-10, EG(ES 700 F5)-10, EG(Nyagraph FP)-10, EG(TEG 315)-10, EG(Nyagraph KP251)-10 [127], CNT-1, m-CNT-0.5, m-CNT-1, m-CNT-2, m-CNT-4 [128], • CNT-1, m-CNT-0.5, m-CNT-1, m-CNT-2 [129], + MWCNT-1, MWCNT-3, MWCNT-5, m-MWCNT-1, m-MWCNT-3, m-MWCNT-5 [130], × MWCNT-1, MWCNT-3 [131], * MWCNT-3 [132], - MWCNT-10, CF-10 [133], I CF-3, CF-8, CB-5 [134], — AC-7.5 [108], VGCNF-4, VGCNF-8, VGCNF-12 [6]. 


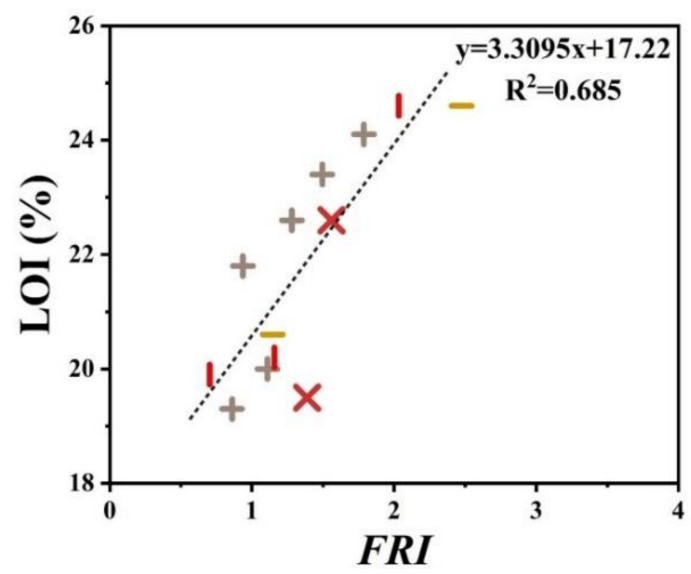

Figure 11. FRI values of PP as a function of LOI test results. Symbols are indicative of different types of carbon-based flame retardant used.

\section{Bio-Based Flame Retardants}

In recent years, due to sustainability issues, the use of bio-based additives has also been investigated in PP. However, the number of research papers is limited on this subject. Table 5 gives the name and loading percentage of these bio-based FR. The obtained results from cone calorimetry, LOI, and UL-94 tests are also listed in Table 5. Figures 12 and 13 display UL-94 and LOI results as a function of FRI for bio-based flame retardant in PP, respectively.

Table 5. Flame-retardant PP materials containing bio-based (Bio) flame retardants. Data are extracted from the literature: cone calorimetry parameters (TTI, pHRR, THR), LOI, and UL-94 values. The FRI values were calculated by authors of the present review. The name and the percentage of flame retardants are provided in separate columns. "wt.\%" was used for loading level of additives, while "—" stands for the systems free of additive or the neat PP. * FR means flame retardant. Since all comparisons were made in terms of FRI, classification of polymers in terms of their flame-retardant properties was not surveyed based on the chemistry of additives, heat flux, sample thickness, etc.

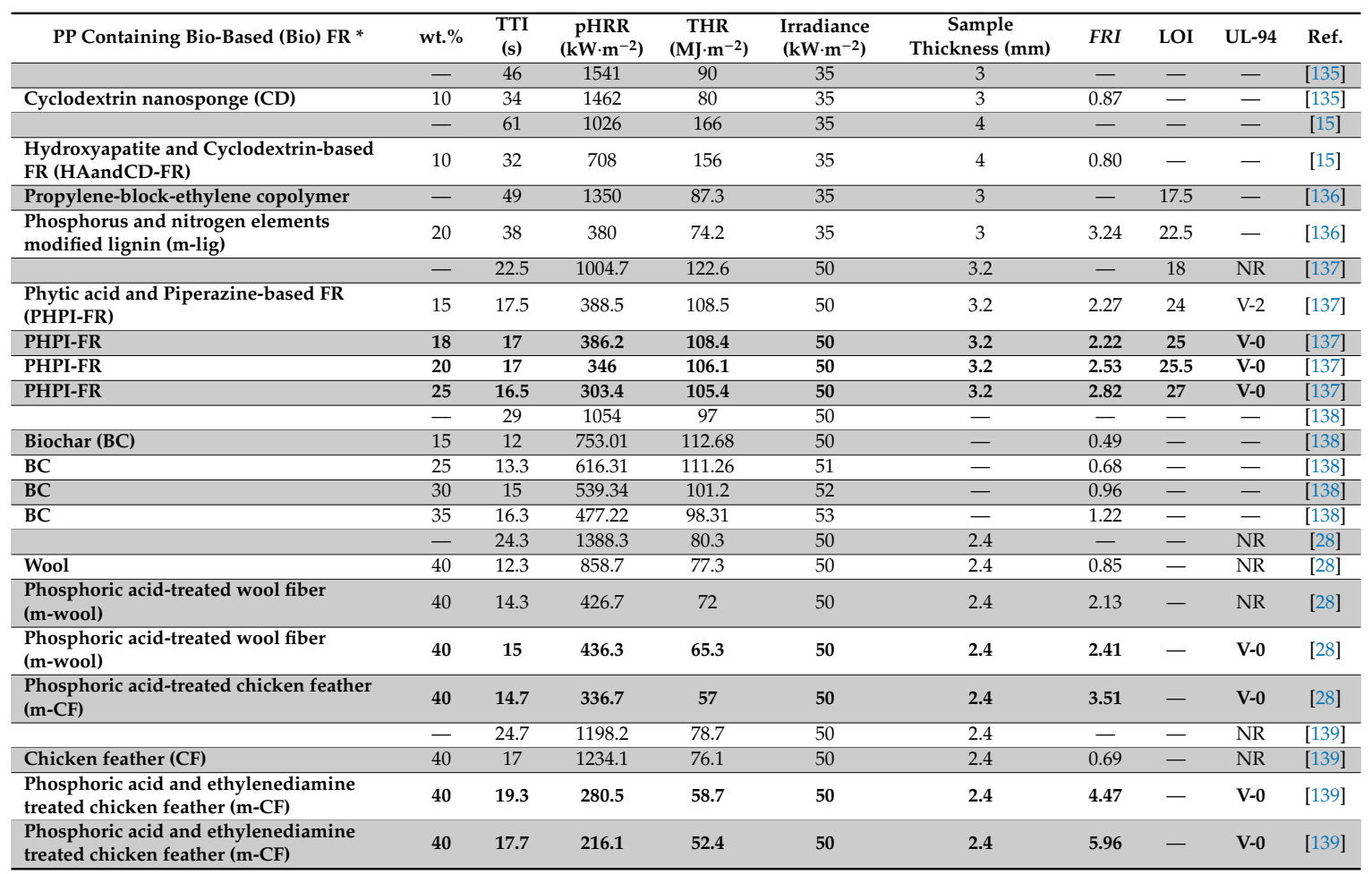






Figure 12. FRI values versus UL-94 test results. Symbols are indicative of different types of bio-based flame retardant (FR) used. The vertical intervals in each category, i.e., V-0, V-1, V-2, and NR, are schematically representative of the amount of additive used. For example, two data distinguished by different symbols having the same or very close $F R I$ values (horizontal quantity) in a given category (e.g., V-1) may have different vertical quantities, e.g., both reveal V-1 behavior in UL-94 test, but the upper contains more FR in PP.



Figure 13. FRI values of PP as a function of LOI test results. Symbols are indicative of different types of bio-based flame retardant used. The green triangles are related to a mixture of phytic acid and piperazine-based FR. The increase of LOI is directly related to the percentage of FR loading, 15, 18, 20, and $25 \mathrm{wt} . \%$.

FRI values are plotted as a function of loading percentage of bio-based FR in Figure 14. It can be observed that a high quantity of bio-based FR, $40 \mathrm{wt}$ \% is needed to achieve FRI equal to 6.

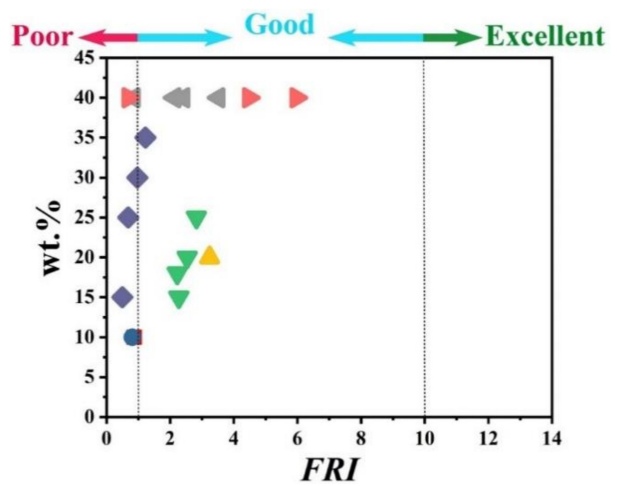

Figure 14. FRI values as a function of bio-based FR type and content. Symbols are indicative of different

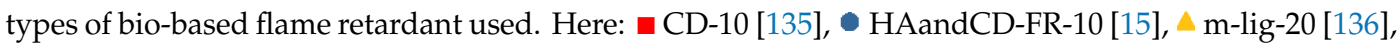
$\checkmark$ PHPI-FR-15, PHPI-FR-18, PHPI-FR-20, PHPI-FR-25 [137], BC-15, BC-25, BC-30, BC-35 [138], 4 Wool-40, m-wool-40, m-wool-40, m-CF-40 [28], > CF-40, m-CF-40, m-CF-40 [139]. 


\section{Combination of Flame Retardants}

As observed in previous sections, using an additive alone can to a limited extent improve flame-retardant properties of PP. Combination of flame retardants is a strategy to improve further the flame retardancy via synergism between various flame retardants [140-142]. Moreover, the quantity of the used flame retardant can be reduced in polymer so as to prevent mechanical properties deterioration. Different combinative additive systems were considered in PP. The corresponded data are collected and summarized in Table 6 . The third column gives the ratio between flame retardants.

Table 6. The flame retardancy performance of PP containing various combinations of flame retardants in terms of FRI ( ${ }^{*}$ the name and percentage of incorporated flame retardants are given after PP). $\mathrm{P}=$ phosphorus $\mathrm{FR}, \mathrm{Np}=$ non-phosphorus $\mathrm{FR}, \mathrm{N}=$ nitrogen $\mathrm{FR}, \mathrm{nN}=$ non-nitrogen-based FR, $\mathrm{M}=$ mineral FR, $\mathrm{Bio}=$ bio-based FR, $\mathrm{nBio}=$ non bio-based FR (one can also consider some nitrogen-based FRs containing phosphorus element as the combination of phosphorus and nitrogen resulting in synergism, Table 2). Since all comparisons were made in terms of FRI, classification of polymers in terms of their flame-retardant properties was not surveyed based on the chemistry of additives, heat flux, sample thickness, etc.

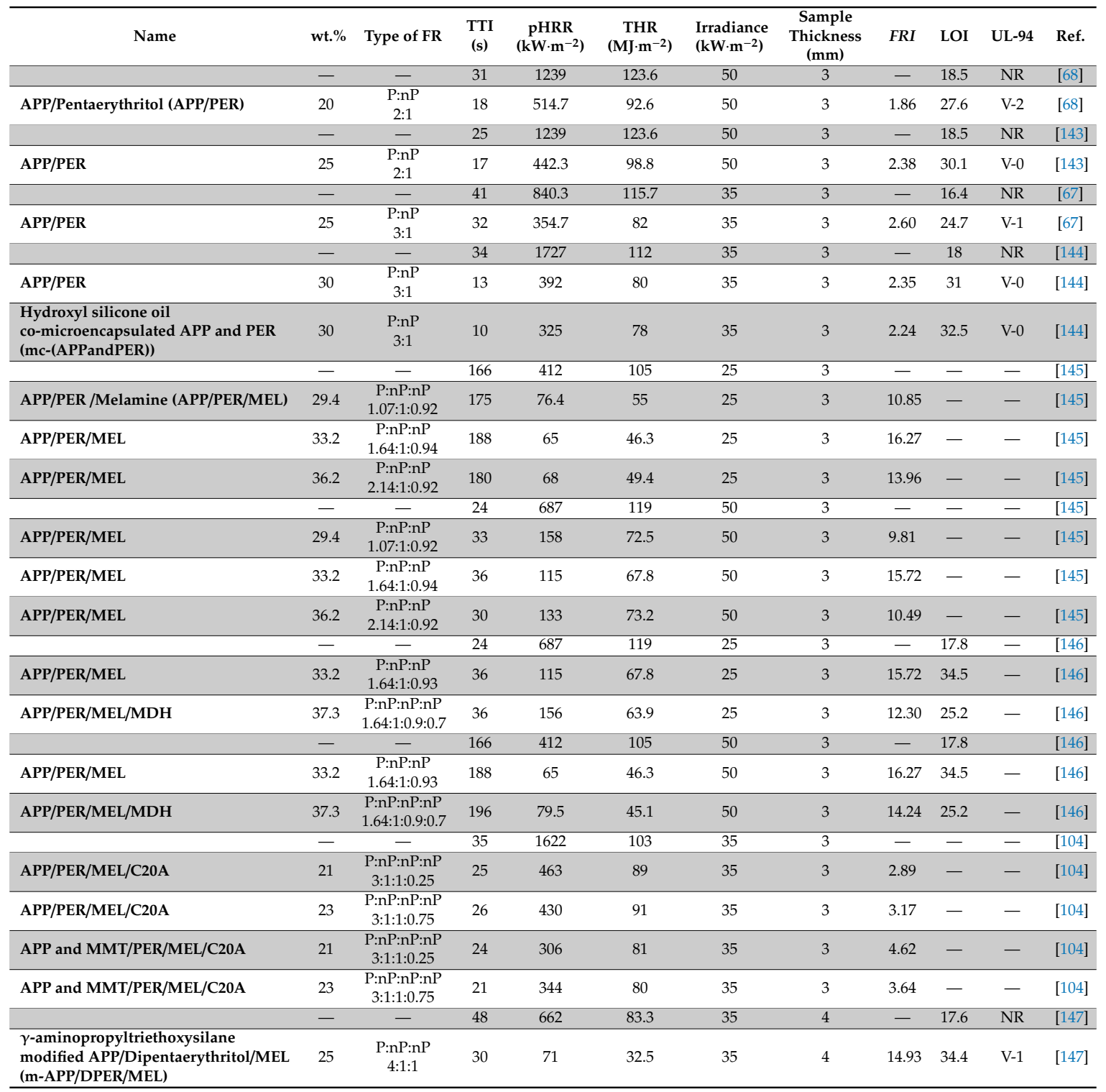


Table 6. Cont.

\begin{tabular}{|c|c|c|c|c|c|c|c|c|c|c|c|}
\hline Name & wt. $\%$ & Type of FR & $\begin{array}{l}\text { TTI } \\
\text { (s) }\end{array}$ & $\underset{\left(\mathbf{k W} \cdot \mathrm{m}^{-2}\right)}{\mathrm{pHRR}}$ & $\begin{array}{c}\text { THR } \\
\left(\mathrm{MJ} \cdot \mathrm{m}^{-2}\right)\end{array}$ & $\begin{array}{l}\text { Irradiance } \\
\left(\mathrm{kW} \cdot \mathrm{m}^{-2}\right)\end{array}$ & $\begin{array}{c}\text { Sample } \\
\text { Thickness } \\
(\mathrm{mm})\end{array}$ & $F R I$ & LOI & UL-94 & Ref. \\
\hline \multirow[t]{2}{*}{$\begin{array}{l}\gamma \text {-aminopropyltriethoxysilane } \\
\text { modified APP/ DPER/MEL/SEP } \\
\text { (m-APP-/DPER/MEL/SEP) }\end{array}$} & 25 & $\begin{array}{l}\text { P:nP:nP:nP } \\
\text { 4:1:1:0.25 }\end{array}$ & 29 & 51 & 30.8 & 35 & 4 & 21.20 & 36 & $\mathrm{~V}-0$ & [147] \\
\hline & - & - & 48 & 1007 & 126.3 & 35 & 3.2 & - & 17.5 & NR & [148] \\
\hline APP/PER & 18 & $\begin{array}{l}\text { P:nP } \\
3: 1\end{array}$ & 45 & 423.5 & 112 & 35 & 3.2 & 2.51 & 24.6 & NR & [148] \\
\hline \multirow[t]{2}{*}{$\begin{array}{l}\text { APP/PER/Adenosine monophosphate } \\
\text { embedded Melamine fomaldehyde } \\
\text { (APP/PER/MFA) }\end{array}$} & 18 & $\begin{array}{l}\text { P:nP:nP } \\
\text { 3:1:0.2 }\end{array}$ & 49 & 355.1 & 108.1 & 35 & 3.2 & 3.38 & 27 & V-0 & [148] \\
\hline & - & - & 70 & 1267 & 147 & 50 & 3 & - & 17.5 & NR & [149] \\
\hline \multirow[t]{2}{*}{ APP/PER } & 30 & $\begin{array}{c}\text { P:nP } \\
3: 1\end{array}$ & 40 & 321 & 80 & 50 & 3 & 4.14 & 29.5 & V-1 & [149] \\
\hline & - & - & 47 & 991.4 & 140.8 & 35 & 3.2 & - & 18.4 & NR & [150] \\
\hline $\begin{array}{l}\text { APP/PER /Triazine-based FR: N, N', } \\
\mathrm{N}^{\prime \prime}-1,3 \text {, 5-triazine-2, 4, } \\
\text { 6-triyltris-glycine (APP/PER/TA-FR) }\end{array}$ & - & - & 36 & 799.3 & 170.9 & 35 & 4 & - & 18 & NR & [72] \\
\hline APP/PER & 25 & $\begin{array}{c}\text { P:nP } \\
2: 1\end{array}$ & 23 & 322 & 144.5 & 35 & 4 & 1.87 & 31 & V-1 & [72] \\
\hline \multirow[t]{2}{*}{ APP/PER/NOR116 } & 25 & $\begin{array}{l}\text { P:nP:nP } \\
\text { 2:1:0.06 }\end{array}$ & 33 & 313.8 & 136.5 & 35 & 4 & 2.92 & 35 & V-0 & [72] \\
\hline & - & - & 51 & 888 & 125 & 35 & 3.2 & - & 17.5 & NR & [151] \\
\hline APP/PER & 18 & $\begin{array}{c}\text { P:nP } \\
3: 1\end{array}$ & 45 & 439 & 111 & 35 & 3.2 & 2.00 & 24.6 & NR & [151] \\
\hline $\begin{array}{l}\text { APP/PER/Guanine: nitrogenous } \\
\text { bases (APP/PER/G-bases) }\end{array}$ & 18 & $\begin{array}{l}\text { P:nP:nP } \\
\text { 3:1:0.3 }\end{array}$ & 46 & 324 & 105 & 35 & 3.2 & 2.94 & 27.6 & NR & [151] \\
\hline \multirow[t]{2}{*}{$\begin{array}{l}\text { APP/PER/Uracil: nitrogenous bases } \\
\text { (APP/PER/U-bases) }\end{array}$} & 18 & $\begin{array}{c}\text { P:nP:nP } \\
\text { 3:1:0.3 }\end{array}$ & 46 & 293 & 105 & 35 & 3.2 & 3.25 & 28.7 & V-0 & [151] \\
\hline & - & - & 38 & 886 & 144 & 50 & 3 & - & 17.6 & NR & [152] \\
\hline \multirow[t]{2}{*}{ APP/PER/Kaol } & 28.5 & $\begin{array}{c}\text { P:nP:nP } \\
3: 1: 0.2\end{array}$ & 22 & 222 & 131 & 50 & 4 & 2.78 & 33 & $\mathrm{~V}-0$ & {$[70]$} \\
\hline & - & - & 70 & 415.6 & 99.6 & 35 & 3 & - & 17 & NR & [153] \\
\hline APP/PER & 29 & $\begin{array}{c}\text { P:nP } \\
3: 1 \\
\end{array}$ & 21 & 160.7 & 94.2 & 35 & 3 & 0.82 & 29.5 & $\mathrm{~V}-0$ & [153] \\
\hline APP/PER/MMT & 29 & $\begin{array}{l}\text { P:nP:nP } \\
\text { 3:1:0.46 }\end{array}$ & 42 & 149.8 & 69.5 & 35 & 3 & 2.38 & 34.5 & $\mathrm{~V}-0$ & [153] \\
\hline \multirow[t]{2}{*}{$\begin{array}{l}\text { APP/PER/Melamine modified MMT } \\
\text { (APP/PER/m-MMT) }\end{array}$} & 29 & $\begin{array}{l}\text { P:nP:nP } \\
\text { 3:1:0.46 }\end{array}$ & 37 & 157.9 & 55.1 & 35 & 3 & 2.51 & 36.5 & $\mathrm{~V}-0$ & [153] \\
\hline & - & - & 70 & 415.6 & 99.6 & 35 & 3 & - & 17 & NR & [154] \\
\hline APP/PER & 29 & $\begin{array}{c}\text { P:nP } \\
3: 1 \\
\end{array}$ & 21 & 160.7 & 94.2 & 35 & 3 & 0.82 & 29.5 & $\mathrm{~V}-0$ & [154] \\
\hline APP/PER/MMT & 29 & $\begin{array}{l}\text { P:nP:nP } \\
\text { 3:1:0.46 }\end{array}$ & 42 & 149.8 & 69.5 & 35 & 3 & 2.38 & 34.5 & $\mathrm{~V}-0$ & [154] \\
\hline $\begin{array}{l}\text { APP/PER/Melamine modified MMT } \\
\text { (APP/PER/m-MMT) }\end{array}$ & 29 & $\begin{array}{l}\text { P:nP:nP } \\
\text { 3:1:0.46 }\end{array}$ & 37 & 157.9 & 55.1 & 35 & 3 & 2.51 & 36.5 & $\mathrm{~V}-0$ & [154] \\
\hline \multirow[t]{2}{*}{$\begin{array}{l}\text { APP/PER/Triphenylphonium } \\
\text { modified MMT (APP/PER/m-MMT) }\end{array}$} & 29 & $\begin{array}{l}\text { P:nP:nP } \\
\text { 3:1:0.46 }\end{array}$ & 38 & 168.2 & 84.7 & 35 & 3 & 1.57 & 34.8 & $\mathrm{~V}-0$ & [154] \\
\hline & - & - & 50 & 720 & 136 & 35 & 4 & - & 17 & NR & [155] \\
\hline APP/PER & 25 & $\begin{array}{c}\text { P:nP } \\
3: 1\end{array}$ & 39 & 267 & 111 & 35 & 4 & 2.57 & 26.3 & V-1 & [155] \\
\hline $\begin{array}{l}\text { APP/PER/Zn-Ni-Al } \\
\text { LDH(APP/PER/LDH) }\end{array}$ & 25 & $\begin{array}{l}\text { P:nP:nP } \\
\text { 3:1:0.16 }\end{array}$ & 35 & 296 & 109 & 35 & 4 & 2.12 & 27 & V-1 & [155] \\
\hline $\begin{array}{l}\text { APP/PER/Azobenzene-4, } 4^{\prime}- \\
\text { dicarboxylic acid modified Ni-Zn-Al } \\
\text { LDH } \\
\text { (APP/PER/m-LDH) }\end{array}$ & 25 & $\begin{array}{l}\text { P:nP:nP } \\
\text { 3:1:0.16 }\end{array}$ & 39 & 271 & 102 & 35 & 4 & 2.76 & 29.3 & V-0 & [155] \\
\hline
\end{tabular}


Table 6. Cont.

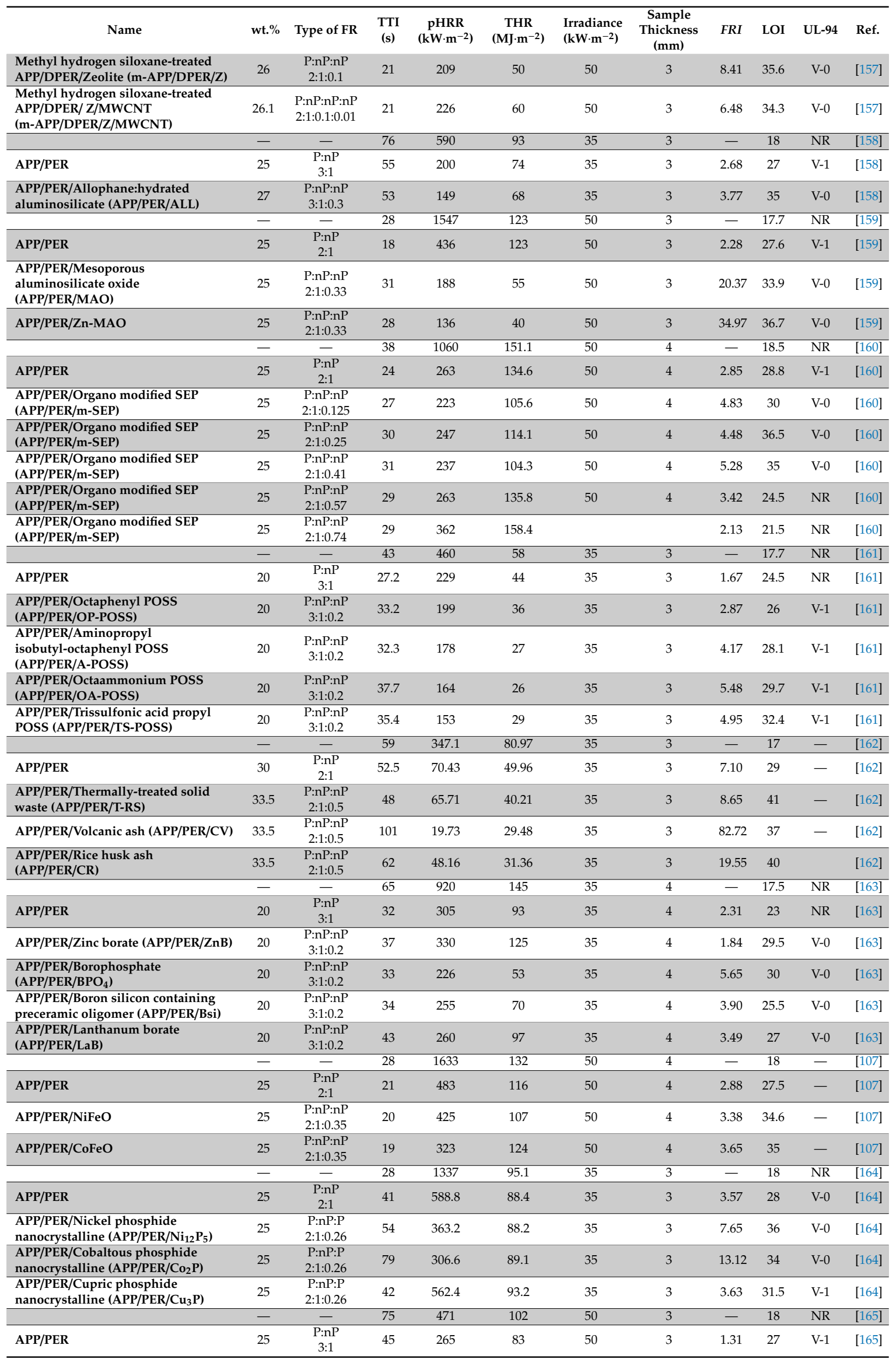


Table 6. Cont.

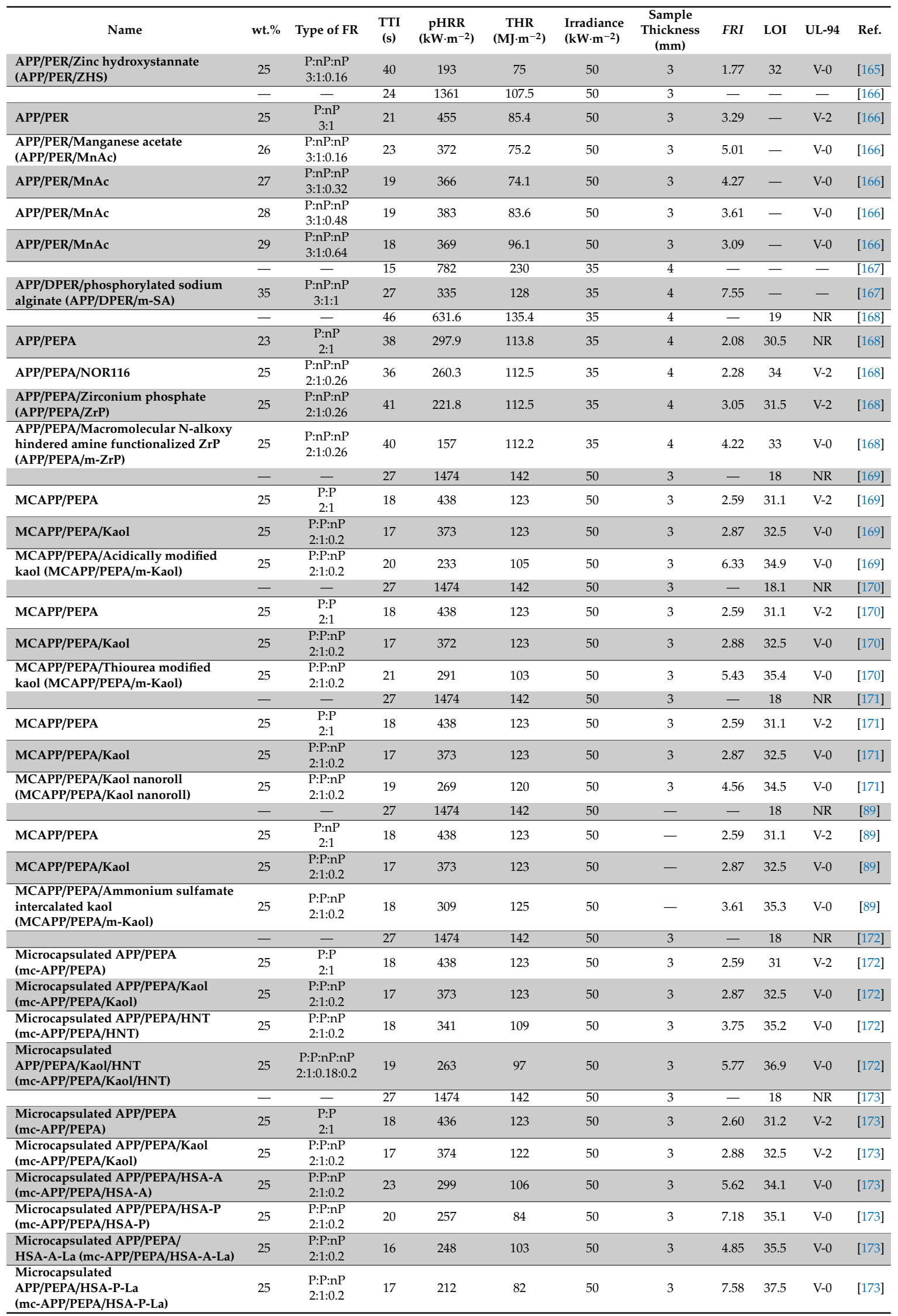


Table 6. Cont

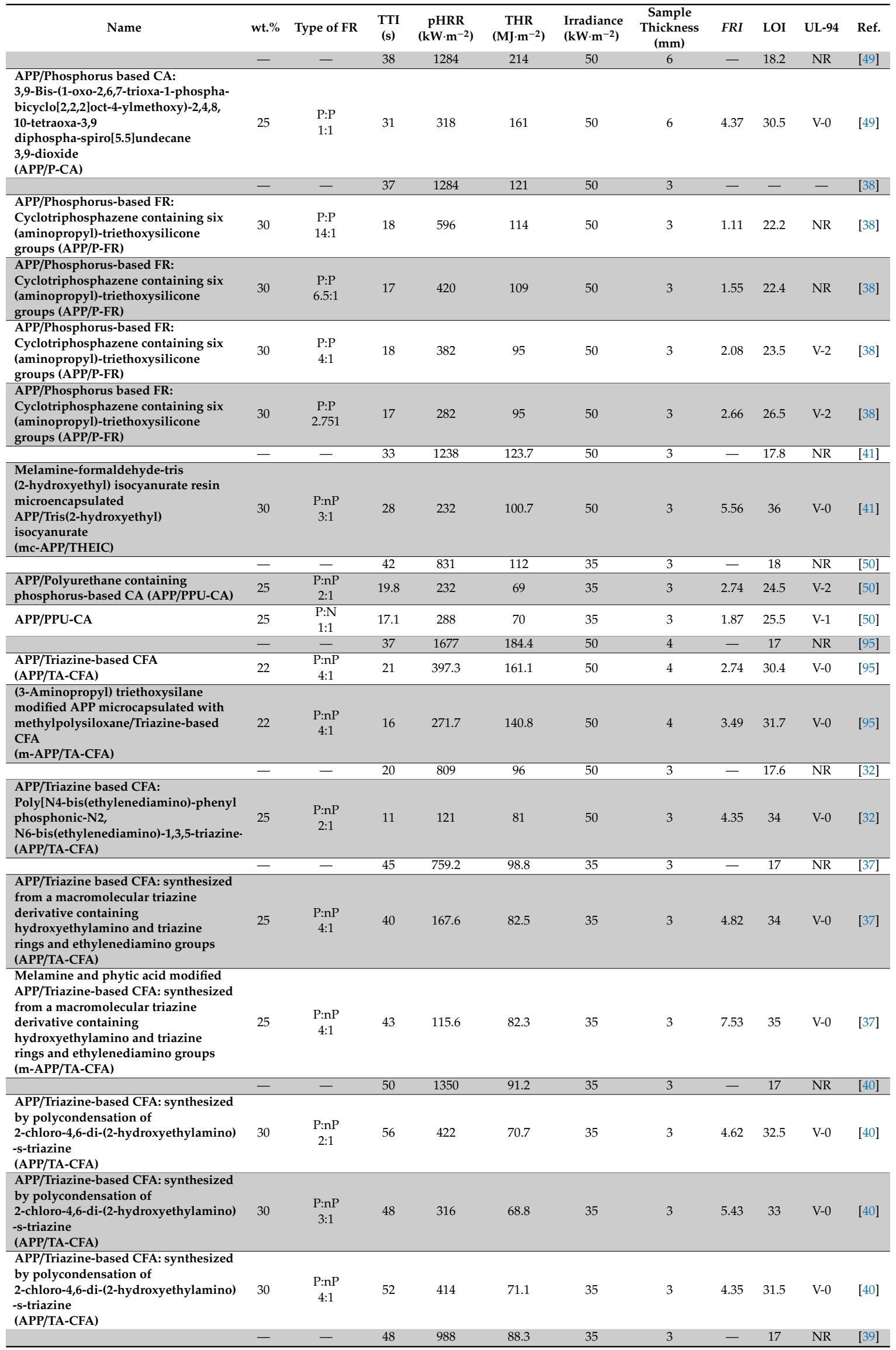


Table 6. Cont

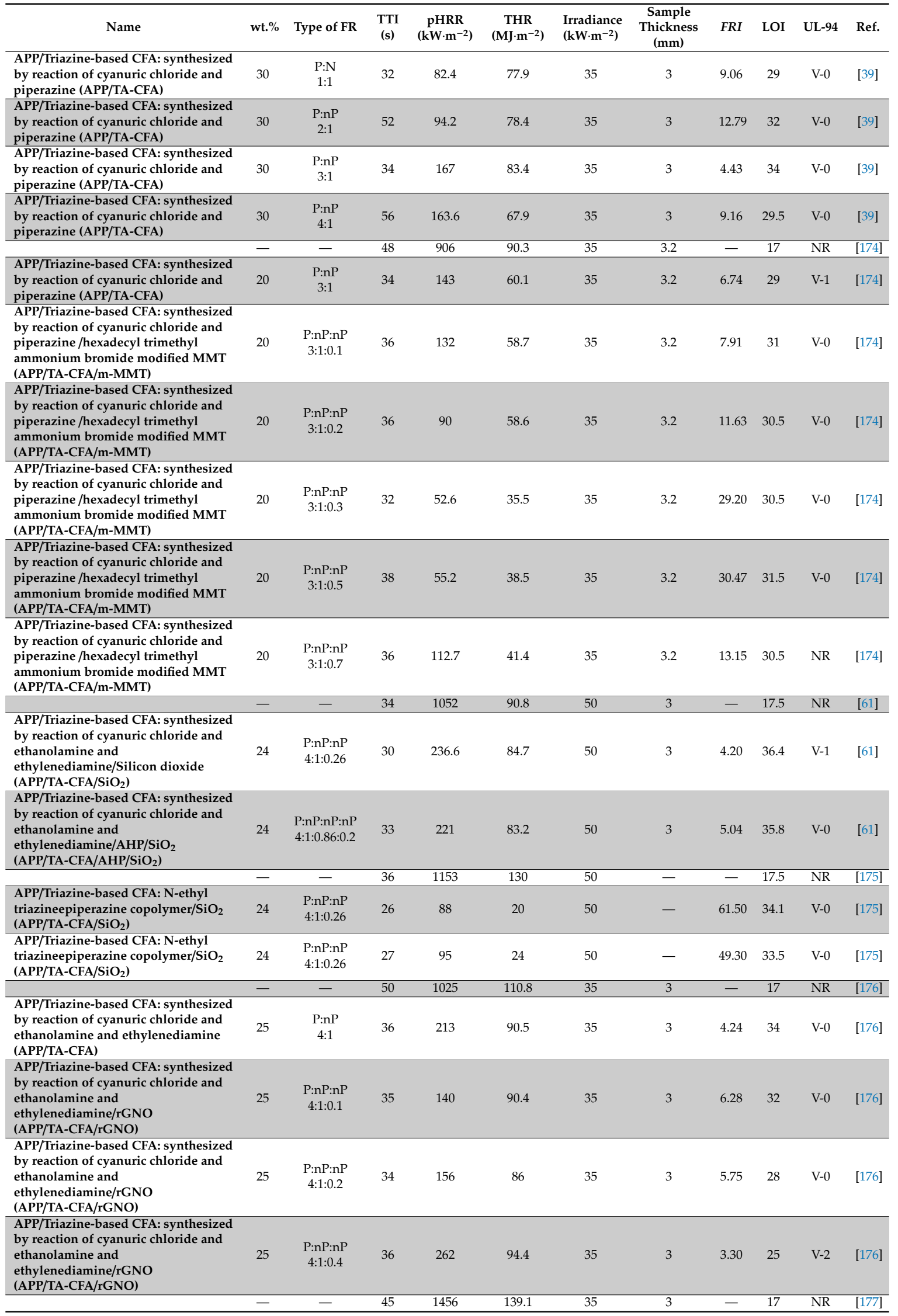


Table 6. Cont.

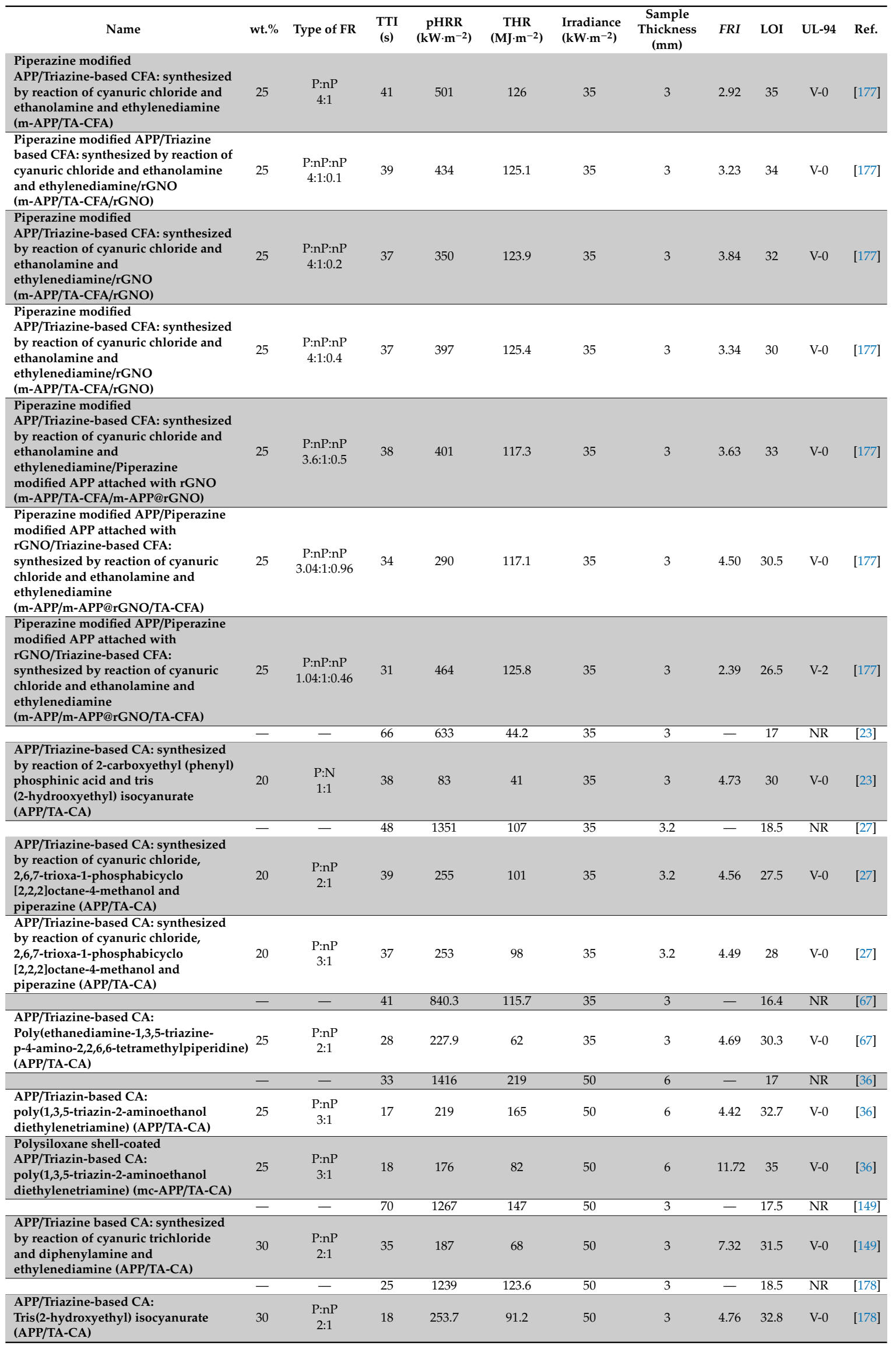


Table 6. Cont

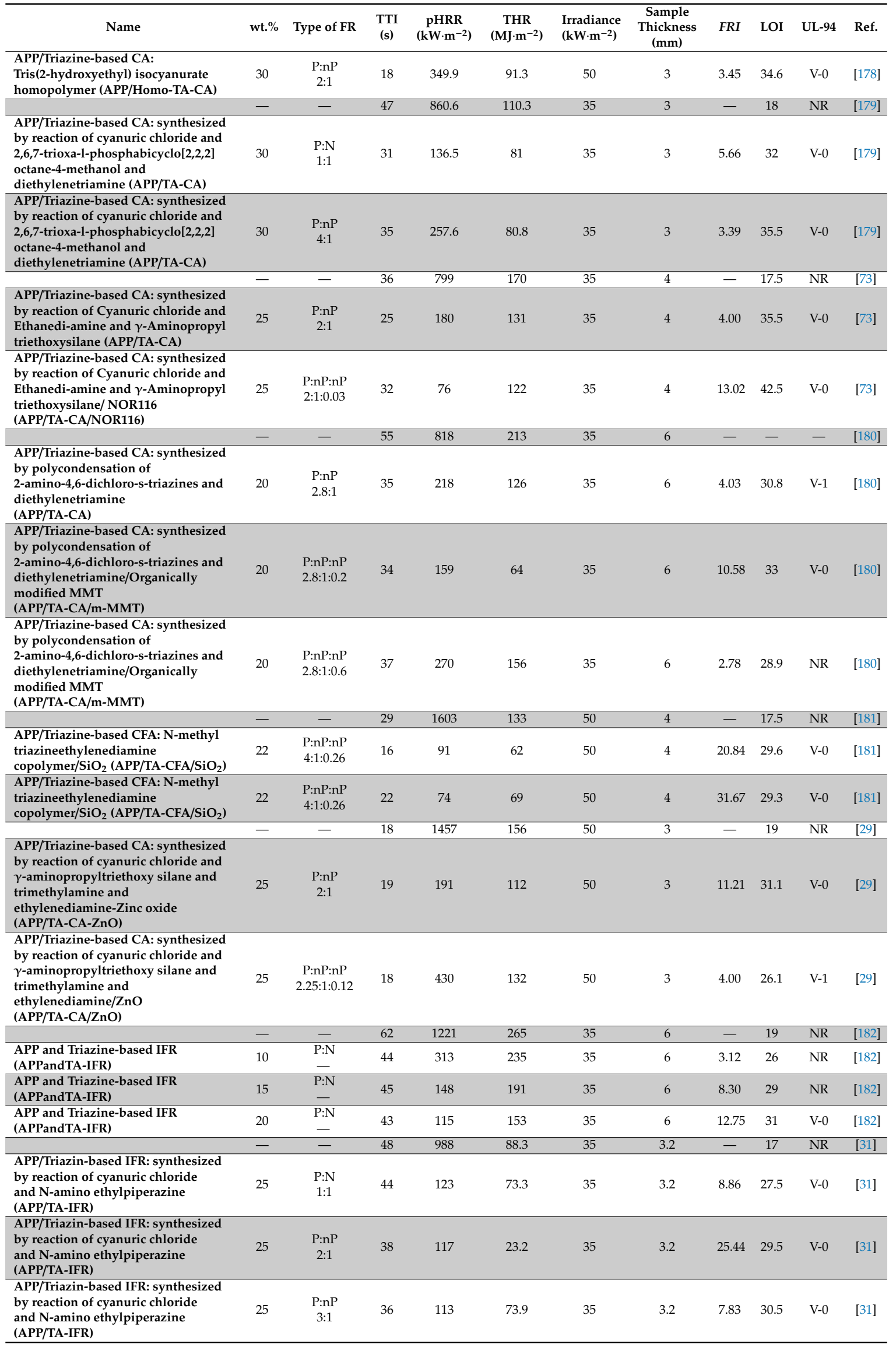


Table 6. Cont.

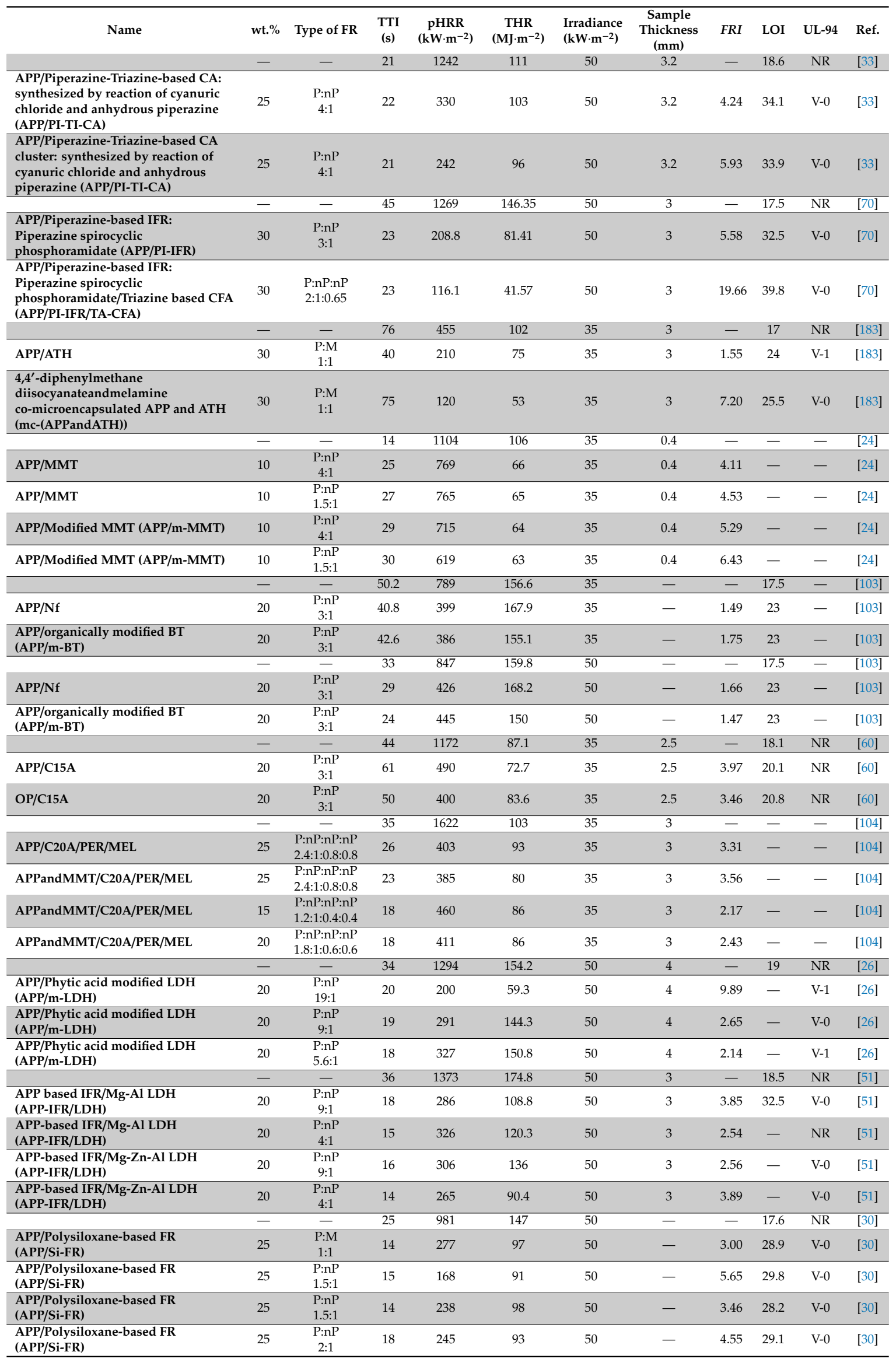


Table 6. Cont.

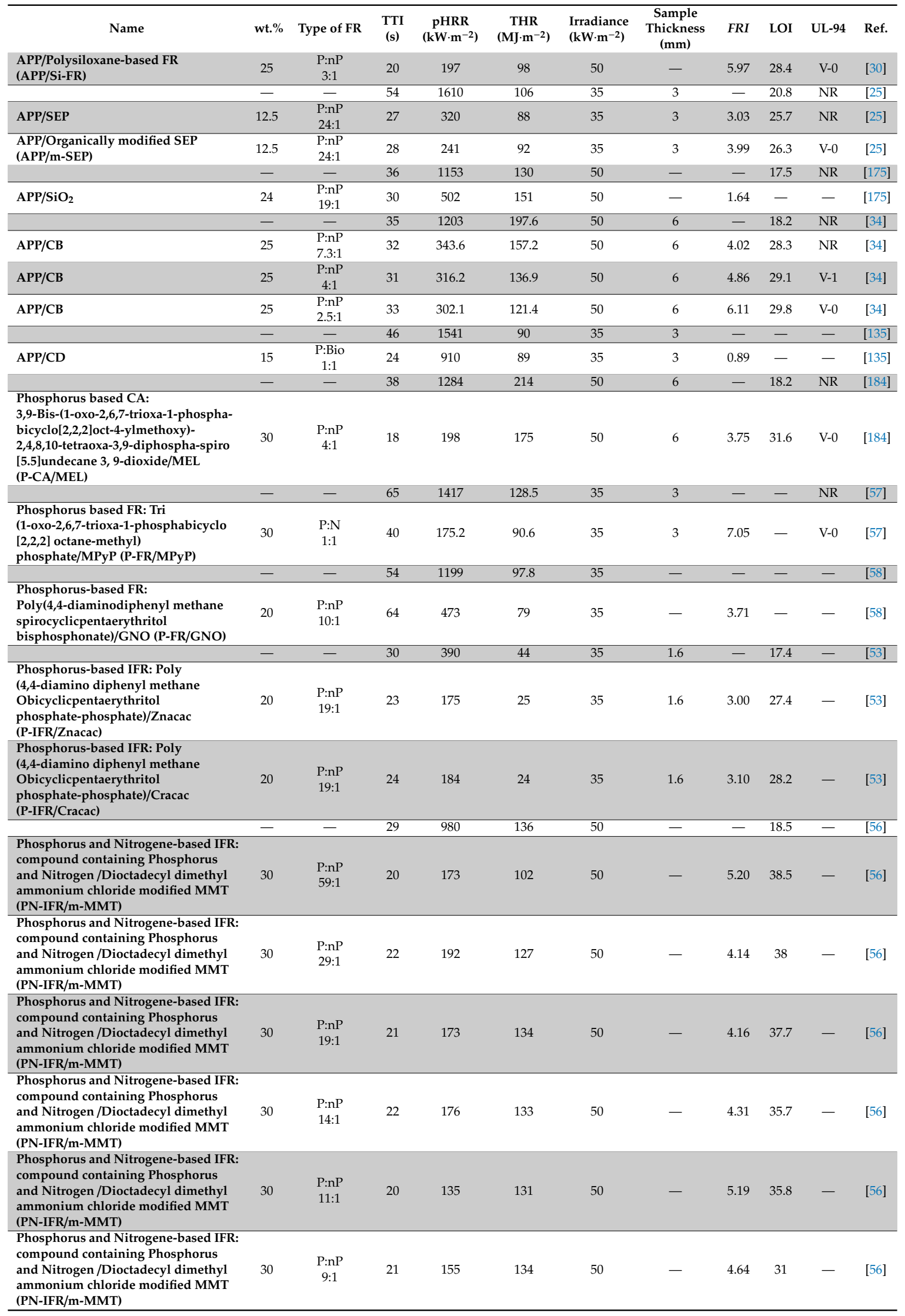


Table 6. Cont

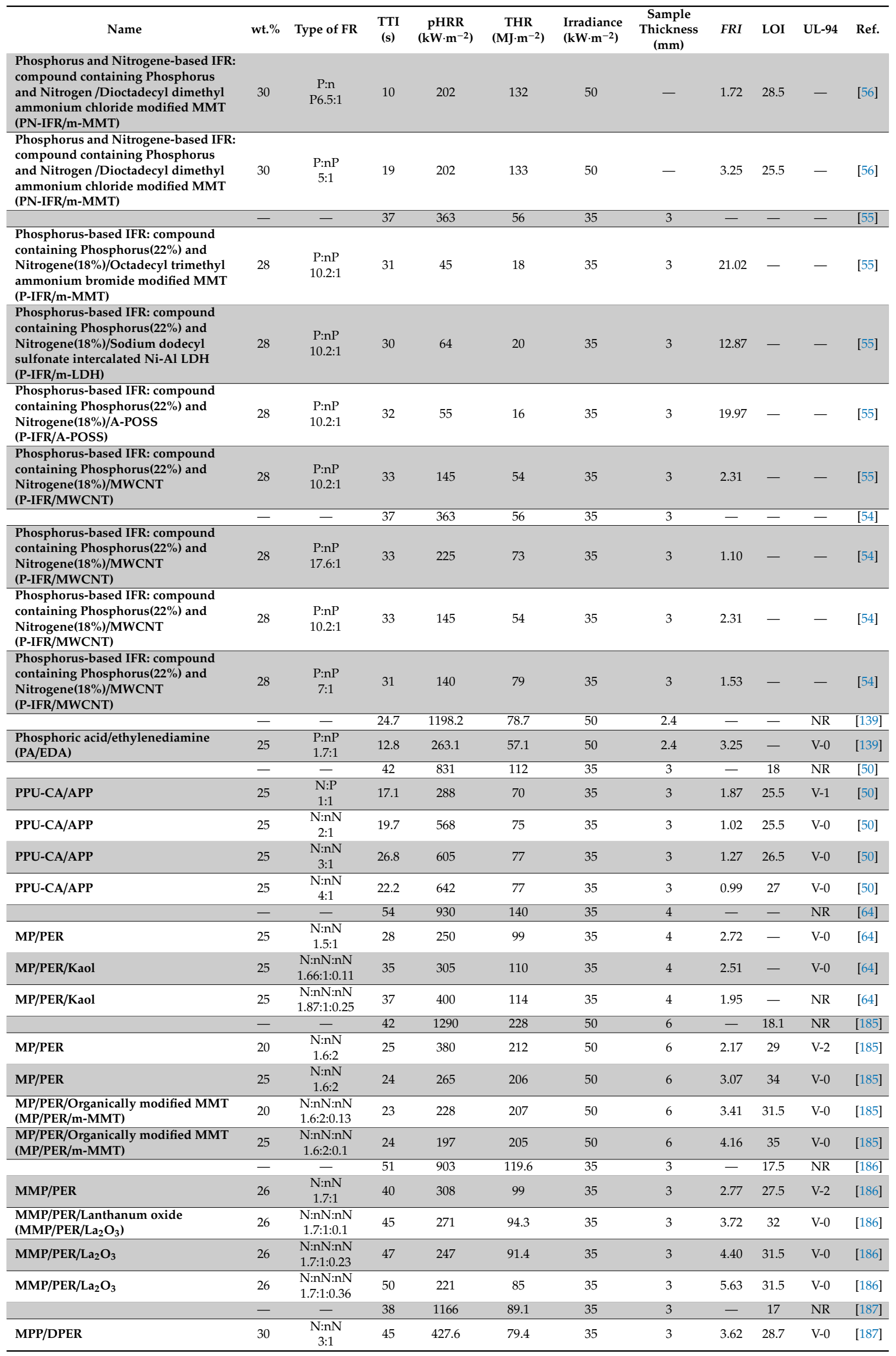


Table 6. Cont

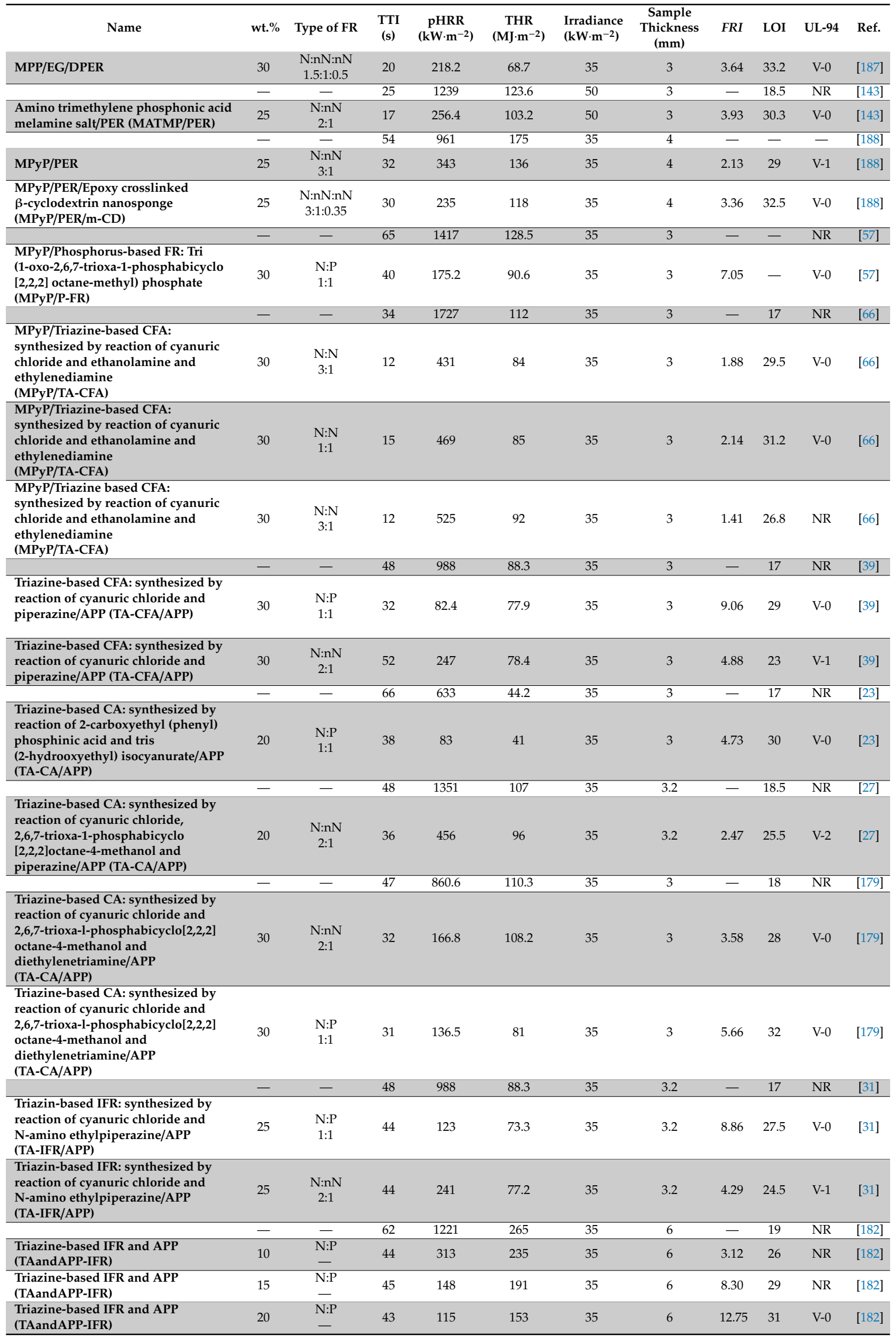


Table 6. Cont.

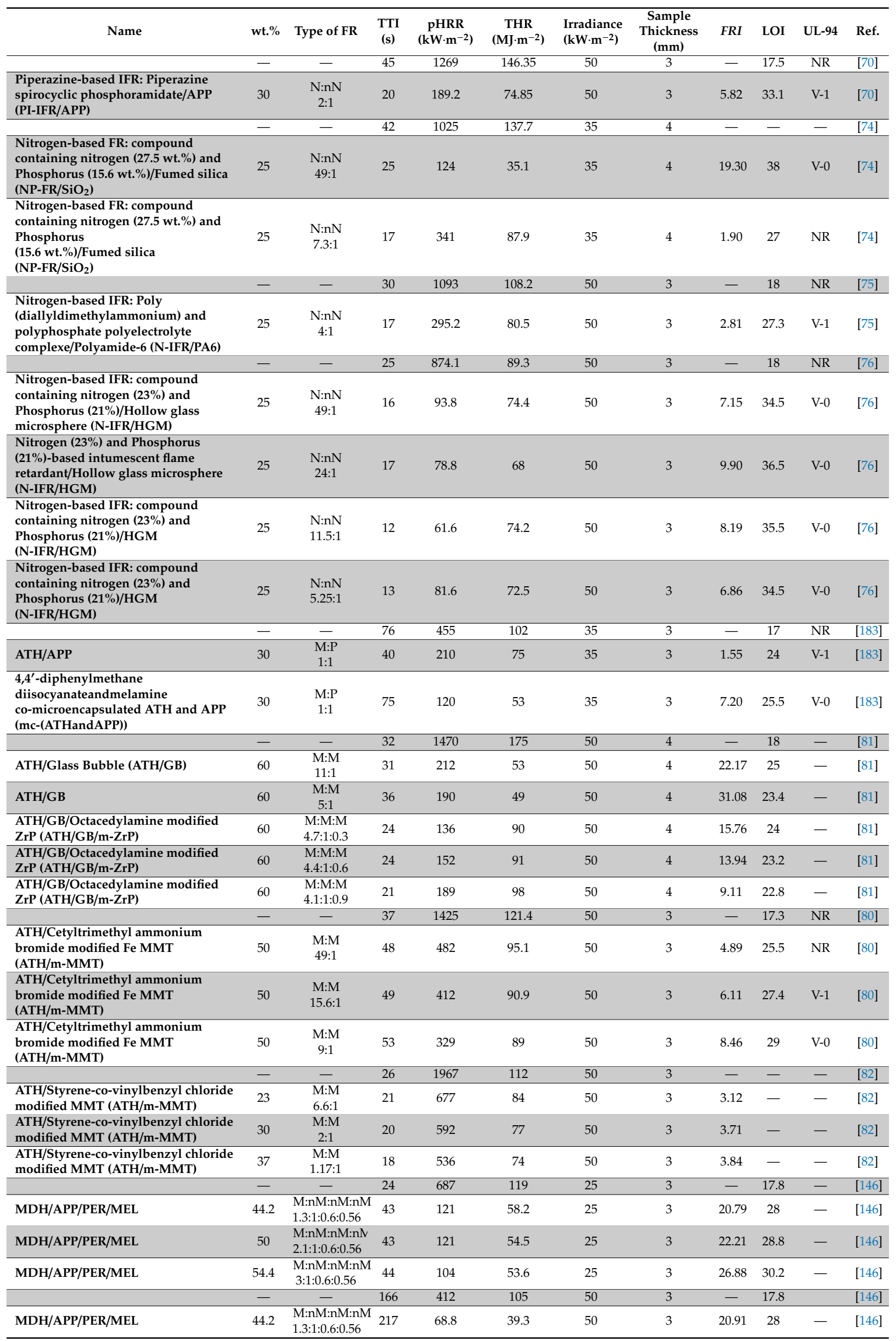


Table 6. Cont.

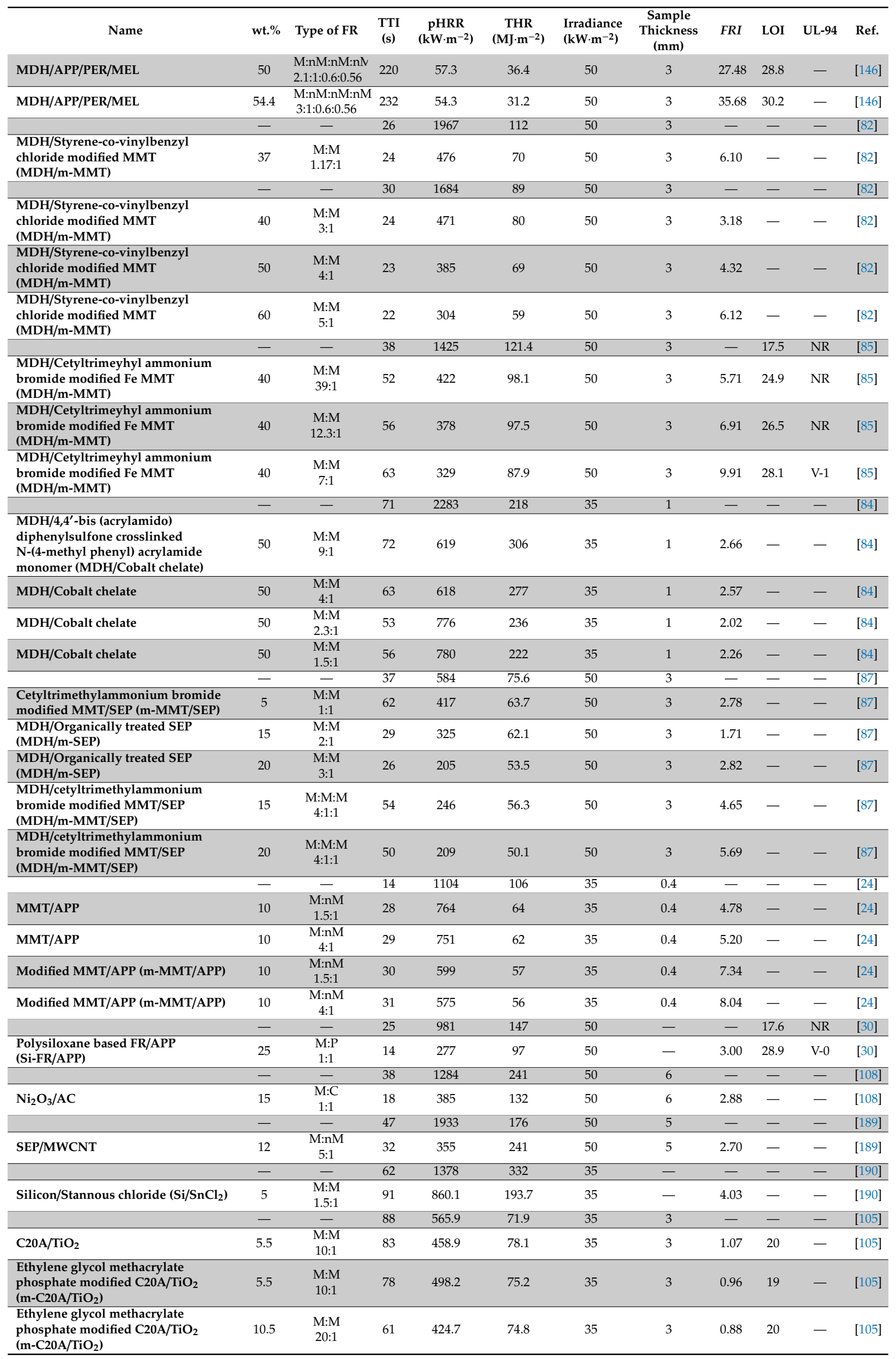


Table 6. Cont.

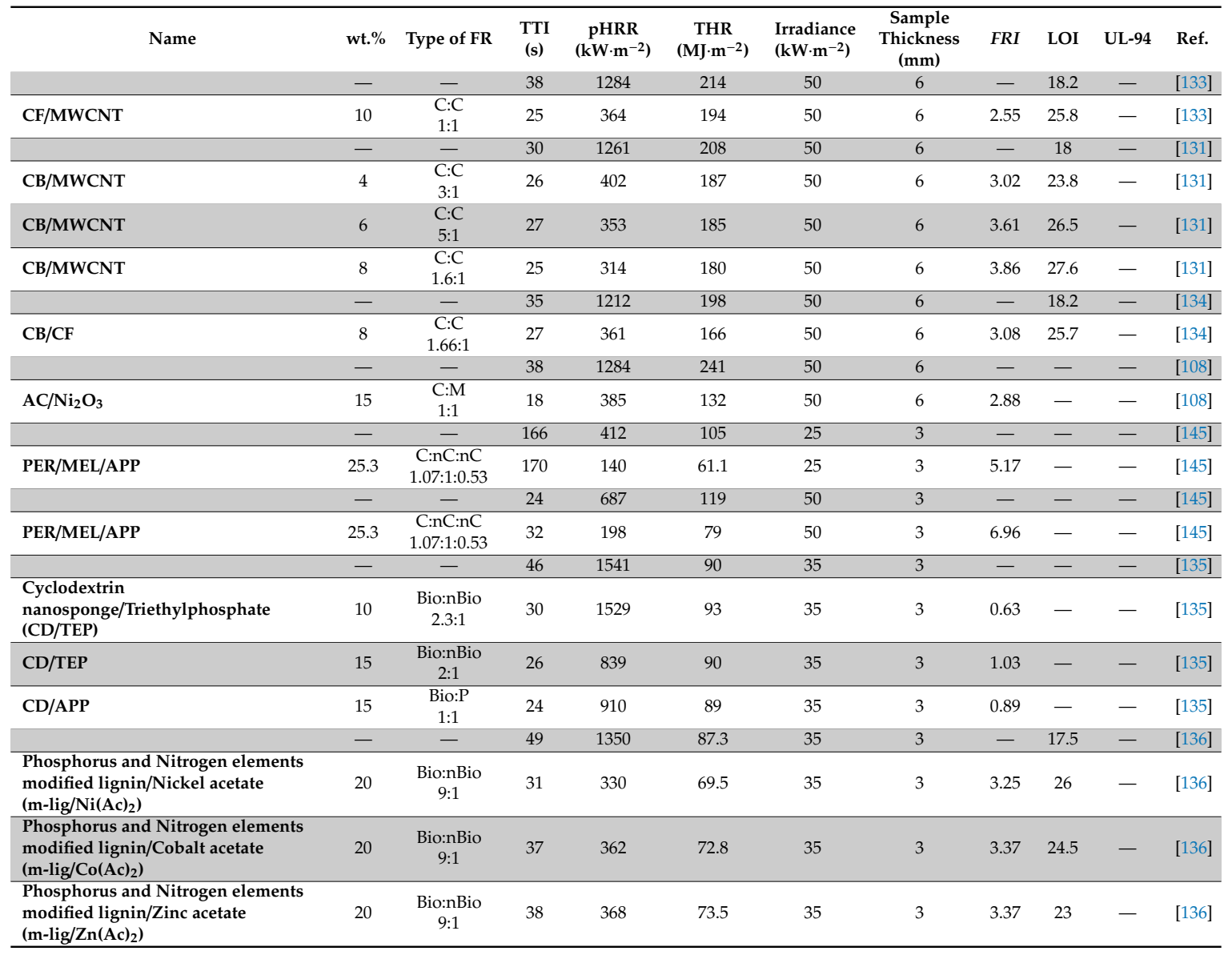

Figure 15 displays the performance of different combinatorial additive systems used for PP. It can be clearly observed from the left-hand side figure that cases with FRI values above 10 (Excellent zone) are more frequent compared to all previous cases in which only one additive was used. More interestingly, the combination of additives appeared a useful strategy where very high FRI values (event more than 50 ) took place at intermediate loadings (25-30 wt.\%). For achieving a high $F R I$ value, the combination of several types of flame retardants is needed, for example, phosphorus, intumescent, and mineral flame retardants [150] or phosphorus, nitrogen, and mineral flame retardants [164].

Figure 16 shows that V-0 level in UL-94 is automatically obtained in the case of combined flame retardant systems used in PP regardless of the FRI value. However, no correlation exists between the FRI and LOI (Figure 17). The complexity of polymer-filler interaction can be considered as the main reason for diversity of properties. 

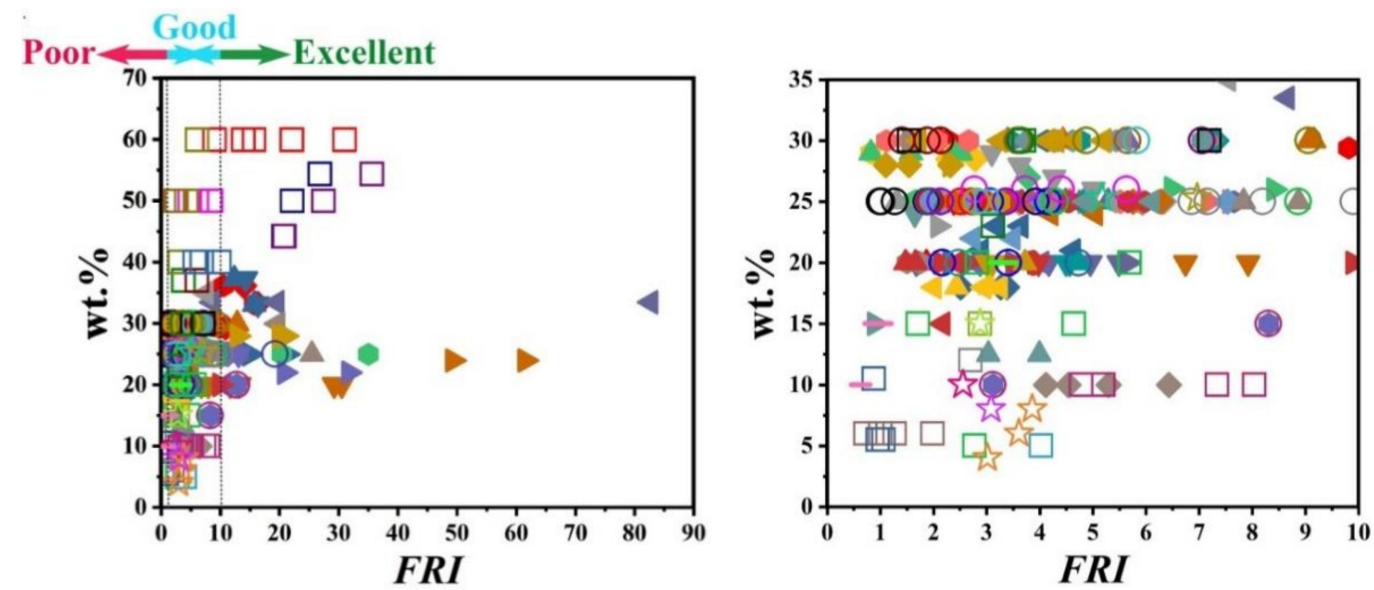

Figure 15. FRI values as a function of combinatorial FR additives and their content in PP in long-shot (left-hand figure) and close-up (right-hand figure) views. Symbols are indicative of different types of combinatorial flame retardant used. Here: ^ APP-13.2/PER-6.8 [68], v APP-16.7/PER-8.3 [143], 4 APP-18.7/PER-6.3 [67], > APP-22.5/PER-7.5, mc-(APP-22.5\&PER-7.5) [144], • APP-10.5/PER-9.8/ MEL-9.1， APP-15.3/PER-9.3/MEL-8.8， APP-19.1/PER-8.9/MEL-8.2 [145]， APP-10.5/PER-9.8/ MEL-9.1, APP-15.3/PER-9.3/MEL-8.8, APP-19.1/PER-8.9/MEL-8.2 [145], ^ APP-15.3/PER-9.3/MEL-8.6, APP-14.3/PER-8.7/MEL-8.1/MDH-6.2 [146], จ APP-15.3/PER-9.3/MEL-8.6, APP-14.3/PER-8.7/MEL-8.1/ MDH-6.2 [146], 4 APP-12/PER-4/MEL-4/C20A-1, APP-12/PER-4/MEL-4/C20A-3, APP\&MMT-12/ PER-4/MEL-4/C20A-1, APP\&MMT-12/PER-4/MEL-4/C20A-3 [104] m-APP-16.6/DPER-4.2/MEL-4.2, m-APP-16/DPER-4/MEL-4/SEP-1 [147], • APP-13.5/PER-4.5, APP-12.75/PER-4.25/MF-1, APP-12.75/ PER-4.25/MFA-1 [148], • APP-22.5/PER-7.5 [149], $\triangle$ APP-12.7/PER-5.3, APP-12/PER-5/TA-FR-1 [150], $\nabla$ APP-16.67/PER-8.33, APP-16.33/PER-8.17/NOR116-0.5 [72], \ APP-13.5/PER-4.5, APP-12.75/ PER-4.25/G-bases-1， APP-12.75/PER-4.25/U-bases-1 [151], APP-17.2/DPER-7.8, m-APP-17.2/ DPER-7.8, APP-16.2/DPER-7.8/ATH-1 [152], APP-21.4/PER-7.1, APP-20.3/PER-6.8/Kaol-1.4 [70], APP-21.75/PER-7.25, APP-19.5/PER-6.5/MMT-3, APP-19.5/PER-6.5/m-MMT-3 [153], $\triangle$ APP-21.75/ PER-7.25, APP-19.5/PER-6.5/MMT-3, APP-19.5/PER-6.5/m-MMT-3, APP-19.5/PER-6.5/m-MMT-3 [154], $\checkmark$ APP-18.75/PER-6.25, APP-18/PER-6/LDH-1, APP-18/PER-6/m-LDH-1 [155], 4 APP-18.75/ PER-6.25， APP-18/PER-6/m-SiR-1， APP-18/PER-6/m-SiR-1， APP-16.5/PER-5.5/m-SiR-3 [156]， m-APP-16.7/DPER-8.3, m-APP-16.7/DPER-8.3/Z-1, m-APP-16.7/DPER-8.3/Z-1/MWCNT-0.1 [157], - APP-18.75/PER-6.25, APP-18.75/PER-6.25/ALL-2 [158], APP-16.7/PER-8.3, APP-15/PER-7.5/ MAO-2.5, APP-15/PER-7.5/Zn-MAO-2.5 [159]， A APP-16.7/PER-8.3， APP-16/PER-8/m-SEP-1， APP-15.3/PER-7.7/m-SEP-2, APP-14.7/PER-7.3/m-SEP-3, APP-14/PER-7/m-SEP-4, APP-13.3/PER-6.7/ m-SEP-5 [160], $\nabla$ APP-15/PER-5, APP-14.25/PER-4.75/OP-POSS-1, APP-14.25/PER-4.75/A-POSS-1, APP-14.25/PER-4.75/OA-POSS-1, APP-14.25/PER-4.75/TS-POSS-1 [161], 4 APP-20/PER-10 APP-19/ PER-9.5/T-RS-5, APP-19/PER-9.5/CV-5, APP-19/PER-9.5/CR-5 [162], APP-15/PER-5, APP-14.25/ PER-4.75/ZnB-1， APP-14.25/PER-4.75/BPO 4 -1， APP-14.25/PER-4.75/Bsi-1， APP-14.25/PER-4.75/ LaB-1 [163], A APP-18.75/PER-6.25, APP-17.25/PER-5.75/NiFeO-2, APP-17.25/PER-5.75/CoFeO-2 [107], - APP-16.67/PER-8.33, APP-15.33/PER-7.67/Ni ${ }_{12} \mathrm{P}_{5}-2$, APP-15.33/PER-7.67/Co 2 P-2, APP-15.33/ PER-7.67/Cu ${ }_{3}$ P-2 [164], $\triangle$ APP-18.75/PER-6.25, APP-18/PER-6/ZHS-1 [165], V APP-18.75/PER-6.25, APP-18.75/PER-6.25/MnAc-1, APP-18.75/PER-6.25/MnAc-2, APP-18.75/PER-6.25/MnAc-3, APP-18.75/ PER-6.25/MnAc-4 [166], \ APP-21/DPER-7/m-SA-7 [167], \ APP-15.4/PEPA-7.6, APP-15.4/PEPA-7.6/ NOR116-2, APP-15.4/PEPA-7.6/ZrP-2, APP-15.4/PEPA-7.6/m-ZrP-2 [168], MCAPP-16.7/PEPA-8.3, MCAPP-15.7/PEPA-7.8/Kaol-1.5, MCAPP-15.7/PEPA-7.8/m-Kaol-1.5 [169], MCAPP-16.7/PEPA-8.3, MCAPP-15.7/PEPA-7.8/Kaol-1.5, MCAPP-15.7/PEPA-7.8/m-Kaol-1.5 [170], ^ MCAPP-16.7/PEPA-8.3, MCAPP-15.7/PEPA-7.8/Kaol-1.5, MCAPP-15.7/PEPA-7.8/Kaol nanoroll-1.5 [171], จ MCAPP-16.7/ PEPA-8.3, MCAPP-15.7/PEPA-7.8/Kaol-1.5, MCAPP-15.7/PEPA-7.8/m-Kaol-1.5 [89], \& mc-APP-16.7/ PEPA-8.3, mc-APP-15.7/PEPA-7.8/Kaol-1.5, mc-APP-15.7/PEPA-7.8/HNT-1.5, mc-APP-15.7/PEPA-7.8/ Kaol-1.35/HNT-0.15 [172], mc-APP-16.7/PEPA-8.3, mc-APP-15.7/PEPA-7.8/Kaol-1.5, mc-APP-15.7/ 
PEPA-7.8/HSA-A-1.5, mc-APP-15.7/PEPA-7.8/HSA-P-1.5, mc-APP-15.7/PEPA-7.8/HSA-A-La-1.5, mc-APP-15.7/PEPA-7.8/HSA-P-La-1.5 [173], • APP-12.5/P-CA-12.5 [49], • APP-28/PhZ-FR-2, APP-26/ PhZ-FR-4, APP-24/PhZ-FR-6, APP-22/PhZ-FR-8 [38], $\triangle$ mc-APP-22.5/THEIC-7.5 [41], $\nabla$ APP-16.67/ PPU-CA-8.33, APP-12.5/PPU-CA-12.5 [50], \ APP-17.6/TA-CFA-4.4, m-APP-17.6/TA-CFA-4.4 [95], ।

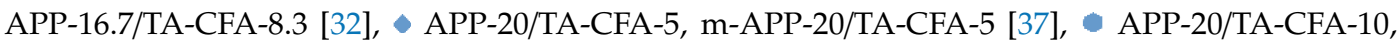
APP-22.5/TA-CFA-7.5, APP-24/TA-CFA-6 [40], $\triangle$ APP-15/TA-CFA-15, APP-20/TA-CFA-10, APP-22.5/ TA-CFA-7.5, APP-24/TA-CFA-6 [39], \ APP-15/TA-CFA-5, APP-14.63/TA-CFA-4.87/m-MMT-0.5, APP-14.25/TA-CFA-4.75/m-MMT-1， APP-13.87/TA-CFA-4.63/m-MMT-1.5， APP-13.5/TA-CFA-4.5/ m-MMT-2, APP-12.75/TA-CFA-4.25/m-MMT-3 [174], \ APP-18.24/TA-CFA-4.56/SiO ${ }_{2}-1.2$, APP-15.66/ TA-CFA-3.91/AHP-3.4/SiO 2 -1.03 [61], APP-18.24/TA-CFA-4.56/SiO 2 -1.2, APP-18.24/TA-CFA-4.56/ $\mathrm{SiO}_{2}$-1.2 [175], $\quad$ APP-20/TA-CFA-5, APP-19.6/TA-CFA-4.9/rGNO-0.5, APP-19.2/TA-CFA-4.8/rGNO-1, APP-18.4/TA-CFA-4.6/rGNO-2 [176], m-APP-20/TA-CFA-5, m-APP-19.6/TA-CFA-4.9/rGNO-0.5, m-APP-19.2/TA-CFA-4.8/rGNO-1， m-APP-18.4/TA-CFA-4.6/rGNO-2， m-APP-17.6/TA-CFA-4.9/ m-APP@rGNO-2.5, m-APP-15.2/m-APP@rGNO-5/TA-CFA-4.8, m-APP-10.4/m-APP@rGNO-10/ TA-CFA-4.6 [177], \ APP-10/TA-CA-10 [23], $\nabla$ APP-13.33/TA-CA-6.67, APP-15/TA-CA-5 [27], APP-16.7/TA-CA-8.3 [67], $\rightarrow$ APP-18.75/TA-CA-6.25, mc-APP-18.75/TA-CA-6.25 [36], • APP-13.33/ TA-CA-6.67 [149], - APP-20/TA-CA-10, APP-20/Homo-TA-CA-10 [178], \ APP-15/TA-CA-15,

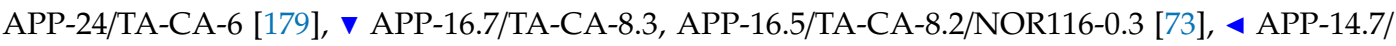
TA-CA-5.3， APP-14/TA-CA-5/m-MMT-1， APP-12.5/TA-CA-4.5/m-MMT-3 [180], • APP-16.72/ TA-CFA-4.18/SiO 2 -1.1, APP-16.72/TA-CFA-4.18/SiO 2 -1.1 [181], APP-16.7/TA-CA-ZnO-8.3 [29], APP\&TA-IFR-10, APP\&TA-IFR-15, APP\&TA-IFR-20 [182]， A APP-12.5/TA-IFR-12.5, APP-16.67/ TA-IFR-8.33, APP-18.75/TA-IFR-6.25 [31], $\nabla$ APP-20/PI-TA-CA-5, APP-20/PI-TA-CA-5 [33], \ APP-22.5/ PI-IFR-7.5, APP-16.4/PI-IFR-8.2/TA-CFA-5.4 [70], • APP-15/ATH-15, mc-(APP-15\&ATH-15) [183], • APP-8/MMT-2, APP-6/MMT-4, APP-8/m-MMT-2, APP-6/m-MMT-4 [24], APP-15/Nf-5, APP-15/ m-BT-5 [103], \ APP-15/Nf-5, APP-15/m-BT-5 [103], $\nabla$ APP-15/C15A-5, OP-15/C15A-5 [60], 4 APP-12/C20A-5/PER-4/MEL-4, APP\&MMT-12/C20A-5/PER-4/MEL-4, APP\&MMT-6/C20A-5/ PER-2/MEL-2, APP\&MMT-9/C20A-5/PER-3/MEL-3 [104], APP-19/m-LDH-1, APP-18/m-LDH-2, APP-17/m-LDH-3 [26], APP-IFR-18/LDH-2, APP-IFR-16/LDH-4, APP-IFR-18/LDH-2, APP-IFR-16/ LDH-4 [51], APP-12.5/Si-FR-12.5, APP-15/Si-FR-10, APP-13.8/Si-FR-9.2, APP-16.67/Si-FR-8.33, APP-18.75/Si-FR-6.25 [30], $\triangle$ APP-12/SEP-0.5, APP-12/m-SEP-0.5 [25], $\nabla$ APP-22.8/SiO $2-1.2$ [175], $\checkmark$ APP-22/CB-3, APP-20/CB-5, APP-18/CB-7 [34], $>$ APP-7.5/CD-7.5 [135], P-CA-24/MEL-6 [184], - P-FR-15/MPyP-15 [57], $\triangle$ P-FR-20/GNO-2 [58], จ P-IFR-19/Znacac-1, P-IFR-19/Cracac-1 [53], PN-IFR-29.5/m-MMT-0.5， PN-IFR-29/m-MMT-1， PN-IFR-28.5/m-MMT-1.5， PN-IFR-28/m-MMT-2, PN-IFR-27.5/m-MMT-2.5, PN-IFR-27/m-MMT-3, PN-IFR-26/m-MMT-4, PN-IFR-25/m-MMT-5 [56], । P-IFR-25.5/m-MMT-2.5, P-IFR-25.5/m-LDH-2.5, P-IFR-25.5/A-POSS-2.5, P-IFR-25.5/MWCNT-2.5 [55], • P-IFR-26.5/MWCNT-1.5, P-IFR-25.5/MWCNT-2.5, P-IFR-24.5/MWCNT-3.5 [54], PA-16/EDA-9 [139], C PPU-CA-12.5/APP-12.5, PPU-CA-16.67/APP-8.33, PPU-CA-18.75/APP-6.25, PPU-CA-20/APP-5 [50], C MP-15/PER-10, MP-15/PER-9/Kaol-1, MP-15/PER-8/Kaol-2 [64], C MP-12.3/PER-7.7, MP-15.4/ PER-9.6, MP-11.7/PER-7.3/m-MMT-1, MP-14.7/PER-9.3/m-MMT-1 [185], C MMP-16.64/PER-9.36, MMP-16/PER-9/La ${ }_{2} \mathrm{O}_{3}-1$, MMP-15.36/PER-8.64/La ${ }_{2} \mathrm{O}_{3}-2$, MMP-14.72/PER-8.28/La $2 \mathrm{O}_{3}-3$ [186], o MPP-22.5/DPER-7.5, MPP-15/EG-10/DPER-5 [187], O MATMP-16.7/PER-8.3 [143], ○ MPyP-18.75/PER- 
6.25, MPyP-17.25/PER-5.75/m-CD-2 [188], O MPyP-15/P-FR-15 [57], C MPyP-22.5/TA-CFA-7.5, MPyP-15/TA-CFA-15, TA-CFA-22.5/MPyP-7.5 [66], O TA-CFA-15/APP-15, TA-CFA-20/APP-10 [39], C TA-CA-10/APP-10 [23], C TA-CA-13.33/APP-6.67 [27], C TA-CA-20/APP-10, TA-CA-15/APP-15 [179], TA-IFR-12.5/APP-12.5, TA-IFR-16.67/APP-8.33 [31], ○ TA\&APP-IFR-10, TA\&APP-IFR-15, TA\&APP-IFR-20 [182], C PI-IFR-20/APP-10 [70], C N-FR-24.5/ $\mathrm{SiO}_{2}-0.5, \mathrm{~N}-\mathrm{FR}-22 / \mathrm{SiO}_{2}-3$ [74], c N-IFR-20/PA6-5 [75]， N-IFR-24.5/HGM-0.5， N-IFR-24/HGM-1， N-IFR-23/HGM-2, N-IFR-22/ HGM-3 [76], $\square$ ATH-15/APP-15, mc-(ATH-15\&APP-15) [183], ᄃ ATH-55/GB-5, ATH-50/GB-10, ATH-47/GB-10/m-ZrP-3, ATH-44/GB-10/m-ZrP-6, ATH-41/GB-10/m-ZrP-9 [81], ᄃ ATH-49/m-MMT-1, ATH-47/m-MMT-3, ATH-45/m-MMT-5 [80], $\square$ ATH-20/m-MMT-3, ATH-20/m-MMT-10, ATH-20/ m-MMT-17 [82], $\sqcap$ MDH-16.6/APP-12.7/PER-7.7/MEL-7.2, MDH-25/APP-11.5/PER-7/MEL-6.5, MDH-31.8/APP-10.4/PER-6.3/MEL-5.9 [146], $\sqcap$ MDH-16.6/APP-12.7/PER-7.7/MEL-7.2, MDH-25/ APP-11.5/PER-7/MEL-6.5, MDH-31.8/APP-10.4/PER-6.3/MEL-5.9 [146], $\sqcap$ MDH-20/m-MMT-17 [82], \ulcorner MDH-30/m-MMT-10, MDH-40/m-MMT-10, MDH-50/m-MMT-10 [82], $\sqcap$ MDH-39/m-MMT-1, MDH-37/ m-MMT-3, MDH-35/m-MMT-5 [85], ᄃ MDH-45/Cobalt chelate-5, MDH-40/Cobalt chelate-10, MDH-35/ Cobalt chelate-15, MDH-30/Cobalt chelate-20 [84], $\ulcorner$ m-MMT-2.5/SEP-2.5, MDH-10/m-SEP-5, MDH-15/ m-SEP-5, MDH-10/m-MMT-2.5/SEP-2.5, MDH-15/m-MMT-2.5/SEP-2.5 [87], $\sqcap$ MMT-6/APP-4, MMT-8/ APP-2, m-MMT-6/APP-4, m-MMT-8/APP-2 [24], $\left\ulcorner\right.$ Si-FR-12.5/APP-12.5 [30], $\square \mathrm{Ni}_{2} \mathrm{O}_{3}-7.5 / A C-7.5$ [108], SEP-10/MWCNT-2 [189], $\sqsubset$ C30B-3/ACPB-3, C30B-3/BUPB-3, C30B-3/MEPB-3, C30B-3/PBPA-3 [191], $\square \mathrm{Si}-3 / \mathrm{SnCl}_{2}-2$ [190], $\left\ulcorner\mathrm{C} 20 \mathrm{~A}-5 / \mathrm{TiO}_{2}-0.5, \mathrm{~m}-\mathrm{C} 20 \mathrm{~A}-5 / \mathrm{TiO}_{2}-0.5, \mathrm{~m}-\mathrm{C} 20 \mathrm{~A}-10 / \mathrm{TiO}_{2}-0.5\right.$ [105], 战 CF-5/ MWCNT-5 [133], CB-3/MWCNT-1, CB-5/MWCNT-1, CB-5/MWCNT-3 [131], CB-5/CF-3 [134], AC-7.5/ $\mathrm{Ni}_{2} \mathrm{O}_{3}-7.5$ [108], 出 PER-10.4/MEL-9.7/APP-5.2 [145], 解 PER-10.4/MEL-9.7/APP-5.2 [145], - CD-7/TEP-3, CD-10/TEP-5, CD-7.5/APP-7.5 [135], - m-lig-18/Ni(Ac) $)_{2}-2$, m-lig-18/Co- (Ac) ${ }_{2}-2$, m-lig-18/Zn(Ac) $)_{2}-2$ [136].

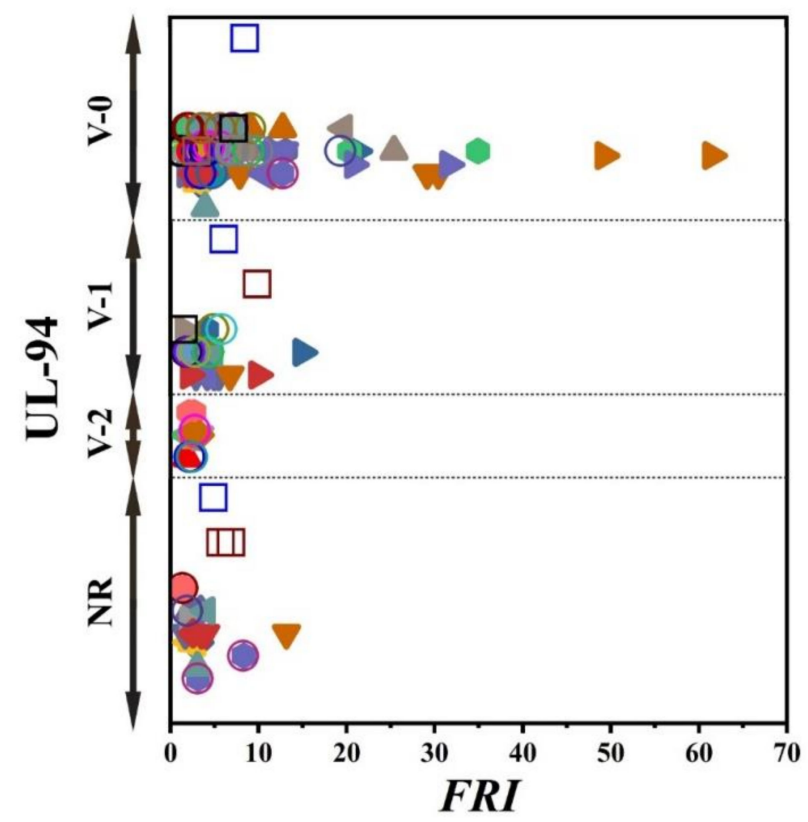

Figure 16. FRI values versus UL-94 test results. Symbols are indicative of combination of flame retardant (FR) additives used in PP. The vertical intervals in each category, i.e., V-0, V-1, V-2, and NR, are schematically representative of the amount of additive used. For example, two data distinguished by different symbols having the same or very close $F R I$ values (horizontal quantity) in a given category (e.g., V-1), may have different vertical quantities, e.g., both reveal V-1 behavior in UL-94 test, but the upper contains more FR in PP. 

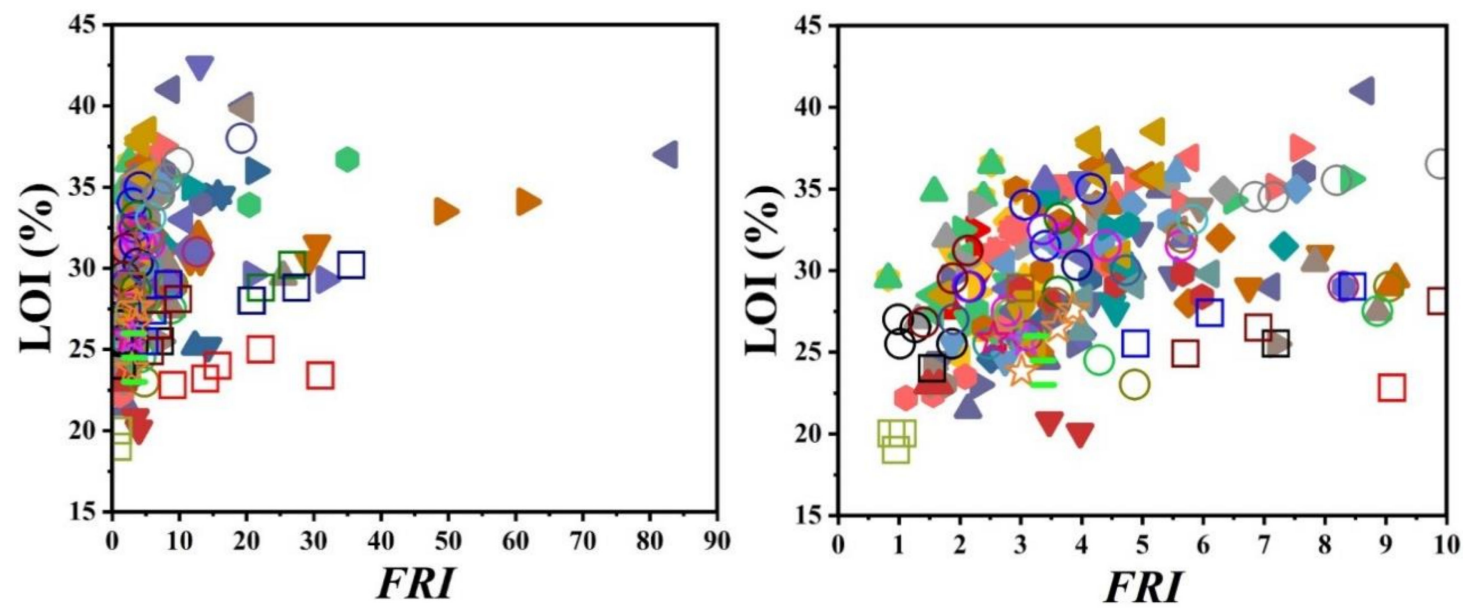

Figure 17. FRI values of PP as a function of LOI test results in long-shot (left-hand figure) and close-up (right-hand figure). Symbols are indicative of different types of blend flame retardants used. The left-side plot reveals that FRI values above 10 (Excellent zone) took place in several cases, which is in contradiction with all previous cases in which only one additive was used.

\section{Conclusions and Future Perspective}

This work opens new avenues to the experts working on "flame retardant polyolefins", the title of a Special Issue entitled "Flame Retardant Polyolefins" in Polymers journal for which this work is designed and carried out. In this work, more than 150 research papers from the literature dealing with the flame retardancy of PP were analyzed, classified, and discussed in terms of flame retardancy performance. From the selected papers were extracted cone calorimetry data to calculate Flame Retardancy Index $(F R I)$ as a measure or label of flame retardant performance. To have a comprehensive overview of flame retardant PP materials, works on PP flame retardancy were categorized in terms of additives used in classes including: phosphorus-based, nitrogen-based, mineral, carbon-based, bio-based, and hybrid combinatorial flame retardants composed of two or more additives. The analysis of efficiency of flame retardancy was performed in terms of the FRI variation as a function of wt.\% of additives used. The analysis quite obviously unveiled the superiority of the combination of additives over the use of each one separately. In addition, the UL-94 and LOI values available in each class of additives were plotted in terms of the FRI so as to find possible correlation between analyses made in the literature. This work provided a pool of data on flame-retardant PP materials for future research on PP materials. It was elucidated that $F R I$ can satisfactorily make possible classification of PP materials in terms of flame retardancy performance. The present work provides those research works that claim achieving synergistic effect of two or more flame retardants with a clear measure of flame retardant performance as Poor, Good, and Excellent labels assigned to PP materials, based on cone calorimetry data. Moreover, future works on LOI and UL-94 tests can be added to the data used here so as to draw a more detailed picture of flame retardancy behavior of PP materials. The approach can be used to make judgement about other flame retardant polyolefins. Moreover, we believe that the mechanical properties of FR polymers should also be considered in the future, but it is pertinent to the completeness of data in the literature. The importance of mechanical properties springs from the fact that highly loaded systems are prone to mechanical failure as a consequence of stress concentration. All in all, the type and the percentage of FRs in polymers affect both the mechanical and flame retardant properties of polymers; therefore, optimization of both properties is of importance.

Author Contributions: Conceptualization, H.V. and M.R.S.; methodology, H.V.; validation, H.V. and M.R.S.; formal analysis, F.S., V.A. and E.M.; investigation, F.D., G.N., V.A. and R.S.; data curation, H.V.; writing-original draft preparation, F.S. and E.M.; writing-review and editing, H.V. and M.R.S.; visualization, H.V. and M.R.S.; supervision, H.V. and M.R.S. All authors have read and agreed to the published version of the manuscript.

Funding: This research received no external funding. 
Acknowledgments: The authors would like to acknowledge Reza Sheibani, the Head of Research \& Development Center, Marun Petrochemical Company, Mahshahr, Iran, for providing E.M. with an opportunity to visit petrochemical plant, discussing practical processing criticisms in developing flame-retardant PP, and giving advice on concerns of engineers working on petrochemical plants who intend to make PP flame retardant.

Conflicts of Interest: The authors declare no conflict of interest.

\section{References}

1. Laoutid, F.; Bonnaud, L.; Alexandre, M.; Lopez-Cuesta, J.-M.; Dubois, P. New prospects in flame retardant polymer materials: From fundamentals to nanocomposites. Mater. Sci. Eng. R Rep. 2009, 63, $100-125$. [CrossRef]

2. Vahabi, H.; Jouyandeh, M.; Cochez, M.; Khalili, R.; Vagner, C.; Ferriol, M.; Movahedifar, E.; Ramezanzadeh, B.; Rostami, M.; Ranjbar, Z. Short-lasting fire in partially and completely cured epoxy coatings containing expandable graphite and halloysite nanotube additives. Prog. Org. Coat. 2018, 123, 160-167. [CrossRef]

3. Rad, E.R.; Vahabi, H.; de Anda, A.R.; Saeb, M.R.; Thomas, S. Bio-epoxy resins with inherent flame retardancy. Prog. Org. Coat. 2019, 135, 608-612. [CrossRef]

4. Tripathi, D. Practical Guide to Polypropylene; iSmithers Rapra Publishing: Shawbury Shewsbury Shropshire, UK, 2002.

5. Motahari, S.; Motlagh, G.H.; Moharramzadeh, A. Thermal and flammability properties of polypropylene/silica aerogel composites. J. Macromol. Sci. Part B 2015, 54, 1081-1091. [CrossRef]

6. Morgan, A.B.; Liu, W. Flammability of thermoplastic carbon nanofiber nanocomposites. Fire Mater. 2011, 35, 43-60. [CrossRef]

7. Maddah, H.A. Polypropylene as a promising plastic: A review. Am. J. Polym. Sci. 2016, 6, 1-11.

8. Shubhra, Q.T.; Alam, A.; Quaiyyum, M. Mechanical properties of polypropylene composites: A review. J. Thermoplast Compos. Mater. 2013, 26, 362-391. [CrossRef]

9. Spoerk, M.; Holzer, C.; Gonzalez-Gutierrez, J. Material extrusion-based additive manufacturing of polypropylene: A review on how to improve dimensional inaccuracy and warpage. J. Appl. Polym. Sci. 2020, 137, 48545. [CrossRef]

10. Dabrowska, I.; Fambri, L.; Pegoretti, A.; Slouf, M.; Vackova, T.; Kolarik, J. Spinning, drawing and physical properties of polypropylene nanocomposite fibers with fumed nanosilica. Express Polym. Lett. 2015, 9, 277-290. [CrossRef]

11. Allahvaisi, S. Polypropylene in the Industry of Food Packaging; IN TECH: Janeza, Croatia, 2012.

12. Yusuf, M. A Review on Flame Retardant Textile Finishing: Current and Future Trends. Curr. Smart Mater. 2018, 3, 99-108. [CrossRef]

13. Gulrez, S.K.; Ali Mohsin, M.; Shaikh, H.; Anis, A.; Pulose, A.M.; Yadav, M.K.; Qua, E.H.P.; Al-Zahrani, S. A review on electrically conductive polypropylene and polyethylene. Polym. Compos. 2014, 35, 900-914. [CrossRef]

14. Patil, A.; Patel, A.; Purohit, R. An overview of polymeric materials for automotive applications. Mater. Today Proc. 2017, 4, 3807-3815. [CrossRef]

15. Vahabi, H.; Paran, S.M.R.; Shabanian, M.; Dumazert, L.; Sonnier, R.; Movahedifar, E.; Zarrintaj, P.; Saeb, M.R. Triple-faced polypropylene: Fire retardant, thermally stable, and antioxidative. J. Vinyl Addit. Technol. 2019, 25, 366-376. [CrossRef]

16. Vahabi, H.; Dumazert, L.; Khalili, R.; Saeb, M.R.; Cuesta, J.-M.L. Flame retardant PP/PA6 blends: A recipe for recycled wastes. Flame Retard. Therm. Stab. Mater. 2019, 2, 1-8. [CrossRef]

17. Hajibeygi, M.; Mousavi, M.; Shabanian, M.; Vahabi, H. The effect of phosphorus based melamine-terephthaldehyde resin and $\mathrm{Mg}$-Al layered double hydroxide on the thermal stability, flame retardancy and mechanical properties of polypropylene MgO composites. Mater. Today Commun. 2020, 23, 100880. [CrossRef]

18. Pani, B.; Sidhaarath, S.; Dhirendra, S. Studies on the effects of various flame retardants on polypropylene. Am. J. Polym. Sci. 2013, 3, 63-69.

19. Vahabi, H.; Kandola, B.K.; Saeb, M.R. Flame retardancy index for thermoplastic composites. Polymers 2019, 11, 407. [CrossRef] 
20. Movahedifar, E.; Vahabi, H.; Saeb, M.R.; Thomas, S. Flame retardant epoxy composites on the road of innovation: An analysis with flame retardancy index for future development. Molecules 2019, $24,3964$. [CrossRef] [PubMed]

21. Zhang, S.; Horrocks, A.R. A review of flame retardant polypropylene fibres. Prog. Polym. Sci. 2003, 28, 1517-1538. [CrossRef]

22. Li, Q.; Jiang, P.; Su, Z.; Wei, P.; Wang, G.; Tang, X. Synergistic effect of phosphorus, nitrogen, and silicon on flame-retardant properties and char yield in polypropylene. J. Appl. Polym. Sci. 2005, 96, 854-860. [CrossRef]

23. Duan, L.; Yang, H.; Song, L.; Hou, Y.; Wang, W.; Gui, Z.; Hu, Y. Hyperbranched phosphorus/nitrogen-containing polymer in combination with ammonium polyphosphate as a novel flame retardant system for polypropylene. Polym. Degrad. Stab. 2016, 134, 179-185. [CrossRef]

24. Hanna, A.; Nour, M.; Souaya, E.; Abdelmoaty, A. Studies on the flammability of polypropylene/ammonium polyphosphate and montmorillonite by using the cone calorimeter test. Open Chem. 2018, 16, 108-115. [CrossRef]

25. Pappalardo, S.; Russo, P.; Acierno, D.; Rabe, S.; Schartel, B. The synergistic effect of organically modified sepiolite in intumescent flame retardant polypropylene. Eur. Polym. J. 2016, 76, 196-207. [CrossRef]

26. Kalali, E.N.; Montes, A.; Wang, X.; Zhang, L.; Shabestari, M.E.; Li, Z.; Wang, D.Y. Effect of phytic acid-modified layered double hydroxide on flammability and mechanical properties of intumescent flame retardant polypropylene system. Fire Mater. 2018, 42, 213-220. [CrossRef]

27. Wang, W.; Wen, P.; Zhan, J.; Hong, N.; Cai, W.; Gui, Z.; Hu, Y. Synthesis of a novel charring agent containing pentaerythritol and triazine structure and its intumescent flame retardant performance for polypropylene. Polym. Degrad. Stab. 2017, 144, 454-463. [CrossRef]

28. Jung, D.; Bhattacharyya, D. Keratinous fiber based intumescent flame retardant with controllable functional compound loading. ACS Sustain. Chem. Eng. 2018, 6, 13177-13184. [CrossRef]

29. Xu, B.; Wu, X.; Ma, W.; Qian, L.; Xin, F.; Qiu, Y. Synthesis and characterization of a novel organic-inorganic hybrid char-forming agent and its flame-retardant application in polypropylene composites. J. Anal. Appl. Pyrolysis 2018, 134, 231-242. [CrossRef]

30. Zhao, Z.; Jin, Q.; Zhang, N.; Guo, X.; Yan, H. Preparation of a novel polysiloxane and its synergistic effect with ammonium polyphosphate on the flame retardancy of polypropylene. Polym. Degrad. Stab. 2018, 150, 73-85. [CrossRef]

31. Wen, P.; Feng, X.; Kan, Y.; Hu, Y.; Yuen, R.K. Synthesis of a novel triazine-based polymeric flame retardant and its application in polypropylene. Polym. Degrad. Stab. 2016, 134, 202-210. [CrossRef]

32. Xu, Z.-Z.; Huang, J.-Q.; Chen, M.-J.; Tan, Y.; Wang, Y.-Z. Flame retardant mechanism of an efficient flame-retardant polymeric synergist with ammonium polyphosphate for polypropylene. Polym. Degrad. Stab. 2013, 98, 2011-2020. [CrossRef]

33. Tang, W.; Qian, L.; Chen, Y.; Qiu, Y.; Xu, B. Intumescent flame retardant behavior of charring agents with different aggregation of piperazine/triazine groups in polypropylene. Polym. Degrad. Stab. 2019, 169, 108982. [CrossRef]

34. Yang, H.; Guan, Y.; Ye, L.; Wang, S.; Li, S.; Wen, X.; Chen, X.; Mijowska, E.; Tang, T. Synergistic effect of nanoscale carbon black and ammonium polyphosphate on improving thermal stability and flame retardancy of polypropylene: A reactive network for strengthening carbon layer. Compos. Part B Eng. 2019, 174, 107038. [CrossRef]

35. Shao, Z.-B.; Deng, C.; Tan, Y.; Chen, M.-J.; Chen, L.; Wang, Y.-Z. An efficient mono-component polymeric intumescent flame retardant for polypropylene: Preparation and application. ACS Appl. Mater. Interfaces 2014, 6, 7363-7370. [CrossRef] [PubMed]

36. Deng, C.-L.; Du, S.-L.; Zhao, J.; Shen, Z.-Q.; Deng, C.; Wang, Y.-Z. An intumescent flame retardant polypropylene system with simultaneously improved flame retardancy and water resistance. Polym. Degrad. Stab. 2014, 108, 97-107. [CrossRef]

37. Sun, Y.; Yuan, B.; Shang, S.; Zhang, H.; Shi, Y.; Yu, B.; Qi, C.; Dong, H.; Chen, X.; Yang, X. Surface modification of ammonium polyphosphate by supramolecular assembly for enhancing fire safety properties of polypropylene. Compos. Part B Eng. 2020, 181, 107588. [CrossRef]

38. Qin, Z.; Li, D.; Lan, Y.; Li, Q.; Yang, R. Ammonium polyphosphate and silicon-containing cyclotriphosphazene: Synergistic effect in flame-retarded polypropylene. Ind. Eng. Chem. Res. 2015, 54, 10707-10713. [CrossRef] 
39. Wen, P.; Wang, X.; Wang, B.; Yuan, B.; Zhou, K.; Song, L.; Hu, Y.; Yuen, R.K. One-pot synthesis of a novel s-triazine-based hyperbranched charring foaming agent and its enhancement on flame retardancy and water resistance of polypropylene. Polym. Degrad. Stab. 2014, 110, 165-174. [CrossRef]

40. Wen, P.; Wang, X.; Xing, W.; Feng, X.; Yu, B.; Shi, Y.; Tang, G.; Song, L.; Hu, Y.; Yuen, R.K. Synthesis of a novel triazine-based hyperbranched char foaming agent and the study of its enhancement on flame retardancy and thermal stability of polypropylene. Ind. Eng. Chem. Res. 2013, 52, 17015-17022. [CrossRef]

41. Jiang, Z.; Liu, G. Microencapsulation of ammonium polyphosphate with melamine-formaldehyde-tris (2-hydroxyethyl) isocyanurate resin and its flame retardancy in polypropylene. Rsc Adv. 2015, 5, 88445-88455. [CrossRef]

42. Yu, S.; Xiao, S.; Zhao, Z.; Huo, X.; Wei, J. Microencapsulated ammonium polyphosphate by polyurethane with segment of dipentaerythritol and its application in flame retardant polypropylene. Chin. J. Chem. Eng. 2019, 27, 1735-1743. [CrossRef]

43. Deng, C.L.; Deng, C.; Zhao, J.; Fang, W.H.; Lin, L.; Wang, Y.Z. Water resistance, thermal stability, and flame retardation of polypropylene composites containing a novel ammonium polyphosphate microencapsulated by UV-curable epoxy acrylate resin. Polym. Adv. Technol. 2014, 25, 861-871. [CrossRef]

44. Zheng, Z.; Qiang, L.; Yang, T.; Wang, B.; Cui, X.; Wang, H. Preparation of microencapsulated ammonium polyphosphate with carbon source-and blowing agent-containing shell and its flame retardance in polypropylene. J. Polym. Res. 2014, 21, 443. [CrossRef]

45. Chen, M.; Xu, Y.; Chen, X.; Ma, Y.; He, W.; Yu, J.; Zhang, Z. Thermal stability and combustion behavior of flame-retardant polypropylene with thermoplastic polyurethane-microencapsulated ammonium polyphosphate. High Perform. Polym. 2014, 26, 445-454. [CrossRef]

46. Shao, Z.-B.; Deng, C.; Tan, Y.; Chen, M.-J.; Chen, L.; Wang, Y.-Z. Flame retardation of polypropylene via a novel intumescent flame retardant: Ethylenediamine-modified ammonium polyphosphate. Polym. Degrad. Stab. 2014, 106, 88-96. [CrossRef]

47. Shao, Z.-B.; Deng, C.; Tan, Y.; Yu, L.; Chen, M.-J.; Chen, L.; Wang, Y.-Z. Ammonium polyphosphate chemically-modified with ethanolamine as an efficient intumescent flame retardant for polypropylene. J. Mater. Chem. A 2014, 2, 13955-13965. [CrossRef]

48. Deng, C.-1.; Deng, C.; Zhao, J.; Li, R.-m.; Fang, W.-h.; Wang, Y.-z. Simultaneous improvement in the flame retardancy and water resistance of PP/APP through coating UV-curable pentaerythritol triacrylate onto APP. Chin. J. Polym. Sci. 2015, 33, 203-214. [CrossRef]

49. Tian, N.; Wen, X.; Jiang, Z.; Gong, J.; Wang, Y.; Xue, J.; Tang, T. Synergistic effect between a novel char forming agent and ammonium polyphosphate on flame retardancy and thermal properties of polypropylene. Ind. Eng. Chem. Res. 2013, 52, 10905-10915. [CrossRef]

50. Zhang, T.; Tao, Y.; Zhou, F.; Sheng, H.; Qiu, S.; Ma, C.; Hu, Y. Synthesis of a hyperbranched phosphoruscontaining polyurethane as char forming agent combined with ammonium polyphosphate for reducing fire hazard of polypropylene. Polym. Degrad. Stab. 2019, 165, 207-219. [CrossRef]

51. Wang, X.; Spörer, Y.; Leuteritz, A.; Kuehnert, I.; Wagenknecht, U.; Heinrich, G.; Wang, D.-Y. Comparative study of the synergistic effect of binary and ternary LDH with intumescent flame retardant on the properties of polypropylene composites. RSC Adv. 2015, 5, 78979-78985. [CrossRef]

52. Zhang, C.; Guo, X.; Ma, S.; Zheng, Y.; Xu, J.; Ma, H. Synthesis of a novel branched cyclophosphazene-PEPA flame retardant and its application on polypropylene. J. Therm. Anal. Calorim. 2019, 137, 33-42. [CrossRef]

53. Song, P.; Fang, Z.; Tong, L.; Jin, Y.; Lu, F. Effects of metal chelates on a novel oligomeric intumescent flame retardant system for polypropylene. J. Anal. Appl. Pyrolysis 2008, 82, 286-291. [CrossRef]

54. Du, B.; Fang, Z. Effects of carbon nanotubes on the thermal stability and flame retardancy of intumescent flame-retarded polypropylene. Polym. Degrad. Stab. 2011, 96, 1725-1731. [CrossRef]

55. Du, B.; Ma, H.; Fang, Z. How nano-fillers affect thermal stability and flame retardancy of intumescent flame retarded polypropylene. Polym. Adv. Technol. 2011, 22, 1139-1146. [CrossRef]

56. Chen, Y.J.; Wang, C.; Yang, C.Z. Synergism between Intumescent Flame Retardant and Organo-Montmorillonite in Polypropylene Nanocomposites; Advanced Materials Research; Trans Tech Publications: Bäch, Switzerland, 2013; pp. 502-507. [CrossRef]

57. He, Q.; Lu, H.; Song, L.; Hu, Y.; Chen, L. Flammability and thermal properties of a novel intumescent flame retardant polypropylene. J. Fire Sci. 2009, 27, 303-321. 
58. Yu, B.; Wang, X.; Qian, X.; Xing, W.; Yang, H.; Ma, L.; Lin, Y.; Jiang, S.; Song, L.; Hu, Y. Functionalized graphene oxide/phosphoramide oligomer hybrids flame retardant prepared via in situ polymerization for improving the fire safety of polypropylene. Rsc Adv. 2014, 4, 31782-31794. [CrossRef]

59. Salaün, F.; Creach, G.; Rault, F.; Giraud, S. Microencapsulation of bisphenol-A bis (diphenyl phosphate) and influence of particle loading on thermal and fire properties of polypropylene and polyethylene terephtalate. Polym. Degrad. Stab. 2013, 98, 2663-2671. [CrossRef]

60. Dahiya, J.B.; Kumar, N.; Bockhorn, H. Fire performance and thermal stability of polypropylene nanocomposites containing organic phosphinate and ammonium polyphosphate additives. Fire Mater. 2014, 38, 1-12. [CrossRef]

61. Xu, M.-j.; Wang, J.; Ding, Y.-h.; Li, B. Synergistic effects of aluminum hypophosphite on intumescent flame retardant polypropylene system. Chin. J. Polym. Sci. 2015, 33, 318-328. [CrossRef]

62. Li, H.; Ning, N.; Zhang, L.; Wang, Y.; Liang, W.; Tian, M. Different flame retardancy effects and mechanisms of aluminium phosphinate in PPO, TPU and PP. Polym. Degrad. Stab. 2014, 105, 86-95. [CrossRef]

63. Zhou, S.; Song, L.; Wang, Z.; Hu, Y.; Xing, W. Flame retardation and char formation mechanism of intumescent flame retarded polypropylene composites containing melamine phosphate and pentaerythritol phosphate. Polym. Degrad. Stab. 2008, 93, 1799-1806. [CrossRef]

64. Abdelkhalik, A.; Makhlouf, G.; Hassan, M.A. Manufacturing, thermal stability, and flammability properties of polypropylene containing new single molecule intumescent flame retardant. Polym. Adv. Technol. 2019, 30, 1403-1414. [CrossRef]

65. Wang, X.; Li, Y.; Liao, W.; Gu, J.; Li, D. A new intumescent flame-retardant: Preparation, surface modification, and its application in polypropylene. Polym. Adv. Technol. 2008, 19, 1055-1061. [CrossRef]

66. Chen, X.; Jiao, C. Flame retardancy and thermal Degradation of intumescent flame retardant polypropylene material. Polym. Adv. Technol. 2011, 22, 817-821. [CrossRef]

67. Chen, H.; Wang, J.; Ni, A.; Ding, A.; Han, X.; Sun, Z. The effects of a macromolecular charring agent with gas phase and condense phase synergistic flame retardant capability on the properties of PP/IFR composites. Materials 2018, 11, 111. [CrossRef]

68. Gao, S.; Zhao, X.; Liu, G. Synthesis of an integrated intumescent flame retardant and its flame retardancy properties for polypropylene. Polym. Degrad. Stab. 2017, 138, 106-114. [CrossRef]

69. Shao, Z.-B.; Zhang, M.-X.; Han, Y.; Yang, X.-D.; Jin, J.; Jian, R.-K. A highly efficient gas-dominated and water-resistant flame retardant for non-charring polypropylene. RSC Adv. 2017, 7, 51919-51927. [CrossRef]

70. Li, B.; Zhan, Z.; Zhang, H.; Sun, C. Flame retardancy and thermal performance of polypropylene treated with the intumescent flame retardant, piperazine spirocyclic phosphoramidate. J. Vinyl Addit. Technol. 2014, 20, 10-15. [CrossRef]

71. Yang, R.; Ma, B.; Zhang, X.; Li, J. Fire retardance and smoke suppression of polypropylene with a macromolecular intumescent flame retardant containing caged bicyclic phosphate and piperazine. J. Appl. Polym. Sci. 2019, 136, 47593. [CrossRef]

72. Xie, H.; Lai, X.; Zhou, R.; Li, H.; Zhang, Y.; Zeng, X.; Guo, J. Effect and mechanism of N-alkoxy hindered amine on the flame retardancy, UV aging resistance and thermal degradation of intumescent flame retardant polypropylene. Polym. Degrad. Stab. 2015, 118, 167-177. [CrossRef]

73. Lai, X.; Qiu, J.; Li, H.; Zhou, R.; Xie, H.; Zeng, X. Thermal degradation and combustion behavior of novel intumescent flame retardant polypropylene with N-alkoxy hindered amine. J. Anal. Appl. Pyrolysis 2016, 120, 361-370. [CrossRef]

74. Ye, L.; Wu, Q.; Qu, B. Synergistic effects of fumed silica on intumescent flame-retardant polypropylene. J. Appl. Polym. Sci. 2010, 115, 3508-3515. [CrossRef]

75. Zhang, L.; Yi, D.; Hao, J. Poly (diallyldimethylammonium) and polyphosphate polyelectrolyte complexes as an all-in-one flame retardant for polypropylene. Polym. Adv. Technol. 2019, 31, 260-272. [CrossRef]

76. Kang, B.-h.; Yang, X.-y.; Lu, X. Effect of hollow glass microsphere on the flame retardancy and combustion behavior of intumescent flame retardant polypropylene composites. Polym. Bull. 2019, 77, 1-18. [CrossRef]

77. Vahabi, H.; Raveshtian, A.; Fasihi, M.; Sonnier, R.; Saeb, M.R.; Dumazert, L.; Kandola, B.K. Competitiveness and synergy between three flame retardants in poly (ethylene-co-vinyl acetate). Polym. Degrad. Stab. 2017, 143, 164-175. [CrossRef] 
78. Vahabi, H.; Shabanian, M.; Aryanasab, F.; Laoutid, F.; Benali, S.; Saeb, M.R.; Seidi, F.; Kandola, B.K. Three in one: $\beta$-cyclodextrin, nanohydroxyapatite, and a nitrogen-rich polymer integrated into a new flame retardant for poly (lactic acid). Fire Mater. 2018, 42, 593-602. [CrossRef]

79. Vahabi, H.; Sonnier, R.; Taguet, A.; Otazaghine, B.; Saeb, M.R.; Beyer, G. Halloysite nanotubes (HNTs)/polymer nanocomposites: Thermal degradation and flame retardancy. In Clay Nanoparticles; Elsevier: Amsterdam, The Netherlands, 2020; pp. 67-93. [CrossRef]

80. Liu, L.; Zhang, H.; Sun, L.; Kong, Q.; Zhang, J. Flame-retardant effect of montmorillonite intercalation iron compounds in polypropylene/aluminum hydroxide composites system. J. Therm. Anal. Calorim. 2016, 124, 807-814. [CrossRef]

81. Pérez, N.; Qi, X.-L.; Nie, S.; Acuña, P.; Chen, M.-J.; Wang, D.-Y. Flame retardant polypropylene composites with low densities. Materials 2019, 12, 152. [CrossRef]

82. Zhang, J.; Wilkie, C.A. Fire Retardancy of Polypropylene-Metal Hydroxide Nanocomposites; ACS Publications: Washington, DC, USA, 2006.

83. Molesky, F.; Falk, D.P. Comparison of Smoke Measurements of the Cone Calorimeter and ASTM E-662 Smoke Chamber in Flame Retardant Polypropylene. J. Fire Sci. 1991, 9, 60-68. [CrossRef]

84. Shehata, A. A new cobalt chelate as flame retardant for polypropylene filled with magnesium hydroxide. Polym. Degrad. Stab. 2004, 85, 577-582. [CrossRef]

85. Kong, Q.; Wu, H.; Zhang, H.; Zhang, X.; Zhao, W.; Zhang, J. Effect of Fe-montmorillonite on flammability behavior in polypropylene/magnesium hydroxide composites. J. Nanosci. Nanotechnol. 2016, 16, 8287-8293. [CrossRef]

86. Oyama, H.T.; Sekikawa, M.; Ikezawa, Y. Influence of the polymer/inorganic filler interface on the mechanical, thermal, and flame retardant properties of polypropylene/magnesium hydroxide composites. J. Macromol. Sci. Part B 2011, 50, 463-483. [CrossRef]

87. Marosfoi, B.; Garas, S.; Bodzay, B.; Zubonyai, F.; Marosi, G. Flame retardancy study on magnesium hydroxide associated with clays of different morphology in polypropylene matrix. Polym. Adv. Technol. 2008, 19, 693-700. [CrossRef]

88. Tang, W.; Li, H.; Zhang, S.; Sun, J.; Gu, X. The intercalation of ammonium sulfamate into kaolinite and its effect on the fire performance of polypropylene. J. Thermoplast. Compos. Mater. 2018, 31, 1352-1370. [CrossRef]

89. Tang, W.; Zhang, S.; Sun, J.; Gu, X. Flame retardancy and thermal stability of polypropylene composite containing ammonium sulfamate intercalated kaolinite. Ind. Eng. Chem. Res. 2016, 55, 7669-7678. [CrossRef]

90. Batistella, M.; Otazaghine, B.; Sonnier, R.; Petter, C.; Lopez-Cuesta, J.-M. Fire retardancy of polypropylene/kaolinite composites. Polym. Degrad. Stab. 2016, 129, 260-267. [CrossRef]

91. Zoromba, M.S.; Nour, M.A.; Eltamimy, H.E.; El-Maksoud, S.A.A. Effect of modified layered double hydroxide on the flammability and mechanical properties of polypropylene. Sci. Eng. Compos. Mater. 2018, 25, 101-108. [CrossRef]

92. Manzi-Nshuti, C.; Songtipya, P.; Manias, E.; del Mar Jimenez-Gasco, M.; Hossenlopp, J.M.; Wilkie, C.A. Polymer nanocomposites using zinc aluminum and magnesium aluminum oleate layered double hydroxides: Effects of the polymeric compatibilizer and of composition on the thermal and fire properties of PP/LDH nanocomposites. Polym. Degrad. Stab. 2009, 94, 2042-2054. [CrossRef]

93. Wu, T.; Kong, Q.; Zhang, H.; Zhang, J. Thermal stability and flame retardancy of polypropylene/NiAl layered double hydroxide nanocomposites. J. Nanosci. Nanotechnol. 2018, 18, 1051-1056. [CrossRef]

94. Nyambo, C.; Wang, D.; Wilkie, C.A. Will layered double hydroxides give nanocomposites with polar or non-polar polymers? Polym. Adv. Technol. 2009, 20, 332-340. [CrossRef]

95. Zhang, S.; Liu, X.; Gu, X.; Jiang, P.; Sun, J. Flammability and thermal behavior of polypropylene composites containing dihydrogen phosphate anion-intercalated layered double hydroxides. Polym. Compos. 2015, 36, 2230-2237. [CrossRef]

96. Qin, H.; Zhang, S.; Zhao, C.; Hu, G.; Yang, M. Flame retardant mechanism of polymer/clay nanocomposites based on polypropylene. Polymer 2005, 46, 8386-8395. [CrossRef]

97. Zhu, F.; Liu, D.; Cai, G.; Tan, X.; Wang, J.; Lu, H.; Wilkie, C.A. Thermal stability and flammability performance of polypropylene composites with silica pillared montmorillonites. Polym. Adv. Technol. 2014, 25, 211-216. [CrossRef] 
98. Zhang, J.; Wilkie, C.A. Polyethylene and polypropylene nanocomposites based on polymerically-modified clay containing alkylstyrene units. Polymer 2006, 47, 5736-5743. [CrossRef]

99. Qin, H.; Zhang, S.; Zhao, C.; Feng, M.; Yang, M.; Shu, Z.; Yang, S. Thermal stability and flammability of polypropylene/montmorillonite composites. Polym. Degrad. Stab. 2004, 85, 807-813. [CrossRef]

100. Zhang, J.; Jiang, D.D.; Wilkie, C.A. Thermal and flame properties of polyethylene and polypropylene nanocomposites based on an oligomerically-modified clay. Polym. Degrad. Stab. 2006, 91, 298-304. [CrossRef]

101. Su, S.; Jiang, D.D.; Wilkie, C.A. Poly (methyl methacrylate), polypropylene and polyethylene nanocomposite formation by melt blending using novel polymerically-modified clays. Polym. Degrad. Stab. 2004, 83, 321-331. [CrossRef]

102. Zheng, X.; Jiang, D.D.; Wang, D.; Wilkie, C.A. Flammability of styrenic polymer clay nanocomposites based on a methyl methacrylate oligomerically-modified clay. Polym. Degrad. Stab. 2006, 91, 289-297. [CrossRef]

103. Szustakiewicz, K.; Kiersnowski, A.; Gazińska, M.; Bujnowicz, K.; Pigłowski, J. Flammability, structure and mechanical properties of PP/OMMT nanocomposites. Polym. Degrad. Stab. 2011, 96, 291-294. [CrossRef]

104. Yi, D.; Yang, R.; Wilkie, C.A. Full scale nanocomposites: Clay in fire retardant and polymer. Polym. Degrad. Stab. 2014, 105, 31-41. [CrossRef]

105. Alsharif, M.A.; Zadhoush, A.; Mortazavi, S.M. Thermal Degradation and Flammability Properties of Polypropylene Nanocomposite Using Organoclay-graft-poly (Ethylene Glycol Methacrylate Phosphate). Adv. Polym. Technol. 2014, 33. [CrossRef]

106. Yuan, B.; Chen, G.; Zou, Y.; Shang, S.; Sun, Y.; Yu, B.; He, S.; Chen, X. Alumina nanoflake-coated graphene nanohybrid as a novel flame retardant filler for polypropylene. Polym. Adv. Technol. 2019, 30, 2153-2158. [CrossRef]

107. Dong, M.; Gu, X.; Zhang, S. Effects of compound oxides on the fire performance of polypropylene composite. Ind. Eng. Chem. Res. 2014, 53, 8062-8068. [CrossRef]

108. Gong, J.; Tian, N.; Liu, J.; Yao, K.; Jiang, Z.; Chen, X.; Wen, X.; Mijowska, E.; Tang, T. Synergistic effect of activated carbon and $\mathrm{Ni} 2 \mathrm{O} 3$ in promoting the thermal stability and flame retardancy of polypropylene. Polym. Degrad. Stab. 2014, 99, 18-26. [CrossRef]

109. Song, R.; Fu, Y.; Li, B. Transferring noncharring polyolefins to charring polymers with the presence of $\mathrm{Mo} / \mathrm{Mg} / \mathrm{Ni} / \mathrm{O}$ catalysts and the application in flame retardancy. J. Appl. Polym. Sci. 2013, 129, 138-144. [CrossRef]

110. Dang, L.; Nai, X.; Dong, Y.; Li, W. Functional group effect on flame retardancy, thermal, and mechanical properties of organophosphorus-based magnesium oxysulfate whiskers as a flame retardant in polypropylene. RSC Adv. 2017, 7, 21655-21665. [CrossRef]

111. Rault, F.; Pleyber, E.; Campagne, C.; Rochery, M.; Giraud, S.; Bourbigot, S.; Devaux, E. Effect of manganese nanoparticles on the mechanical, thermal and fire properties of polypropylene multifilament yarn. Polym. Degrad. Stab. 2009, 94, 955-964. [CrossRef]

112. Chen, X.; Yun, Y.; Fan, A.; Yuan, B.; Shang, S.; He, S. The assembly nanohybrid of graphene with lamellar zirconium phenylphosphonate for improving flame retardancy and mechanical properties of polypropylene. Polym. Compos. 2019, 40 (Suppl. S2), E1757-E1765. [CrossRef]

113. Niemczyk, A.; Dziubek, K.; Sacher-Majewska, B.; Czaja, K.; Czech-Polak, J.; Oliwa, R.; Lenża, J.; Szołyga, M. Thermal stability and flame retardancy of polypropylene composites containing siloxane-silsesquioxane resins. Polymers 2018, 10, 1019. [CrossRef]

114. Fina, A.; Tabuani, D.; Camino, G. Polypropylene-polysilsesquioxane blends. Eur. Polym. J. 2010, 46, 14-23. [CrossRef]

115. Fina, A.; Abbenhuis, H.C.; Tabuani, D.; Camino, G. Metal functionalized POSS as fire retardants in polypropylene. Polym. Degrad. Stab. 2006, 91, 2275-2281. [CrossRef]

116. Lecouvet, B.; Sclavons, M.; Bourbigot, S.; Devaux, J.; Bailly, C. Water-assisted extrusion as a novel processing route to prepare polypropylene/halloysite nanotube nanocomposites: Structure and properties. Polymer 2011, 52, 4284-4295. [CrossRef]

117. Shang, S.; Ma, X.; Yuan, B.; Chen, G.; Sun, Y.; Huang, C.; He, S.; Dai, H.; Chen, X. Modification of halloysite nanotubes with supramolecular self-assembly aggregates for reducing smoke release and fire hazard of polypropylene. Compos. Part B Eng. 2019, 177, 107371. [CrossRef] 
118. Nonahal, M.; Rastin, H.; Saeb, M.R.; Sari, M.G.; Moghadam, M.H.; Zarrintaj, P.; Ramezanzadeh, B. Epoxy/PAMAM dendrimer-modified graphene oxide nanocomposite coatings: Nonisothermal cure kinetics study. Prog. Org. Coat. 2018, 114, 233-243. [CrossRef]

119. Yarahmadi, E.; Didehban, K.; Sari, M.G.; Saeb, M.R.; Shabanian, M.; Aryanasab, F.; Zarrintaj, P.; Paran, S.M.R.; Mozafari, M.; Rallini, M. Development and curing potential of epoxy/starch-functionalized graphene oxide nanocomposite coatings. Prog. Org. Coat. 2018, 119, 194-202. [CrossRef]

120. Choolaei, M.; Goodarzi, V.; Khonakdar, H.A.; Jafari, S.H.; Seyfi, J.; Saeb, M.R.; Häußler, L.; Boldt, R. Influence of graphene oxide on crystallization behavior and chain folding surface free energy of poly (vinylidenefluoride-co-hexafluoropropylene). Macromol. Chem. Phys. 2017, 218, 1700103. [CrossRef]

121. Saeb, M.R.; Najafi, F.; Bakhshandeh, E.; Khonakdar, H.A.; Mostafaiyan, M.; Simon, F.; Scheffler, C.; Mäder, E. Highly curable epoxy/MWCNTs nanocomposites: An effective approach to functionalization of carbon nanotubes. Chem. Eng. J. 2015, 259, 117-125. [CrossRef]

122. Yuan, B.; Wang, B.; Hu, Y.; Mu, X.; Hong, N.; Liew, K.M.; Hu, Y. Electrical conductive and graphitizable polymer nanofibers grafted on graphene nanosheets: Improving electrical conductivity and flame retardancy of polypropylene. Compos. Part A Appl. Sci. Manuf. 2016, 84, 76-86. [CrossRef]

123. Yuan, B.; Hu, Y.; Chen, X.; Shi, Y.; Niu, Y.; Zhang, Y.; He, S.; Dai, H. Dual modification of graphene by polymeric flame retardant and $\mathrm{Ni}(\mathrm{OH}) 2$ nanosheets for improving flame retardancy of polypropylene. Compos. Part A Appl. Sci. Manuf. 2017, 100, 106-117. [CrossRef]

124. Yuan, B.; Sheng, H.; Mu, X.; Song, L.; Tai, Q.; Shi, Y.; Liew, K.M.; Hu, Y. Enhanced flame retardancy of polypropylene by melamine-modified graphene oxide. J. Mater. Sci. 2015, 50, 5389-5401. [CrossRef]

125. Hong, N.; Pan, Y.; Zhan, J.; Wang, B.; Zhou, K.; Song, L.; Hu, Y. Fabrication of graphene/Ni-Ce mixed oxide with excellent performance for reducing fire hazard of polypropylene. Rsc Adv. 2013, 3, 16440-16448. [CrossRef]

126. Yuan, B.; Song, L.; Liew, K.M.; Hu, Y. Solid acid-reduced graphene oxide nanohybrid for enhancing thermal stability, mechanical property and flame retardancy of polypropylene. Rsc Adv. 2015, 5, 41307-41316. [CrossRef]

127. Bensabath, T.; Sarazin, J.; Jimenez, M.; Samyn, F.; Bourbigot, S. Intumescent polypropylene: Interactions between physical and chemical expansion. Fire Mater. 2019. [CrossRef]

128. Xu, L.; Guo, Z.; Zhang, Y.; Fang, Z. Flame-retardant-wrapped carbon nanotubes for simultaneously improving the flame retardancy and mechanical properties of polypropylene. J. Mater. Chem. 2008, 18, 5083-5091.

129. Song, P.; Zhao, L.; Cao, Z.; Fang, Z. Polypropylene nanocomposites based on C 60-decorated carbon nanotubes: Thermal properties, flammability, and mechanical properties. J. Mater. Chem. 2011, 21, 7782-7788. [CrossRef]

130. Yang, H.; Ye, L.; Gong, J.; Li, M.; Jiang, Z.; Wen, X.; Chen, H.; Tian, N.; Tang, T. Simultaneously improving the mechanical properties and flame retardancy of polypropylene using functionalized carbon nanotubes by covalently wrapping flame retardants followed by linking polypropylene. Mater. Chem. Front. 2017, 1, 716-726. [CrossRef]

131. Wen, X.; Tian, N.; Gong, J.; Chen, Q.; Qi, Y.; Liu, Z.; Liu, J.; Jiang, Z.; Chen, X.; Tang, T. Effect of nanosized carbon black on thermal stability and flame retardancy of polypropylene/carbon nanotubes nanocomposites. Polym. Adv. Technol. 2013, 24, 971-977. [CrossRef]

132. Fina, A.; Bocchini, S.; Camino, G. Catalytic fire retardant nanocomposites. Polym. Degrad. Stab. 2008, 93, 1647-1655. [CrossRef]

133. Gong, J.; Niu, R.; Wen, X.; Yang, H.; Liu, J.; Chen, X.; Sun, Z.-Y.; Mijowska, E.; Tang, T. Synergistic effect of carbon fibers and carbon nanotubes on improving thermal stability and flame retardancy of polypropylene: A combination of a physical network and chemical crosslinking. RSC Adv. 2014, 5, 5484-5493. [CrossRef]

134. Yang, H.; Gong, J.; Wen, X.; Xue, J.; Chen, Q.; Jiang, Z.; Tian, N.; Tang, T. Effect of carbon black on improving thermal stability, flame retardancy and electrical conductivity of polypropylene/carbon fiber composites. Compos. Sci. Technol. 2015, 113, 31-37. [CrossRef]

135. Alongi, J.; Poskovic, M.; Visakh, P.; Frache, A.; Malucelli, G. Cyclodextrin nanosponges as novel green flame retardants for PP, LLDPE and PA6. Carbohydr. Polym. 2012, 88, 1387-1394. [CrossRef]

136. Yu, Y.; Song, P.a.; Jin, C.; Fu, S.; Zhao, L.; Wu, Q.; Ye, J. Catalytic effects of nickel (cobalt or zinc) acetates on thermal and flammability properties of polypropylene-modified lignin composites. Ind. Eng. Chem. Res. 2012, 51, 12367-12374. [CrossRef] 
137. Gao, Y.-Y.; Deng, C.; Du, Y.-Y.; Huang, S.-C.; Wang, Y.-Z. A novel bio-based flame retardant for polypropylene from phytic acid. Polym. Degrad. Stab. 2019, 161, 298-308. [CrossRef]

138. Das, O.; Bhattacharyya, D.; Hui, D.; Lau, K.-T. Mechanical and flammability characterisations of biochar/polypropylene biocomposites. Compos. Part B Eng. 2016, 106, 120-128. [CrossRef]

139. Jung, D.; Persi, I.; Bhattacharyya, D. Synergistic Effects of Feather Fibers and Phosphorus Compound on Chemically Modified Chicken Feather/Polypropylene Composites. ACS Sustain. Chem. Eng. 2019, 7, 19072-19080. [CrossRef]

140. Tang, Y.; Hu, Y.; Wang, S.; Gui, Z.; Chen, Z.; Fan, W. Intumescent flame retardant-montmorillonite synergism in polypropylene-layered silicate nanocomposites. Polym. Int. 2003, 52, 1396-1400. [CrossRef]

141. Vahabi, H.; Ferry, L.; Longuet, C.; Otazaghine, B.; Negrell-Guirao, C.; David, G.; Lopez-Cuesta, J.-M. Combination effect of polyhedral oligomeric silsesquioxane (POSS) and a phosphorus modified PMMA, flammability and thermal stability properties. Mater. Chem. Phys. 2012, 136, 762-770. [CrossRef]

142. Vahabi, H.; Laoutid, F.; Movahedifar, E.; Khalili, R.; Rahmati, N.; Vagner, C.; Cochez, M.; Brison, L.; Ducos, F.; Ganjali, M.R. Description of complementary actions of mineral and organic additives in thermoplastic polymer composites by Flame Retardancy Index. Polym. Adv. Technol. 2019, 30, 2056-2066. [CrossRef]

143. Gao, S.; Liu, G. Synthesis of amino trimethylene phosphonic acid melamine salt and its application in flame-retarded polypropylene. J. Appl. Polym. Sci. 2018, 135, 46274. [CrossRef]

144. Chen, X.; Jiao, C. Study on flame retardance of co-microencapsulated ammonium polyphosphate and pentaerythritol in polypropylene. J. Fire Sci. 2010, 28, 509-521. [CrossRef]

145. Chiu, S.-H.; Wang, W.-K. Dynamic flame retardancy of polypropylene filled with ammonium polyphosphate, pentaerythritol and melamine additives. Polymer 1998, 39, 1951-1955. [CrossRef]

146. Chiu, S.H.; Wang, W.K. The dynamic flammability and toxicity of magnesium hydroxide filled intumescent fire retardant polypropylene. J. Appl. Polym. Sci. 1998, 67, 989-995. [CrossRef]

147. Huang, N.; Chen, Z.; Wang, J.; Wei, P. Synergistic effects of sepiolite on intumescent flame retardant polypropylene. Express Polym. Lett. 2010, 4, 743-752. [CrossRef]

148. Wang, Z.; Liu, Y.; Li, J. Preparation of nucleotide-based microsphere and its application in intumescent flame retardant polypropylene. J. Anal. Appl. Pyrolysis 2016, 121, 394-402. [CrossRef]

149. Su, X.; Yi, Y.; Tao, J.; Qi, H.; Li, D. Synergistic effect between a novel triazine charring agent and ammonium polyphosphate on flame retardancy and thermal behavior of polypropylene. Polym. Degrad. Stab. 2014, 105, 12-20. [CrossRef]

150. Wang, X.; Wang, Z.; Li, J. Effects of a semi-bio-based triazine derivative on intumescent flame-retardant polypropylene. Polym. Adv. Technol. 2019, 30, 1259-1268. [CrossRef]

151. Wang, Z.; Liu, Y.; Li, J. Regulating effects of nitrogenous bases on the char structure and flame retardancy of polypropylene/intumescent flame retardant composites. ACS Sustain. Chem. Eng. 2017, 5, 2375-2383. [CrossRef]

152. Qin, Z.; Li, D.; Yang, R. Study on inorganic modified ammonium polyphosphate with precipitation method and its effect in flame retardant polypropylene. Polym. Degrad. Stab. 2016, 126, 117-124. [CrossRef]

153. Zhu, H.F.; Li, J.; Xu, L.; Tao, K.; Xue, L.X.; Fan, X.Y. Synergistic Effect between Montmorillonite Intercalated by Melamine and Intumescent Flame Retardant (IFR) on Polypropylene; Advanced Materials Research; Trans Tech Publications: Zurich, Switzerland, 2011; pp. 315-318. [CrossRef]

154. Zhu, H.; Li, J.; Zhu, Y.; Chen, S. Roles of organic intercalation agent with flame retardant groups in montmorillonite (MMT) in properties of polypropylene composites. Polym. Adv. Technol. 2014, 25, 872-880. [CrossRef]

155. Wang, P.-J.; Hu, X.-P.; Liao, D.-J.; Wen, Y.; Hull, T.R.; Miao, F.; Zhang, Q.-T. Dual fire retardant action: The combined gas and condensed phase effects of azo-modified NiZnAl layered double hydroxide on intumescent polypropylene. Ind. Eng. Chem. Res. 2017, 56, 920-932. [CrossRef]

156. Zhang, Y.; He, S.; Wu, J.; Ma, J.; Shao, S.; He, L.; Li, X.; Fang, Z.; Cao, H.; Xi, Z. Application of waste silicon rubber composite treated by N2 plasma in the flame-retardant polypropylene. J. Appl. Polym. Sci. 2019, 136, 48187. [CrossRef]

157. Zhao, Q.; Hu, Y.; Wang, X. Mechanical performance and flame retardancy of polypropylene composites containing zeolite and multiwalled carbon nanotubes. J. Appl. Polym. Sci. 2016, 133. [CrossRef]

158. Su, X.; Li, D.; Tao, J.; Dai, Q. Synergistic effect of allophane with intumescent flame retardants on thermal behavior and fire retardancy of polypropylene. Polym. Bull. 2015, 72, 2089-2104. [CrossRef] 
159. Zhang, S.; Tang, W.; Li, L.; Li, H.; Sun, J.; Gu, X.; Chen, S.; Peng, X.; Bourbigot, S. Fabrication of fly ash-based mesoporous aluminosilicate oxides loaded with zinc and its synergistic fire resistancy in polypropylene. J. Vinyl Addit. Technol. 2020, 26, 135-143. [CrossRef]

160. de Juan, S.; Zhang, J.; Acuña, P.; Nie, S.; Liu, Z.; Zhang, W.; Luisa Puertas, M.; Esteban-Cubillo, A.; Santarén, J.; Wang, D.Y. An efficient approach to improving fire retardancy and smoke suppression for intumescent flame-retardant polypropylene composites via incorporating organo-modified sepiolite. Fire Mater. 2019, 43, 961-970. [CrossRef]

161. Turgut, G.; Dogan, M.; Tayfun, U.; Ozkoc, G. The effects of POSS particles on the flame retardancy of intumescent polypropylene composites and the structure-property relationship. Polym. Degrad. Stab. 2018, 149, 96-111. [CrossRef]

162. Almirón, J.; Roudet, F.; Duquesne, S. Influence of volcanic ash, rice husk ash, and solid residue of catalytic pyrolysis on the flame-retardant properties of polypropylene composites. J. Fire Sci. 2019, 37, 434-451. [CrossRef]

163. Doğan, M.; Yılmaz, A.; Bayramlı, E. Synergistic effect of boron containing substances on flame retardancy and thermal stability of intumescent polypropylene composites. Polym. Degrad. Stab. 2010, 95, 2584-2588. [CrossRef]

164. Zhou, K.; Jiang, S.; Wang, B.; Shi, Y.; Liu, J.; Hong, N.; Hu, Y.; Gui, Z. Combined effect of transition metal phosphide ( $\mathrm{MxPy}, \mathrm{M}=\mathrm{Ni}, \mathrm{Co}$, and $\mathrm{Cu}$ ) and intumescent flame retardant system on polypropylene. Polym. Adv. Technol. 2014, 25, 701-710. [CrossRef]

165. Su, X.; Yi, Y.; Tao, J.; Qi, H. Synergistic effect of zinc hydroxystannate with intumescent flame-retardants on fire retardancy and thermal behavior of polypropylene. Polym. Degrad. Stab. 2012, 97, 2128-2135. [CrossRef]

166. Zhang, Y.; Li, X.; Fang, Z.; Hull, T.R.; Kelarakis, A.; Stec, A.A. Mechanism of enhancement of intumescent fire retardancy by metal acetates in polypropylene. Polym. Degrad. Stab. 2017, 136, 139-145. [CrossRef]

167. Pallmann, J.; Ren, Y.L.; Mahltig, B.; Huo, T.G. Phosphorylated sodium alginate/APP/DPER intumescent flame retardant used for polypropylene. J. Appl. Polym. Sci. 2019, 136, 47794. [CrossRef]

168. Li, J.; Lai, X.; Li, H.; Zeng, X.; Liu, Y.; Zeng, Y.; Jiang, C. Functionalized ZrP nanosheet with free-radical quenching capability and its synergism in intumescent flame-retardant polypropylene. Polym. Adv. Technol. 2019, 31, 602-615. [CrossRef]

169. Tang, W.; Zhang, S.; Sun, J.; Li, H.; Liu, X.; Gu, X. Effects of surface acid-activated kaolinite on the fire performance of polypropylene composite. Thermochim. Acta 2017, 648, 1-12. [CrossRef]

170. Tang, W.; Song, L.; Zhang, S.; Li, H.; Sun, J.; Gu, X. Preparation of thiourea-intercalated kaolinite and its influence on thermostability and flammability of polypropylene composite. J. Mater. Sci. 2017, 52, 208-217. [CrossRef]

171. Tang, W.; Zhang, S.; Gu, X.; Sun, J.; Jin, X.; Li, H. Effects of kaolinite nanoroll on the flammability of polypropylene nanocomposites. Appl. Clay Sci. 2016, 132, 579-588. [CrossRef]

172. Sun, W.; Tang, W.; Gu, X.; Zhang, S.; Sun, J.; Li, H.; Liu, X. Synergistic effect of kaolinite/halloysite on the flammability and thermostability of polypropylene. J. Appl. Polym. Sci. 2018, 135, 46507. [CrossRef]

173. Zhang, S.; Tang, W.; Guo, J.; Jin, X.; Li, H.; Gu, X.; Sun, J. Improvement of flame retardancy and thermal stability of polypropylene by P-type hydrated silica aluminate containing lanthanum. Polym. Degrad. Stab. 2018, 154, 276-284. [CrossRef]

174. Wen, P.; Wang, D.; Liu, J.; Zhan, J.; Hu, Y.; Yuen, R.K. Organically modified montmorillonite as a synergist for intumescent flame retardant against the flammable polypropylene. Polym. Adv. Technol. 2017, 28, 679-685. [CrossRef]

175. Yang, K.; Xu, M.-J.; Li, B. Synthesis of N-ethyl triazine-piperazine copolymer and flame retardancy and water resistance of intumescent flame retardant polypropylene. Polym. Degrad. Stab. 2013, 98, 1397-1406. [CrossRef]

176. Yuan, B.; Fan, A.; Yang, M.; Chen, X.; Hu, Y.; Bao, C.; Jiang, S.; Niu, Y.; Zhang, Y.; He, S. The effects of graphene on the flammability and fire behavior of intumescent flame retardant polypropylene composites at different flame scenarios. Polym. Degrad. Stab. 2017, 143, 42-56. [CrossRef]

177. Yuan, B.; Sun, Y.; Chen, X.; Shi, Y.; Dai, H.; He, S. Poorly-/well-dispersed graphene: Abnormal influence on flammability and fire behavior of intumescent flame retardant. Compos. Part A Appl. Sci. Manuf. 2018, 109, 345-354. [CrossRef] 
178. Gao, S.; Zhao, X.; Liu, G. Synthesis of tris (2-hydroxyethyl) isocyanurate homopolymer and its application in intumescent flame retarded polypropylene. J. Appl. Polym. Sci. 2017, 134. [CrossRef]

179. Yang, R.; Ma, B.; Zhao, H.; Li, J. Preparation, thermal degradation, and fire behaviors of intumescent flame retardant polypropylene with a charring agent containing pentaerythritol and triazine. Ind. Eng. Chem. Res. 2016, 55, 5298-5305. [CrossRef]

180. Liu, Y.; Wang, J.S.; Deng, C.L.; Wang, D.Y.; Song, Y.P.; Wang, Y.Z. The synergistic flame-retardant effect of O-MMT on the intumescent flame-retardant PP/CA/APP systems. Polym. Adv. Technol. 2010, 21, 789-796. [CrossRef]

181. Wang, Y.; Xu, M.-J.; Li, B. Synthesis of N-methyl triazine-ethylenediamine copolymer charring foaming agent and its enhancement on flame retardancy and water resistance for polypropylene composites. Polym. Degrad. Stab. 2016, 131, 20-29. [CrossRef]

182. Enescu, D.; Frache, A.; Lavaselli, M.; Monticelli, O.; Marino, F. Novel phosphorous-nitrogen intumescent flame retardant system. Its effects on flame retardancy and thermal properties of polypropylene. Polym. Degrad. Stab. 2013, 98, 297-305. [CrossRef]

183. Zheng, Z.; Sun, H.; Li, W.; Zhong, S.; Yan, J.; Cui, X.; Wang, H. Co-microencapsulation of ammonium polyphosphate and aluminum hydroxide in halogen-free and intumescent flame retarding polypropylene. Polym. Compos. 2014, 35, 715-729. [CrossRef]

184. Tian, N.; Wen, X.; Gong, J.; Ma, L.; Xue, J.; Tang, T. Synthesis and characterization of a novel organophosphorus flame retardant and its application in polypropylene. Polym. Adv. Technol. 2013, 24, 653-659. [CrossRef]

185. Wang, J.-S.; Wang, G.-H.; Liu, Y.; Jiao, Y.-H.; Liu, D. Thermal stability, combustion behavior, and toxic gases in fire effluents of an intumescent flame-retarded polypropylene system. Ind. Eng. Chem. Res. 2014, 53, 6978-6984. [CrossRef]

186. Wu, J.; Hu, Y.; Song, L.; Kang, W. Synergistic effect of lanthanum oxide on intumescent flame-retardant polypropylene-based formulations. J. Fire Sci. 2008, 26, 399-414.

187. Zheng, Z.; Liu, Y.; Zhang, L.; Wang, H. Synergistic effect of expandable graphite and intumescent flame retardants on the flame retardancy and thermal stability of polypropylene. J. Mater. Sci. 2016, 51, 5857-5871. [CrossRef]

188. Lai, X.; Zeng, X.; Li, H.; Yin, C.; Zhang, H.; Liao, F. Synergistic effect of phosphorus-containing nanosponges on intumescent flame-retardant polypropylene. J. Appl. Polym. Sci. 2012, 125, 1758-1765. [CrossRef]

189. Hapuarachchi, T.D.; Peijs, T.; Bilotti, E. Thermal degradation and flammability behavior of polypropylene/clay/ carbon nanotube composite systems. Polym. Adv. Technol. 2013, 24, 331-338. [CrossRef]

190. Zaikov, G.E.; Lomakin, S.M. Polymer flame retardancy: A new approach. J. Appl. Polym. Sci. 1998, 68, 715-725. [CrossRef]

191. Wang, D.; Echols, K.; Wilkie, C.A. Cone calorimetric and thermogravimetric analysis evaluation of halogen-containing polymer nanocomposites. Fire Mater. Int. J. 2005, 29, 283-294. [CrossRef] 